\title{
PRODUCTION OF BIOACTIVE PHENOLIC COMPOUNDS FROM FRUIT RESIDUES BY SOLID-STATE FERMENTATION AND CARBOHYDRASE TREATMENT
}

\author{
PH.D. DiSSERTATION
}

CAROLINA LORENA ZAMBRANO CARRILLO

Supervisors:

DR. JUDIT KRISCH

ASSOCIATE PROFESSOR

DR. MIKLÓS TAKÓ

ASSISTANT PROFESSOR

DOCTORAL SCHOOL OF BIOLOGY

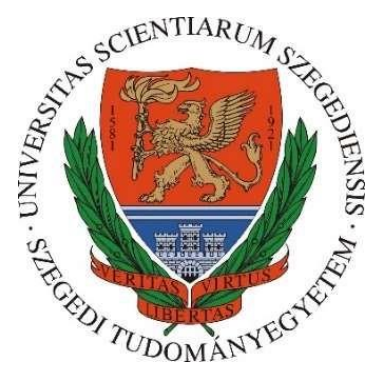

UNIVERSITY OF SZEGED

FACULTY OF SCIENCE AND INFORMATICS

DEPARTMENT OF MICROBIOLOGY

2019

Szeged 


\section{TABLE OF CONTENTS}

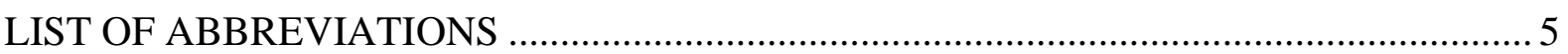

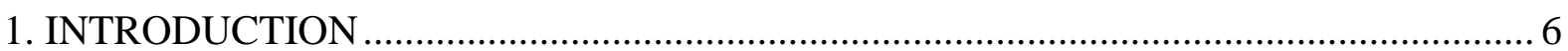

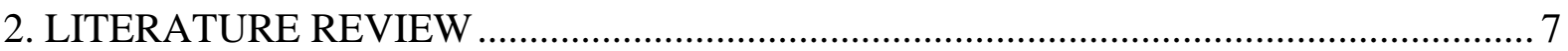

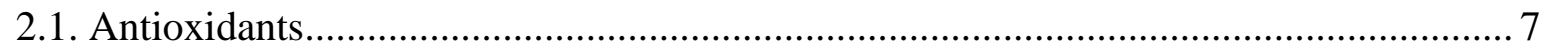

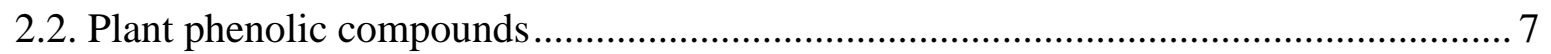

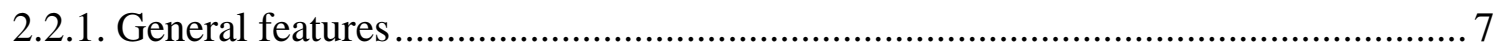

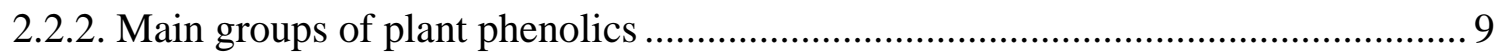

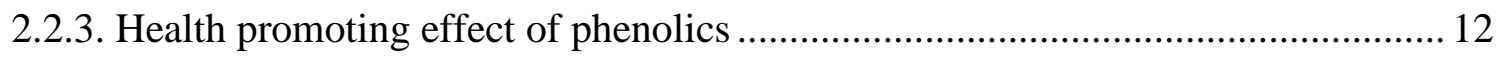

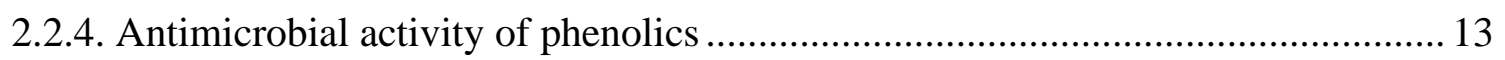

2.2.5. Plant phenolics as anti-quorum sensing and anti-biofilm agents ........................ 15

2.3. Antioxidative fruit substances relevant to this study ............................................... 16

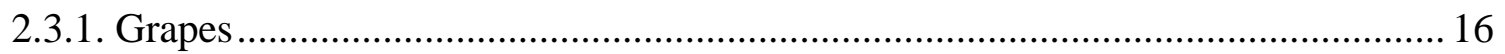

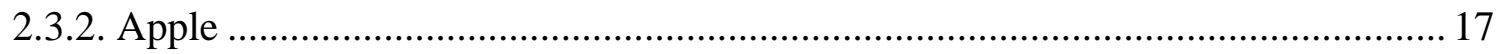

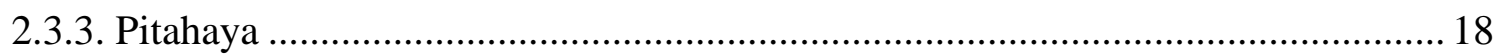

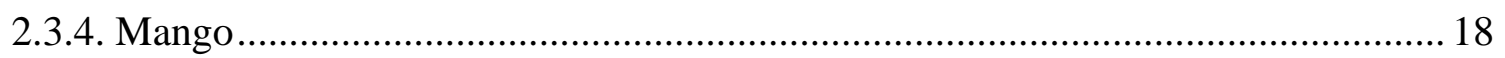

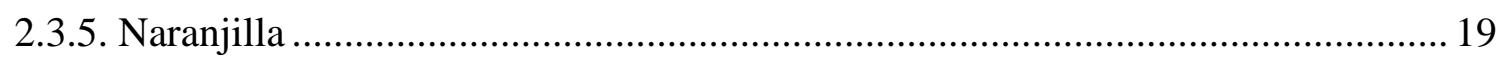

2.4. Fruit and vegetable processing byproducts ......................................................... 20

2.5. Extraction of phenolics from plant materials ............................................................ 21

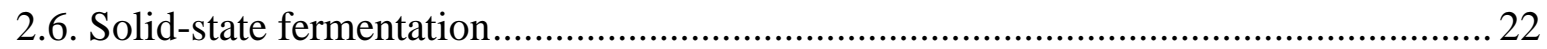

2.6.1. Application of solid-state fermentation on the production of biomolecules ......... 22

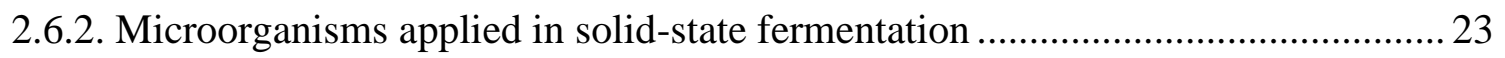

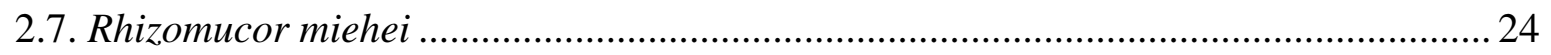

2.8. Application of enzymes to produce plant bioactives .............................................. 25

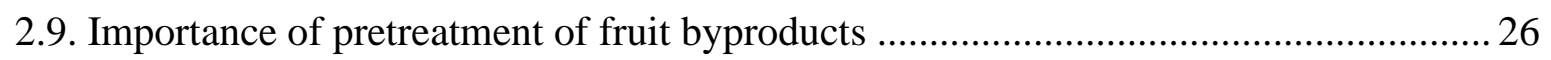

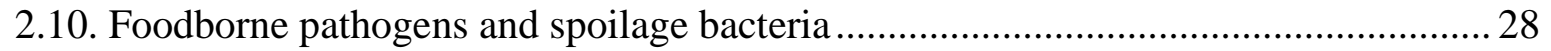

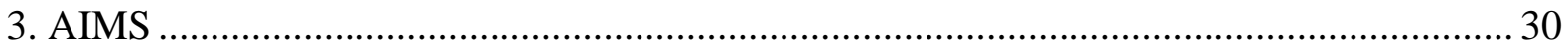

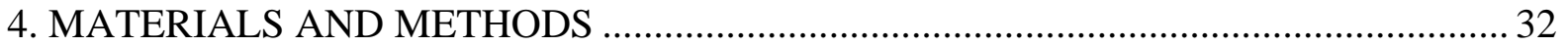

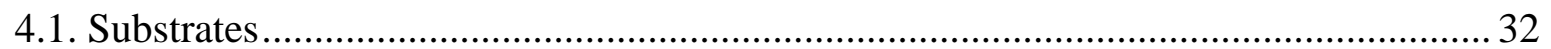

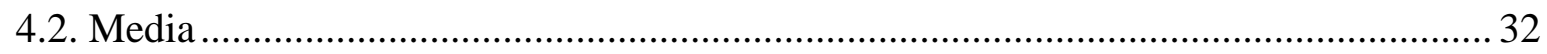

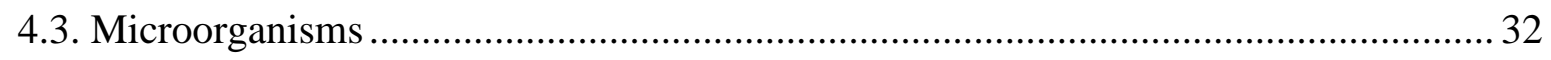

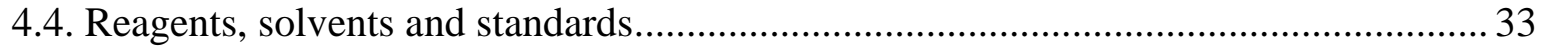


4.5. Substrate preparation 35

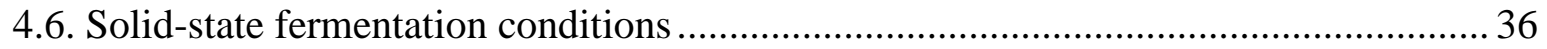

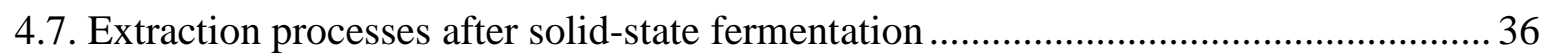

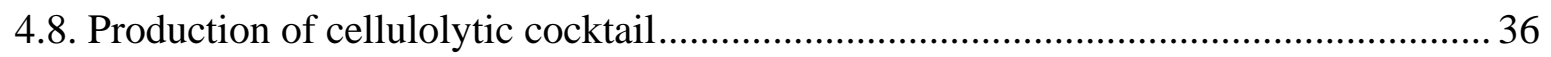

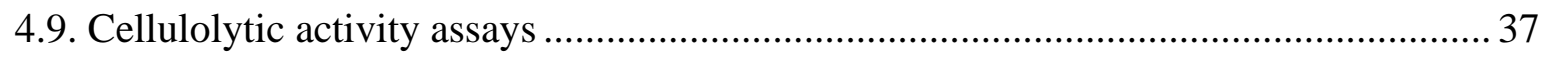

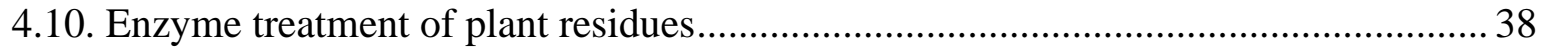

4.11. Extract stock solution preparation for microbiological tests ................................... 38

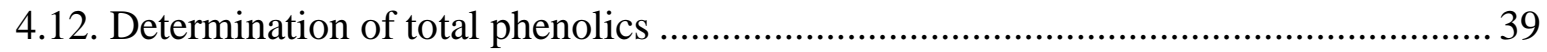

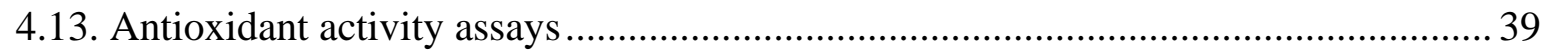

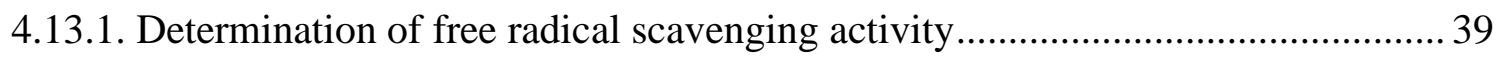

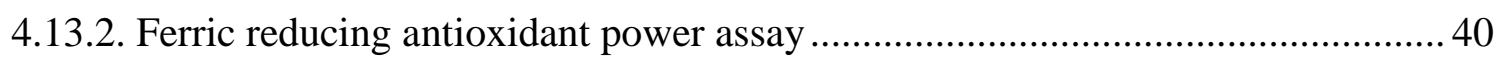

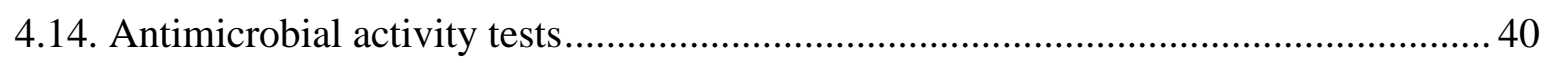

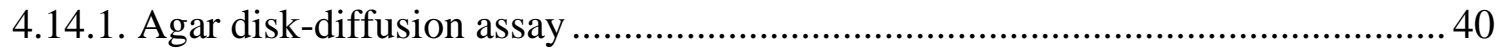

4.14.2. Determination of minimum inhibitory concentration....................................... 41

4.14.3. Determination of minimum bactericidal concentration.................................... 42

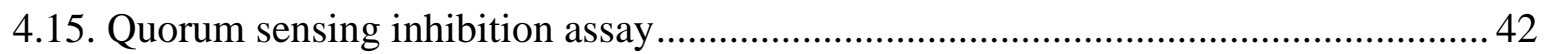

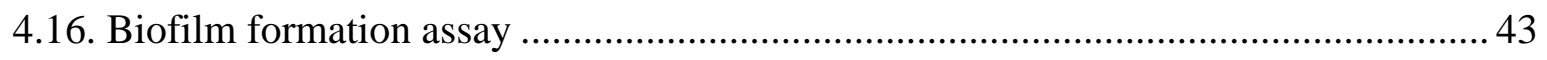

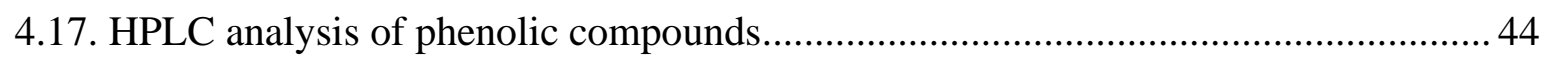

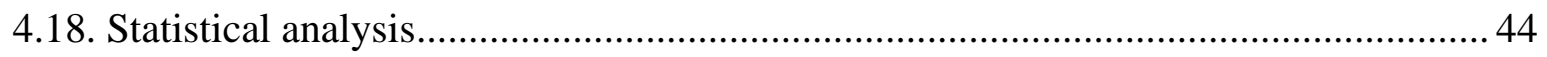

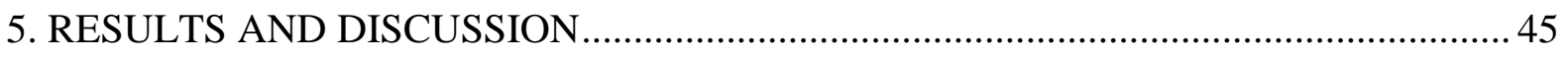

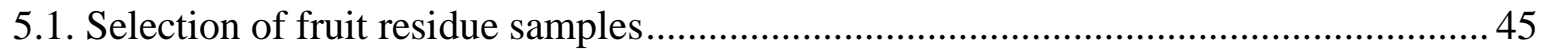

5.2. Solid-state fermentation on oven-dried and lyophilized fruit residues......................... 45

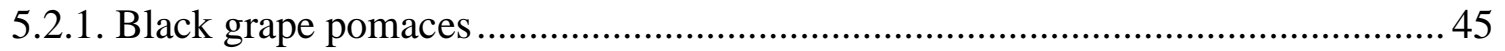

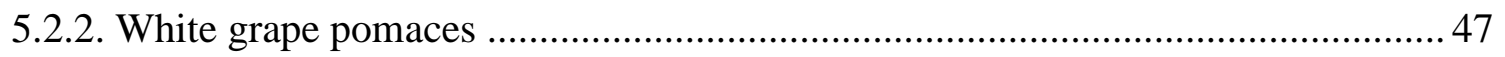

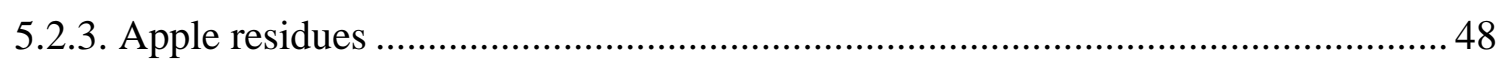

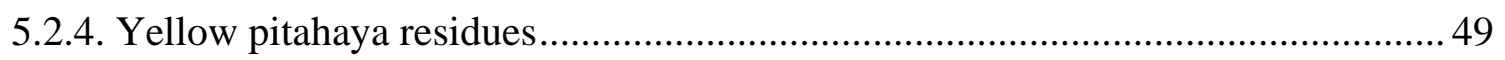

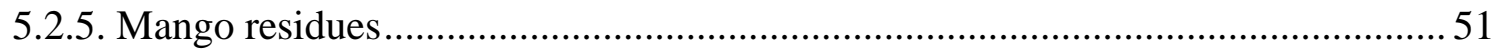

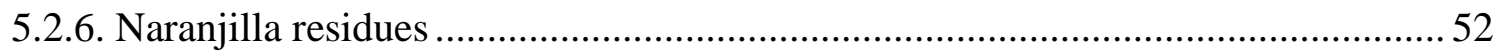

5.2.7. Effect of substrate pretreatment on free phenolics enrichment .............................53

5.3. Enzyme treatment of oven-dried and lyophilized fruit residues................................ 55

5.3.1. Total phenolics and antioxidant activity after enzyme hydrolysis .......................55

5.3.2. Analysis of individual phenolic compounds after enzyme treatments ...................60 60

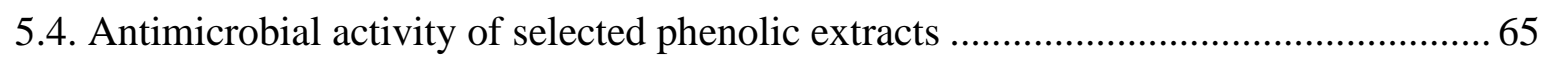

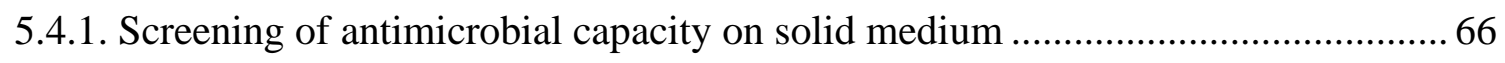


5.4.2. Minimum inhibitory and minimum bactericidal concentrations 69

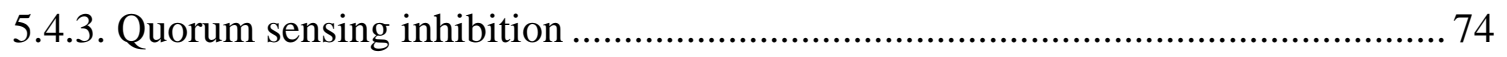

5.4.4. Effects on biofilm formation of food-related bacteria.......................................... 77

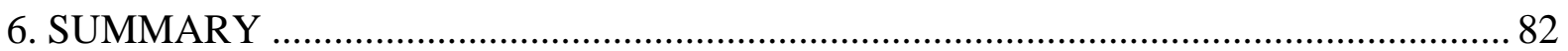

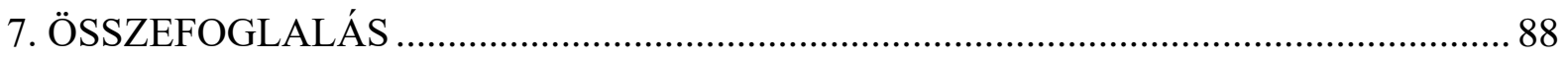

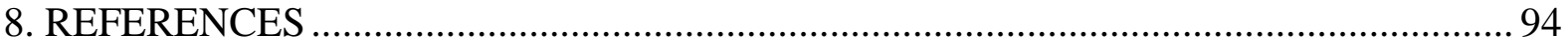

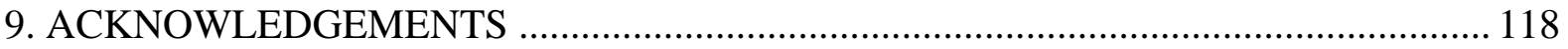

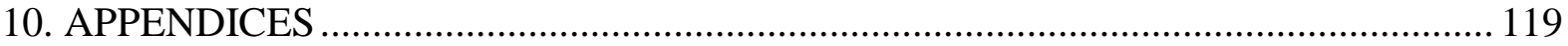

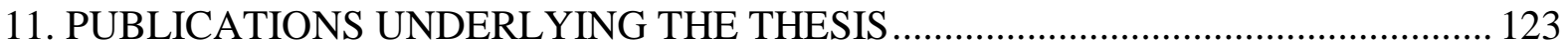

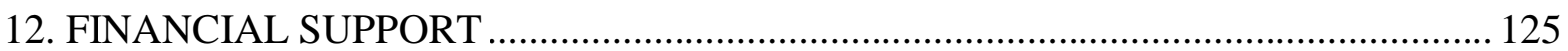




\section{LIST OF ABBREVIATIONS}

anti-QS: anti-quorum sensing

ATCC: American Type Culture Collection, USA

CFU: colony forming unit

DA: oven-dried apple

DBG: oven-dried black grape

DM: dry matter

DMG: oven-dried mango

DN: $\quad$ oven-dried naranjilla

DP: $\quad$ oven-dried pitahaya

DPPH: $\quad$ 1,1-diphenyl-2-picrylhydrazyl

DWG: oven-dried white grape

FPase: filter paper degrading activity

FRAP: ferric reducing antioxidant power

GAE: gallic acid equivalent

HPLC: $\quad$ high-performance liquid chromatography

LA: $\quad$ lyophilized apple

LB: lysogeny broth

LBG: lyophilized black grape

LM: $\quad$ lyophilized mango

LN: $\quad$ lyophilized naranjilla

LP: $\quad$ lyophilized pitahaya

LWG: $\quad$ lyophilized white grape

MBC: minimum bactericidal concentration

ME: $\quad$ malt extract medium

MIC: minimum inhibitory concentration

NRRL: Agricultural Research Service Culture Collection, USA

QS: $\quad$ quorum sensing

ROS: $\quad$ reactive oxygen species

SmF: submerged fermentation

SSF: $\quad$ solid-state fermentation

SZMC: $\quad$ Szeged Microbiological Collection, Szeged, Hungary

TGE: $\quad$ tryptone glucose yeast extract

TPC: $\quad$ total phenolic content

TPTZ: 2,4,6-Tri(2-pyridyl)-s-triazine

TSB: $\quad$ tryptic soy broth 


\section{INTRODUCTION}

Plants contain various phenolic compounds, e.g. hydroxybenzoates, hydroxycinnamates, flavonoids, stilbenes etc., that are involved in defense mechanisms, as well as in pigmentation and adaptation processes. Application of phenolics as additives in food, cosmetic and nutraceutical products has increased which is attributed to their bioactive properties beneficial to the human health. In addition, certain molecules can be used as natural food preservatives or sanitizers as well.

The agro- and food industrial waste of antioxidative plants is a good source of bioactive phenolics. To obtain the compounds, many approaches use different physical and chemical methods such as microwave/ultrasound assisted extraction and solvent treatment. However, most phenolics in plants are bounded in glycoside complexes that results in reduced bioavailability. The carbohydrases, e.g. cellulases and pectinases, can hydrolyze these glycosides releasing the phenolic aglycone molecule. Consequently, fermentation of the substrate using cellulolytic microorganisms, or a carbohydrase-aided extraction may facilitate the mobilization of the phenolic antioxidant.

Many filamentous fungi are used in the industry as valuable producers of carbohydrases. In this context, the enzyme production of zygomycetes fungi has also been continuously screened. In previous experiments performed by our group, the Rhizomисor miehei NRRL 5282 isolate proved to be an excellent cellulolytic fungus with high enzyme activity.

The main objective of our work was to enrich bioactive phenolic compounds from selected antioxidative fruit residues via two approaches: i) in vivo solid-state fermentation with the cellulolytic fungus $R$. miehei NRRL 5282 and ii) in vitro enzyme treatment of the substrate with $R$. miehei derived cellulase cocktail. The residues were planned to be subjected to oven-drying or lyophilization before treatments, and we wanted to supplement the enzyme-aided reactions with pectinases as well. Our goals included the analysis and comparison of the total and individual phenolic contents and the antioxidant activity before and after treatments. Evaluation of additional bioactive properties, i.e. antimicrobial, antiquorum sensing and antibiofilm activities of extracts produced was also planned using food related bacteria and other model organisms. 


\section{LITERATURE REVIEW}

\subsection{Antioxidants}

Antioxidants are substances that inhibit the oxidative processes. The antioxidant compounds could inhibit the formation of hydrogen peroxide, scavenge free radicals and reduce the activity of enzymes (e.g., lipoxygenase, NADH oxidase, cyclooxygenase) responsible for the development of reactive oxygen species (ROS) during aerobic cell metabolism. Source of antioxidants can be endogenous, i.e. produced by the organism, or exogenous, i.e. ingested through the intake (utilization of substances that contain them), natural (e.g., enzymes, vitamins, polyphenols, proteins) or synthetic (e.g., phenolic compounds such as butylated hydroxyanisole and butylated hydroxytoluene) (Anwar et al. 2018). The natural antioxidants are mainly phenolics that can be derived from various plant sources. Safety concerns towards the use of synthetic antioxidants led researchers to explore natural sources of antioxidants with economic viability, high antioxidant potential and improved bioavailability (Shahidi and Ambigaipalan 2015).

\subsection{Plant phenolic compounds}

\subsubsection{General features}

Phenolic phytochemicals are secondary metabolites participating in defense mechanisms in plants. They also have significant roles in other processes, such as pigmentation, adaptation to adverse environmental conditions and incorporation of attractive substances to accelerate pollination. Many fruits, vegetables and plant-based foods and beverages contain phenolic phytochemicals in high amount (Manach et al. 2004). The phenolic compounds can be classified into different groups depending on the number of the phenol rings present and the structural elements that link these rings together (Pandey and Rizvi 2009); there are both simple molecules and highly polymerized compounds (Figure 1). 


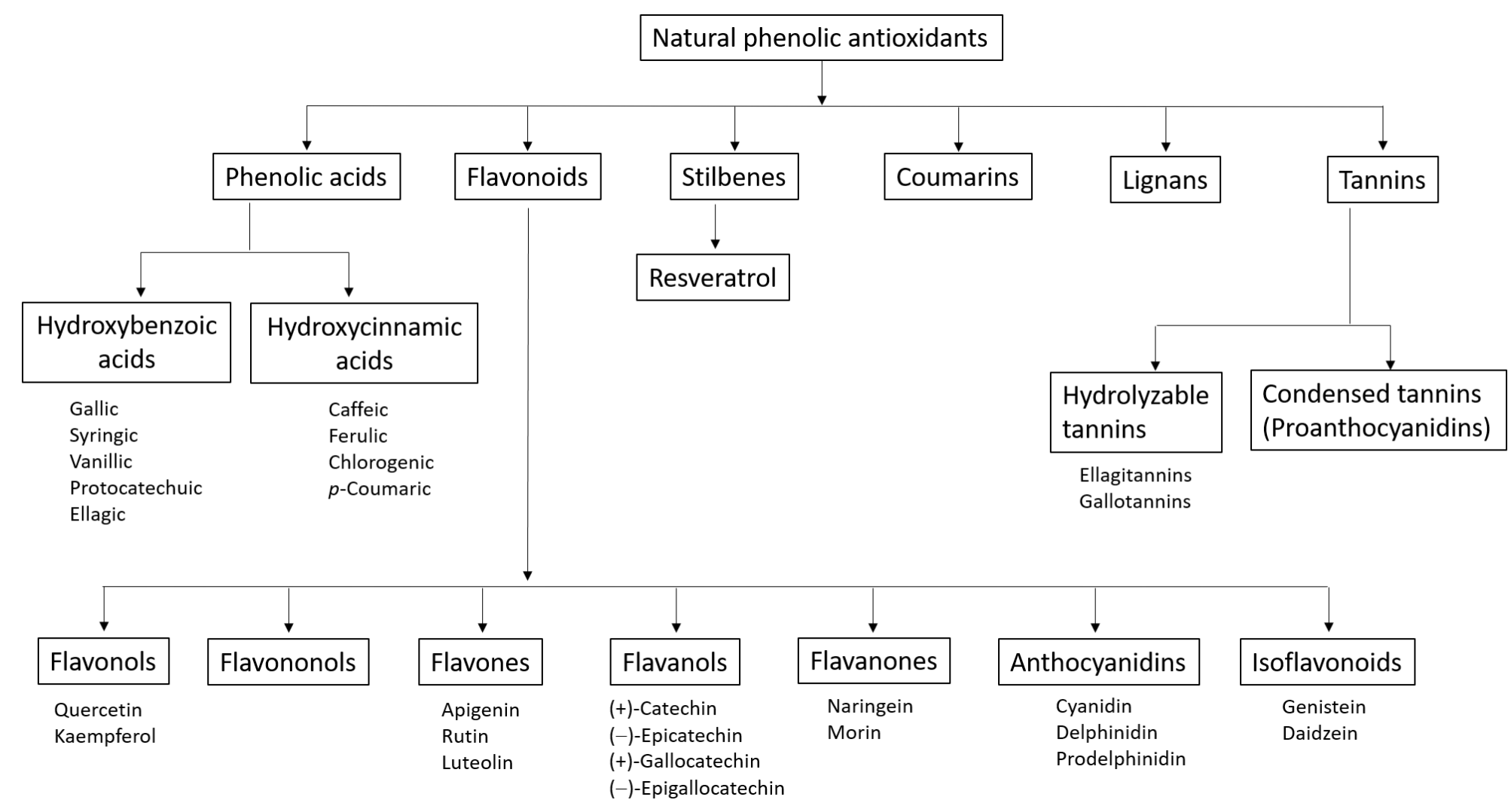

Figure 1. Classification of natural phenolic antioxidants (modified from Shahidi and Ambigaipalan 2015). 
Polyphenols bear one or more hydroxyl substituents. Their number and position are responsible for the antioxidant properties of the phenolics (Balasundram et al. 2006). In plants, about one third of the phenolics is glycosylated by one or more sugars (AcostaEstrada et al. 2014), mainly by glucose (Figure 2). Less frequent is their conjugated form containing carboxylic acid, organic acid, amine and lipid residues. The bioavailability of these bound phenolic compounds is limited due to their reduced absorption in the small intestine. Numerous studies deal with the antioxidant, anti-inflammatory, antibacterial, platelet antiaggregant, antiviral, antifungal, anti-mutagenic and free radical scavenging activities of phenolic substances (Pandey and Rizvi 2009, Bahadoran et al. 2013, Panche et al. 2016, Papuc et al. 2017). In addition, these molecules can modulate some important cellular signaling pathways, regulate cell cycle processes and inhibit certain digestive enzymes such as lipase, $\alpha$-amylase and $\alpha$-glucosidase (Han et al. 2007).

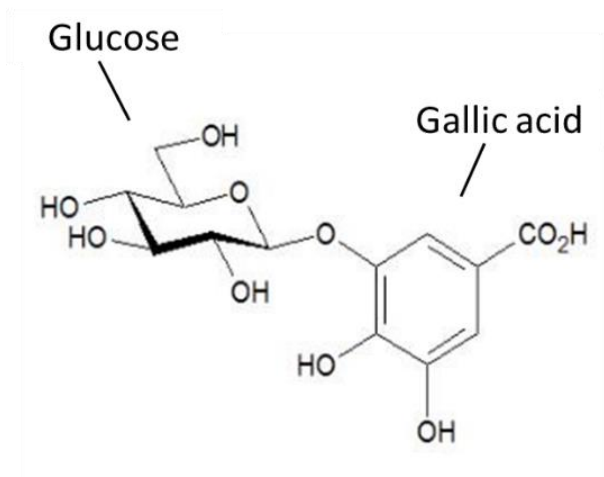

Figure 2. Structure of gallic acid 3-O- $\beta$-D glucopyranoside.

\subsubsection{Main groups of plant phenolics}

$\underline{\text { Phenolic acids }}$

Phenolic acids are found in most foods of vegetable origin, generally in conjugated form. The phenolic acids are divided into two forms according to the acid component (Manach et al. 2004): (1) hydroxybenzoic acids, as derivatives of benzoic acid, can be found in red fruits, roots and bulbs (e.g., radish, onion) in high amount; (2) hydroxycinnamic acids, as derivatives of cinnamic acid, are the most abundant in foods. The most common hydroxybenzoic acids in plants are the gallic acid, $p$-hydroxybenzoic acid, vanillic acid and protocatechuic acid. Hydroxycinnamic acids are mostly found in bounded forms as glycosylated derivatives or esters of quinic acid, shikimic acid and 
tartaric acid. The most common hydroxycinnamic acids in plants are $p$-coumaric, caffeic, ferulic and sinapic acids. These can be found in high concentration in several fruits such as kiwis, apples, cherries and blueberries. Caffeic acid is abundant mostly in fruits concentrated mainly in the peel. Its concentration increases with increasing maturity and represents about $75 \%$ of the total hydroxycinnamic acid content. Ferulic acid is the major phenolic acid in cereals and grains. It is concentrated mainly in the crust of the grain and represents about $90 \%$ of the total of polyphenol mass (Manach et al. 2004). As antioxidants, numbers of phenolic acids are outstanding in reducing power and free radical scavenging activities (Soobrattee et al. 2005, Pereira et al. 2009). Many caffeic acid derivatives can inhibit various enzyme activities such as lipoxygenase and protein kinase (Kang et al. 2008, Doiron et al. 2017).

\section{Flavonoids}

These compounds are widely distributed in plants. Their structure, composition and biological activities are reviewed by Chae et al. (2013) and Panche et al. (2016). Flavonoids generally represent two thirds of the consumed polyphenols (Scalbert and Williamson 2000). Most of them are of low molecular weight and soluble according to their polarity and degree of glycosylation, hydroxylation and acylation. More than 8,000 flavonoids have been identified that can be divided into several subclasses (Table 1). All share a common structure consisting of two aromatic rings that are joined by three carbon atoms that form an oxygenated heterocycle with various levels of hydroxylation and methoxylation (Bravo 1998). Antioxidant activity of flavonoids is based on its potential as reducing agents, hydrogen donors, oxygen radical and oxidative enzyme inhibitors, superoxide radical scavengers and metal chelators. In addition, these compounds are capable of activating antioxidant enzymes as well (Shahidi and Ambigaipalan 2015). Flavonols, e.g. quercetin, myricetin, kaempferol are ubiquitous flavonoids in foods. In nature, they are present in glycosylated and aglycone forms. Among foods and beverages, onions, broccoli, kale, blueberries, red wine and tea contain high amount of flavonols. Flavones are present as luteolin glycosides and apigenin in products such as parsley and celery, as well as in the skin of citrus fruits. Flavanones are found in tomatoes, aromatic plants such as mint, and in citrus fruits where their high concentration is responsible for the bitter taste. Isoflavonoids are found in legume plants, e.g. soybean, in high amount. Numerous forms, e.g. daidzein and genistein, are intensively studied as phytoestrogens (Bacciottini et al. 2007). Flavanols (catechins) are found mostly in nuts, red wine, green tea and chocolate (Shahidi and Ambigaipalan 2015). The (+)-catechin and (-)-epicatechin 
are the main flavanols in fruits, while (+)-gallocatechin, (-)-epigallocatechin and (-)epigallocatechin-3-gallate are found in legumes and tea (Kozłowska and Szostak-Wegierek 2014). Anthocyanins are glycosides of anthocyanidin aglycones. These are water soluble pigments that give red, purple or blue color to leaves, flowers and fruits. Main sources are berry fruits and vegetables such as aubergines, cabbages, beans and onions. Cyanidin is the most common anthocyanidin in foods (Clifford and Scalbert 2000).

Table 1. Types of flavonoids and their dietary sources (Data from Naczk and Shahidi 2004 and Kamboh et al. 2015).

\begin{tabular}{lll}
\hline Subclass & $\begin{array}{l}\text { Commonly occurring } \\
\text { compound }\end{array}$ & Dietary source \\
\hline Flavones & $\begin{array}{l}\text { Chrysin, Apigenin, Sibelin, Rutin, } \\
\text { Luteolin }\end{array}$ & $\begin{array}{l}\text { Peel of various fruits, parsley, } \\
\text { celery, grape, apple }\end{array}$ \\
\hline Flavanones & $\begin{array}{l}\text { Naringin, Naringenin, Taxifolin, } \\
\text { Eriodictyol, Hesperidin, } \\
\text { Isosakuranetin }\end{array}$ & $\begin{array}{l}\text { Citrus, grapefruit, lemon, } \\
\text { orange, tomatoes }\end{array}$ \\
& $\begin{array}{l}\text { Kaempferol, Quercetin, } \\
\text { Myricetin, Isorhamnetin }\end{array}$ & $\begin{array}{l}\text { Leek, broccoli, endive, } \\
\text { grapefruit, black tea, onion, } \\
\text { lettuce, tomato, tea, berries, } \\
\text { apples, olive oil, cranberry, } \\
\text { buckwheat, citrus, red pepper }\end{array}$ \\
\hline Flavonols & & Soybean and soy foods, fruits \\
& & \\
\hline Isoflavonoids & $\begin{array}{l}\text { Genistein, Daidzein, Biochanin } \\
\text { A, Formononentin }\end{array}$ & Tea, red grapes \\
& $\begin{array}{l}\text { Catechin, Gallocatechin, } \\
\text { Epicatechin, Epigallocatechin, } \\
\text { Epicatechin gallate, } \\
\text { Epigallocatechin gallate }\end{array}$ & \\
& $\begin{array}{l}\text { Epigenidin, Cyanidin, } \\
\text { Delphinidin, Pelargonidin, } \\
\text { Malvidin }\end{array}$ & $\begin{array}{l}\text { Stored fruits, cherry, } \\
\text { raspberry, strawberry, grapes, } \\
\text { dark fruits }\end{array}$ \\
\hline Anthocyanins & & \\
& &
\end{tabular}

\section{$\underline{\text { Stilbenes }}$}

More than 400 natural stilbenes are known. These compounds are non-flavonoid polyphenols that are characterized structurally by the presence of a 1,2-diphenylethylene nucleus. Concentration of stilbenes in plants is depended on the presence of the stilbene synthase enzyme catalyzing the biosynthesis (Reinisalo et al. 2015). Main sources of stilbenes are grapes, wine, peanut and sorghum, but in low concentration, they can be found in pistachio, berries, spinach and cabbage. The most studied representatives are the trans-resveratrol and its glycosidic forms that have gained global attention due to their ability to prevent cardiovascular diseases and cancer (Jaganath and Crozier 2010, 
Ravagnan et al. 2013). The study carried out by Gülçin (2010) showed that resveratrol is an effective antioxidant with reducing power, free radical scavenging capacity and hydrogen peroxide scavenging and metal chelating activities. It can also be used to minimize or prevent the oxidation of lipids in pharmaceutical products, maintaining its nutritional quality and prolonging its shelf life (Salehi et al. 2018).

\section{$\underline{\text { Tannins }}$}

Tannins are highly hydroxylated molecules and can form insoluble complexes with carbohydrates and proteins. According to their chemical structure, they are divided into two groups: (1) hydrolysable tannins that are esterified derivatives of gallic acid and hexahydroxydiphenic acid; (2) condensed tannins known as proanthocyanidins, which are polymers of high molecular weight catechins formed by the oxidative condensation between the phenolic ring and the adjacent units or by enzymatic polymerization of flavan3-ol and flavan-3,4-diol units (He et al. 2008). Both the condensed and hydrolysable tannins have high bioactive potential (Bele et al. 2010). The antimicrobial activity of hydrolysable tannins is summarized recently by Ekambaram et al. (2016). However, condensed tannins can inhibit the growth of many microorganisms as well (Abu Zarin et al. 2016, Tomiyama et al. 2016, Assefa et al. 2017).

\subsubsection{Health promoting effect of phenolics}

\section{Effect on cardiovascular diseases}

Polyphenols have a widely demonstrated vasodilator, anti-atherosclerotic, antithrombotic, anti-lipemic, anti-inflammatory and anti-apoptotic action (Quiñones et al. 2012). Compounds such as quercetin, epigallocatechin gallate, resveratrol, flavonols, flavanols, procyanidins and anthocyanins present in tea, wine and cocoa can be used in the prevention and/or treatment of cardiovascular diseases and pathologies associated with oxidative stress. These molecules inhibit the formation of ROS thanks to their antioxidant effect and capacity to chelate heavy metals as iron or copper (Orallo et al. 2002).

\section{$\underline{\text { Anti-diabetes effect }}$}

Diabetes is a public health problem that decreases the quality of life and increases the mortality rate. Studies have shown that the consumption of foods with a high content of polyphenols such as catechins, epicatechins, chlorogenic acids, ferulic acids, caffeic and tannic acids, quercetin and naringenin slows the development of type 2 diabetes (Bahadoran et al. 2013). They reduce the intestinal absorption of carbohydrates (reduces 
the postprandial glycemic level) (Johnston et al. 2005), regulate enzyme activity such as $\alpha$ glucosidase and lipase, reduce inflammation, improve pancreatic function (Iwai 2008), and act synergistically with hypoglycemic medicine (Prabhakar et al. 2013). Therefore, they can be used as supplementary treatments for the control and management of the complications associated with this disease.

\section{$\underline{\text { Anti-cancer effect }}$}

The main causes of cancer can be DNA damage caused by aging, exposure to chemicals, radiation and ultraviolet rays. The anticancer effect of flavonoids can be attributed to several activities such as antioxidative effect, inactivation of ROS, activation of protective enzymes such as glutathione S-transferase and glucuronosyl transferases, increase of apoptosis rate, and inhibition of cell proliferation, lipid peroxidation, angiogenesis and DNA oxidation (Chahar et al. 2011). Flavonoids such as genistein, quercetin, tangeretin, luteolin, daidzein, kaempferol, apigenin, resveratrol and epigallocatechin act in all three stages of cancer: initiation, promotion and progression (Chahar et al. 2011). Regular intake of phenolic compounds, such as green tea polyphenols, milk thistle silymarin and grape proanthocyanidins have been shown to protect the skin from the adverse effects of ultraviolet radiation, one of the causes of skin cancer (Afaq and Katiyar 2011).

\section{$\underline{\text { Anti-aging effect }}$}

Aging is a natural process, a consequence of the accumulation of a great variety of molecular and cellular damages over time. At the same time, it decreases the effectiveness of the antioxidant and repair mechanisms, which produces a progressive decrease of motor and cognitive abilities, increases the risk of diseases and finally death (Harman 2006). Alzheimer's disease is a serious cognitive degenerative disease associated with age. In the study of Porquet et al. (2013), dietary resveratrol could prevent many Alzheimer's markers in mice model. For instance, it reduced cognitive impairment, decreased the amyloid burden and reduced tau hyperphosphorylation. Moreover, it can activate pro-survival routes as well. In another investigation, the epigallocatechin gallate was able to reduce the age-associated inflammation and oxidative stress in rat models (Niu et al. 2013).

\subsubsection{Antimicrobial activity of phenolics}

Phenolic compounds can suppress several microbial virulence factors. For instance, they can inhibit biofilm formation, reduce host ligand adhesion and neutralize bacterial 
toxins (Li et al. 2014). Moreover, these substances can show synergy with antibiotics enhancing their effectiveness and reducing the dose of use. Besides antioxidant activity, the phenolic hydroxyl group plays important role in the antimicrobial activity as well. The hydroxyl group of phenolic compounds can destabilize the cell membrane structures and cause the leakage of cellular components (Xue et al. 2013). In addition, these groups can reduce the $\mathrm{pH}$ gradient across the cytoplasmic membrane (Ultee et al. 2002) and can form hydrogen bonds with active sites of enzymes (Farag et al. 1989).

Due to the above properties, the phenolic compounds can be good candidates for the development of efficient antimicrobials (Ayala-Zavala et al. 2011, Daglia 2012). In this regard, phenolic acids, flavonoids and tannins have gained attention over the last decades (Gyawali and Ibrahim 2014, Shahidi and Ambigaipalan 2015). Several laboratory pilot studies investigated the antimicrobial activity of phenolics. Some interesting recent assays are listed in Table 2.

Table 2. Examples about the antimicrobial activity of individual phenolic compounds.

\begin{tabular}{|c|c|c|c|}
\hline Compounds & Target organism & Antimicrobial activity & Reference \\
\hline $\begin{array}{l}\text { Coumarin, } \\
\text { quercetin }\end{array}$ & $\begin{array}{l}\text { Escherichia coli, } \\
\text { Enterobacter aerogenes, } \\
\text { Salmonella infantis, } \\
\text { Salmonella Typhimurium }\end{array}$ & $\begin{array}{l}\text { Coumarin: MIC*, } 0.625-5 \\
\mathrm{mg} / \mathrm{mL} ; \mathrm{MBC} * *, \geq 5 \mathrm{mg} / \mathrm{mL} \text {. } \\
\text { Quercetin: no effect. }\end{array}$ & $\begin{array}{l}\text { Nitiema et al. } \\
\text { (2012) }\end{array}$ \\
\hline $\begin{array}{l}\text { Gallic acid, } \\
\text { catechin }\end{array}$ & Helicobacter pylori & $\begin{array}{l}\text { Inhibition haloes of } 14 \text { and } 16 \\
\text { mm in the presence of } 1 \mathrm{mg} \\
\text { gallic acid and catechin, } \\
\text { respectively. }\end{array}$ & $\begin{array}{l}\text { Díaz-Gomez } \\
\text { et al. (2013) }\end{array}$ \\
\hline $\begin{array}{l}\text { Ellagic acid, } \\
\text { quercetin-3- } \\
\text { galactoside, } \\
\text { chlorogenic acid, } \\
\text { quercetin }\end{array}$ & $\begin{array}{l}\text { Listeria monocytogenes, } \\
\text { Salmonella Enteritidis }\end{array}$ & $\begin{array}{l}\text { Effective concentrations: } \\
\text { chlorogenic acid, } 500 \mu \mathrm{g} / \mathrm{mL} \text {; } \\
\text { quercetin and quercetin-3- } \\
\text { galactoside, } 200 \mu \mathrm{g} / \mathrm{mL} \text {; ellagic } \\
\text { acid, } 44 \mu \mathrm{g} / \mathrm{mL} \text {. }\end{array}$ & $\begin{array}{l}\text { Shen et al. } \\
\text { (2014) }\end{array}$ \\
\hline $\begin{array}{l}\text { Phloridzin, } \\
\text { phloretin }\end{array}$ & $\begin{array}{l}\text { Staphylococcus aureus, E. } \\
\text { coli }\end{array}$ & $\begin{array}{l}\text { MIC: } \text { S. aureus } 0.50 \text { and } 0.10 \\
\mathrm{mg} / \mathrm{ml} \text {, E. coli } 1.50 \text { and } 0.75 \\
\mathrm{mg} / \mathrm{ml} \text {. }\end{array}$ & $\begin{array}{l}\text { Zhang et al. } \\
\text { (2016) }\end{array}$ \\
\hline $\begin{array}{l}25 \text { phenolic } \\
\text { compounds }\end{array}$ & Streptococcus pyogenes & $\begin{array}{l}\text { 1,2-Naphthoquinone and 5- } \\
\text { hydroxy-1,4-naphthoquinone } \\
\text { MIC: } 0.39-6.25 \mathrm{mg} / \mathrm{ml} \text {; MBC: } \\
100 \mathrm{mg} / \mathrm{ml} .\end{array}$ & $\begin{array}{l}\text { Macé et al. } \\
\text { (2017) }\end{array}$ \\
\hline
\end{tabular}

* MIC, minimum inhibitory concentration; ** MBC, minimum bactericidal concentration

In addition, García-Ruiz et al. (2011) analyzed the antimicrobial activity of 18 phenolic compounds, i.e. hydroxycinnamic acids, hydroxybenzoic acids, stilbenes, flavan3-ols, flavonols and phenolic alcohols, against lactic acid bacteria isolated from wine. 
Flavonols and stilbenes showed the strongest inhibitory effect, while the activity was negligible in case of the flavan-3-ols. In another study, the effect of 15 kinds of phenolic acids, stilbene and flavonoid compounds from grapes were investigated against the growth of spoilage yeasts and acetic acid bacteria. Pterostilbene, resveratrol and luteolin presented high inhibitory effect against all microorganisms tested. Myricetin, $p$-coumaric acid and ferulic acid showed selective antimicrobial activity depending on the species of yeasts and bacteria tested (Pastorkova et al. 2013). In the study of Tenore et al. (2012), the flavonoid and phenolic acid fractions of red pitahaya exhibited good inhibitory effect on the growth of various Gram-positive and Gram-negative bacteria, yeasts and molds.

\subsubsection{Plant phenolics as anti-quorum sensing and anti-biofilm agents}

Many bacteria can form biofilm, that is, communities enclosed in self-synthesized extracellular polymer matrices, attached to biotic or abiotic surfaces. One of the main communication processes regulating biofilm formation and development is the quorum sensing (QS) mechanism based on autoinducer signal molecules. Once colonization has begun, several cell divisions lead to the maturation of the biofilm and expression of certain biofilm related genes. Within the biofilm, the cells are metabolically less active than the planktonic form; therefore, they are significantly less sensitive to the action of antimicrobial agents, which is the main cause of chronic infections (Landini et al. 2010). Biofilms are a potential risk in the food industry, including brewing (Flemming and Ridgway 2009), seafood (Shikongo-Nambabi et al. 2011) and dairy processing (Chmielewski and Frank 2003). Therefore, elimination of biofilms and inhibition of their formation have great importance in today's preservative agent developments.

Certain plant phenolic substances can exhibit anti-biofilm and/or anti-quorum sensing (anti-QS) activities (Silva et al. 2016, Slobodníková et al. 2016, Asfour 2018). Therefore, an effective phenolics-based QS inhibitor could inhibit the biofilm formation of pathogenic bacteria as well (Kalia 2013). Many studies have addressed with this topic. For instance, catechin (Vandeputte et al. 2010), naringenin (Vandeputte et al. 2011) and quercetin (Ouyang et al. 2016) depicted strong anti-QS property against Pseudomonas aeruginosa. Additionally, kiwifruit pulp with high vanillic acid content showed anti-QS and anti-biofilm activities in Serratia marcescens (Sethupathy et al. 2017). Naringenin, quercetin, sinensetin, apigenin and grape seed extracts were effective QS antagonists and biofilm suppressors in pathogenic Escherichia coli strains (Vikram et al. 2010, Sheng et al. 
2016). Studies were done to inhibit and eradicate the Staphylococcus aureus biofilms as well. For instance, the 1,2,3,4,6-penta- $O$-galloyl- $\beta$-D-glucopyranose from Eustigma oblongifolium could block the synthesis of intercellular adhesion compounds in S. aureus, preventing its adherence to solid surfaces (Lin et al. 2011). In addition, phenolic acids such as gallic acid (Luís et al. 2014), ginkgolic acid (Lee et al. 2014) and rosmarinic acid (Slobodníková et al. 2013), and several flavonoids (Cho et al. 2015) also modulated the $S$. aureus biofilm in subinhibitory concentrations. In a comprehensive study, which dealt with human bacterial pathogens, methanol extract from pomegranate, rich in ellagic acid, inhibited the biofilm formation of $S$. aureus, methicillin resistant $S$. aureus (MRSA) and $E$. coli (Bakkiyaraj et al. 2013). The phloretin, a flavonoid present in the apple inhibited the formation of E. coli $\mathrm{O} 157: \mathrm{H} 7$ biofilms without affecting the growth of planktonic cells (Lee et al. 2011). Regarding fungi, eugenol and ellagic acid proved to be effective inhibitors of Candida albicans biofilms (He et al. 2007, Bakkiyaraj et al. 2013).

Based on the above findings, phenolic compounds can be useful tools against various microorganisms, including many foodborne pathogens and spoilage bacteria. Application of phenolics as alternatives or supplements in antibiotic treatments could also be a cost-effective technology worth taken into consideration.

\subsection{Antioxidative fruit substances relevant to this study}

\subsubsection{Grapes}

Grapes are economically important plant species; wine, juice, jam and raisin can be produced from them. More than 77 million tons are produced annually from this fruit (http://www.fao.org/faostat). About $80 \%$ of the total amount is utilized for winemaking purposes (Ayala-Zavala et al. 2011). Pomace represents approximately $30 \%$ of the weight of grapes processed. Its composition varies considerably, depending on grape variety and technology of wine making. Major phenolic compounds in the grape pomace are phenolic acids (e.g., caftaric acid, coutaric acid and trans-fertaric acid), flavonols (e.g., glycosidic forms of quercetin and myricetin) (Souquet et al. 2000) and flavanonols (e.g., astilbin and engeletin) (Lu and Yeap Foo 1999). Stilbenes such as trans- and cis-resveratrol, piceids, astringins, resveratrolosides and pterostilbene can also be found in grapes (Naczk and Shahidi 2006). Grape seeds are a rich source of monomeric phenolic compounds such as (+)-catechin, (-)-epicatechin, (+)-gallocatechin, (-)-epigallocatechin, and their dimeric, 
trimeric and tetrameric proanthocyanidins (Sun and Spranger 2005). Black grapes are one of the major sources of dietary anthocyanins. Majority of these compounds are accumulated in the berry skin. The phenolic compounds in grape pomace and other grape residue extracts exhibit antioxidant, anticancer, antidiabetic, anti-inflammation, antimicrobial and cardioprotective properties (Xia et al. 2010, Teixeira et al. 2014, Yadav et al. 2015). Majority of the flavonoids are found in the skin, whereas about $60-70 \%$ of total polyphenols are stored in grape seeds (Han et al. 2007). More than $70 \%$ of grape polyphenols remain in the pomace after juice processing (Ratnasooriya and Rupasinghe 2012). The grape seeds may be separated from the pomace and used either for production of grape seed oil or grape seed powder/extract as individual food, additive in cosmetics and pharmaceutical industry as well as biomass for biogas production (Cáceres et al. 2012, Dwyer et al. 2014).

\subsubsection{Apple}

The world apple production is estimated to nearly 89 million tons per year (http://www.fao.org/faostat). Antioxidant properties of apple materials highly dependent on the fruit variety, agricultural methods, weather, storage conditions and fruit processing. Apples are a good source of polyphenols, which are predominantly localized in the peels and are extracted into the juice to a minor extent. The major polyphenolic groups present in apple are hydroxycinnamic acids (chlorogenic and p-coumaroylquinic acids), cyanidin-3galactoside, flavan-3-ols/procyanidins (mainly catechin, epicatechin and procyanidins B1 and B2), flavonols (quercetin glycosides), and dihydrochalcones (mainly phloridzin and phloretin-2'-xyloglucoside) (Tsao et al. 2005). Apple pomace is a solid waste generated by cider and apple juice making processes. This substance consists of peel, core, seed and stem residues, which constitute of about 25-35\% mass of the fresh fruit. Apple pomace can be utilized to produce pectin (Schieber et al. 2003), enzymes (Favela-Torres et al. 2006), organic acids (Shojaosadati and Babaeipour 2002), protein, feed (Bhalla and Joshi 1994), ethanol (Parmar and Rupasinghe 2013), aroma compounds (Madrera et al. 2015) and natural antioxidants (Ajila et al. 2011, Zhang et al. 2016). In addition, the ethanolic extract from apple peel exhibited antimicrobial activity against Bacillus cereus and E. coli O157:H7 (Fratianni et al. 2011). 


\subsubsection{Pitahaya}

Pitahaya (known as dragon fruit) is a tropical fruit produced mainly in Asian and Central and South American countries (Le Bellec and Vaillant 2011). There are three species of pitahaya: Hylocereus polyrhizus (red pitahaya), Hylocereus undatus (white pitahaya) and Hylocereus megalanthus (yellow pitahaya) (Lim et al. 2010). The difference is based on their shape, size and color of their flesh (Nurul and Asmah 2014). Bioactive potential of red and white pitahayas is intensively studied (Kim et al. 2011, Tenore et al. 2012), while less attention has been paid to the yellow variety in this regard. Pitahaya contains pectin, fiber, simple sugars (e.g., glucose, fructose and sucrose), vitamins and various minerals (e.g., phosphorus, calcium, potassium, magnesium, iron) (Le Bellec et al. 2006, Nurul and Asmah 2014). Pitahaya is a rich source of phenolic antioxidants; however, there are differences in the phenolic contents of the different varieties and fruit parts (Kim et al. 2011). In addition, red pitahaya contains betacyanins, responsible for the purple color of the peel and flesh (Tenore et al. 2012). After extraction, these compounds can be utilized as natural colorants in foods (Vaillant et al. 2005). The seed and peel fractions of pitahaya have higher antioxidative capacity compared to the flesh (Choo et al. 2016). Pitahaya consumption has many health benefits including hypocholesterolemic, prebiotic, anticancer, anti-inflammatory and antidiabetic effects (Choo et al. 2016, Song et al. 2016). The phenolic fractions of red and white flesh pitahaya fruit demonstrated antimicrobial activity against different pathogens (Nurmahani et al. 2012, Yong et al. 2018). However, there are only scarce data about yellow pitahaya (H. megalanthus) residue samples in this regard (Choo et al. 2016).

\subsubsection{Mango}

Mango (Mangifera indica L.) grows in many tropical countries in the world. From the available varieties, only a few are grown on commercial scale. The global production of mangoes was about 50 million tons in 2017 (http://www.fao.org/faostat). About 35-60\% of the total weight of the fruit remained as byproduct after processing (O'Shea et al. 2012). Mango peel is an important source of dietary fiber, carotenoids, vitamins $\mathrm{C}$ and $\mathrm{E}$, phenolic compounds with good antioxidant activity. The major phenolics in mango are gallic, protocatechuic and syringic acids, kaempferol and quercetin (Ajila and Prasada Rao 2013). The antimicrobial activity of mango seed extracts could be attributed to the presence of 
flavonoids, terpenes, tannins and coumarins (Orijajogun et al. 2014). In this context, it has been reported that the kernel powder of an African mango variety displayed high antimicrobial activity against $S$. aureus, P. aeruginosa, E. coli, Bacillus subtilis and $C$. albicans (Ahmed et al. 2012). Moreover, the study of Gadallah and Abdel Fattah (2011) showed that mango seed extract was more effective against Gram-positive pathogens $(S$. aureus and B. subtilis) than Gram-negative bacteria (E. coli and Salmonella sp.) in minced beef during refrigerated storage. The mango fruit and byproducts displayed high antioxidant activity, radical-scavenging capacity, metal-chelating capacity and tyrosinase inhibitory activity, thus can be used in food, cosmetic, nutraceutical and pharmaceutical applications.

\subsubsection{Naranjilla}

Naranjilla (Solanum quitoense) is the fruit of a subtropical perennial plant that belongs to the Solanaceae family, native in the northwestern Andes. It is used to produce juice, ice creams, candies, jams, jellies, sauces and other cooked confections (AndradeCuvi et al. 2015). Two geographically separated varieties are recognized: $S$. var. quitoense, a spineless form, found in southern Colombia and Ecuador, and S. var. septentrionale, a form with spines that is found in central Colombia, Panama and Costa Rica (Acosta et al. 2009). During ripening, naranjilla turns from green to orange. Sometimes it is consumed and processed at earlier stages of maturity, but the late harvested fruit has sweeter pulp due to the high total soluble solid content. S. quitoense contains simple sugars (e.g., glucose, fructose, sucrose), organic acids, dietary fiber (15\% dry matter, DM), proteins (7.4\% DM), minerals (approx. $52 \mathrm{mg} / 100 \mathrm{~g} \mathrm{DM}$ ), carotenoids (e.g., lutein, zeaxanthin), vitamins (e.g., niacin, thiamine, riboflavin, vitamin $\mathrm{A}$ and $\mathrm{C}$ ), caffeoylquinic acids and their derivatives, and different flavonol glycosides (e.g., quercetin and kaempferol derivatives) (Gancel et al. 2008). The chlorogenic acid and dihydrocaffeoyl spermidine compounds can be found in all parts of the fruit, while the flavonol glycosides are located mainly in the peel. The total phenolic content is superior in the peel than in the flesh. The antioxidant activity of naranjilla is close to those of red grape, peach and pear, but higher than those of kiwi fruit, banana, watermelon, pineapple and cantaloupe (Acosta et al. 2009). 


\subsection{Fruit and vegetable processing byproducts}

The food and agricultural product processing industries generate a large volume of plant byproducts causing difficulties in their disposal and treatment (Socaci et al. 2017). Some possible utilization pathways for these substances are presented in Figure 3. Food processing residues are generally utilized as animal feed, natural fertilizers or as biomass for bioethanol production (Laufenberg et al. 2003, Kruczek et al. 2016). Peels, pulps and seeds from fruits and vegetables, however, could be rich in extractable phytochemicals including phenolic compounds, carotenoids and dietary fibers with relevant bioactivity (Moure et al. 2001). The content of bioactive compounds of the byproduct is often similar or higher than that of the main product (Kunradi Vieira et al. 2009, Ayala-Zavala et al. 2011). For instance, Kalogeropoulos et al. (2012) studied the bioactive composition of tomato whole raw material and its byproduct, wherein tomato peel and seeds had a higher concentration of carotenoids (lycopene and $\beta$-carotene) and phenolic compounds compared to the pulp fraction. Similar results were found in the investigation of brown-colored onion; concentration of flavonols in the outer skin was higher than in the inner parts (Benítez et al. 2011).

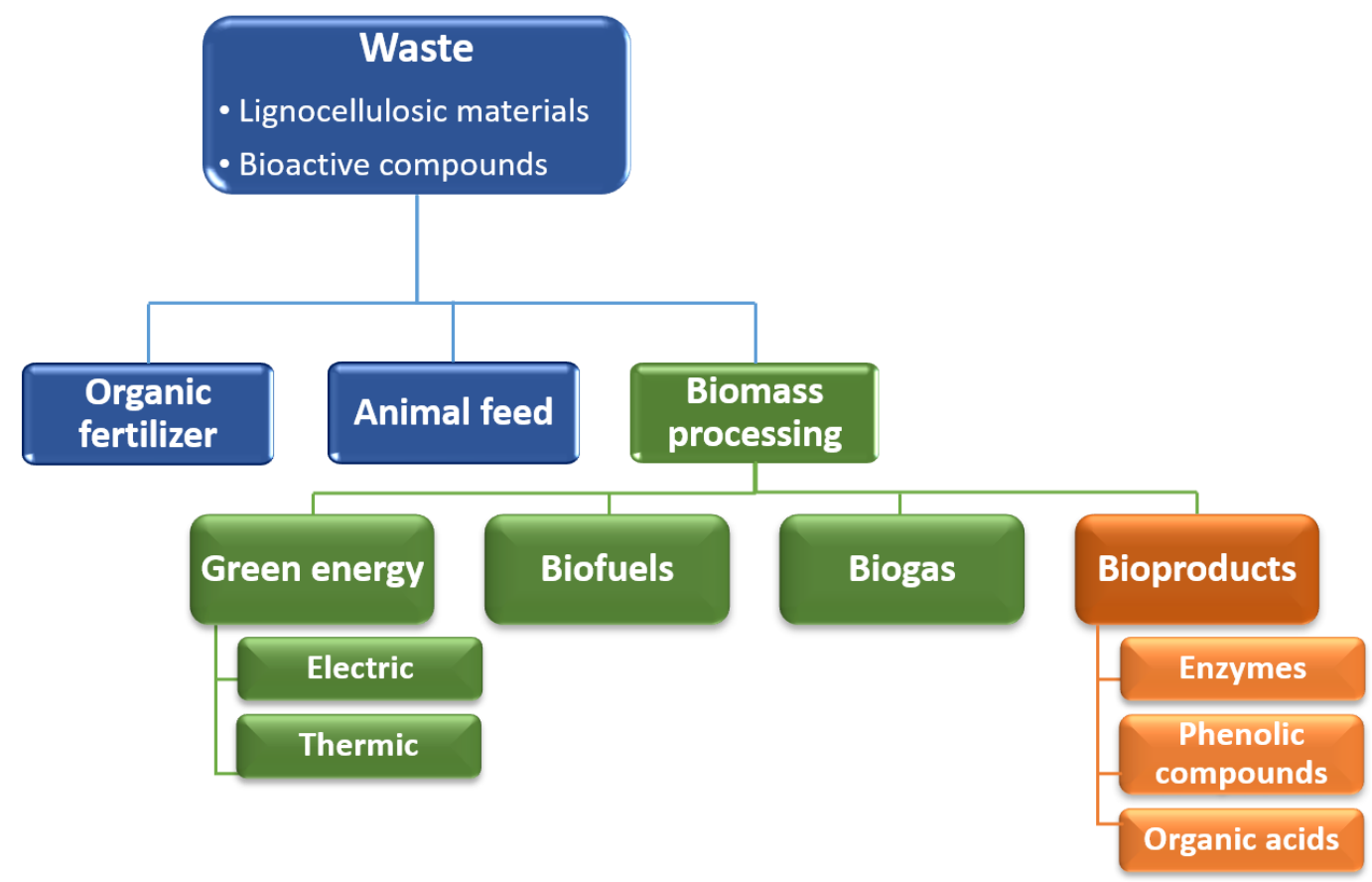

Figure 3. Bioconversion possibilities of agro-industrial residues into value-added products (edited by C. Zambrano). 
Increasing interest can now be observed for the utilization of plant residues to produce natural additives and supplements rich in valuable compounds. The recycling and recovery of these byproducts could be economically attractive for industries to obtain health-promoting compounds as well as developing functional ingredients (Galanakis 2012, Kumar et al. 2017). Pomace is the solid part of the plant, which contains seeds, skin, pulp of the fruits or vegetables, and it can be defined as a byproduct remains after juice pressing. Approximately 25-35\% mass of the raw material generally left after the pressing process (Kruczek et al. 2016). Fruit juices are the principal processed fruit products commercialized in the world.

According to the Food and Agriculture Organization of the United Nations (FAO), the cultivation of apples, grapes and mangoes corresponded to $39 \%$ of the world's fruit production in 2016 and about $45 \%$ of the produced fruits and vegetables are wasted throughout the entire production chain (http://www.fao.org/faostat). Also, pitahaya has growing interest in the exotic fruit market (Le Bellec and Vaillant 2011). In 2016, the waste materials coming from the industrial processing of these fruits were around 25 million tons and most of them were sent to the landfill or used to produce organic fertilizers and animal feed. In past decades, however, the research on the use of the biomass has gained interest for the extraction of biomolecules such as phenolic compounds, organic acids, enzymes, polysaccharides and other industrially important products (De Ancos et al. 2015).

\subsection{Extraction of phenolics from plant materials}

Extraction is the first step for the recovery of phenolic compounds from plant substrates. The yield and purity of the compounds obtained may vary if the phenolics are present in a simple or conjugated form (e.g., compounds linked with pectin, arabinoxylan or mono- or polysaccharide molecules), and other factors of the extraction process such as temperature, time, agitation, presence of inhibitors and sample particle size (Naczk and Shahidi 2004). Conjugated phenolic compounds can be separated by physical (e.g., ultrasound assisted) and chemical methods (e.g., acid, alkaline or enzymatic hydrolysis). The conventional solid-liquid extraction processes such as mechanical agitation and treatment with organic solvents alone or in combination generally achieve different extraction efficiencies (López-Miranda et al. 2016). In this context, the long extraction time at high temperatures demanded by certain solvents can induce thermal decomposition 
leading to activity loss in the phenolic content (Wang and Weller 2006). Physical methods such as microwave and ultrasound-assisted extractions can be conducted with short conversion time and can improve the phenolic content and antioxidant activity of the extract compared to solvent extraction techniques (Nayak et al. 2015). However, these methods require high investment costs and are difficult to carry out on an industrial scale. To extract phenolics, many studies applied organic solvent/alcohol-water mixtures where the water can enlarge the permeability of the cell wall and the extraction of hydrolysable compounds by molecular diffusion (Jayaprakasha et al. 2001). For instance, the study of Alonso et al. (1991) suggests that the ethanol-water mixture improves the recovery of catechins and procyanidins from grape seeds. In another assay, the water-ethanol and water-acetone combinations resulted in higher phenolic yields from grapes compared to those obtained with acetone or ethanol alone (Kallithraka et al. 1995). However, the fermentation and enzyme-assisted extraction methods, alone or in combination with the abovementioned techniques, could provide an alternative way to obtain more phenolic yield with improved antioxidant capacity.

\subsection{Solid-state fermentation}

\subsubsection{Application of solid-state fermentation on the production of biomolecules}

Solid-state fermentation (SSF) is a well applicable method for bioactive compound production and enrichment from fruit and vegetable processing byproducts (LizardiJiménez and Hernández-Martínez 2017). The fermentation process could be defined as the cultivation of microorganisms on the surface and inside of a solid substrate in the absence or in the presence of a very low amount of free water. Agro-industrial wastes generally have high sugar content that are easily assimilated by microorganisms; therefore, they are suitable raw materials as fermenting substrates to produce compounds relevant to industry (Rodríguez Couto 2008). Anyway, the SSF is considered as a technological way in the waste management, which is suitable for the ecofriendly utilization of many agro-industrial byproducts.

The selection of residues depends on its availability, composition and cost. Sugarcane and cassava bagasse, oil cakes, orange peel, apple and grape pomace, coffee husk and wheat bran are the most common fermentation materials used (Krishna 2005). There are important factors in terms of the efficient bioconversion, such as substrate 
pretreatment, moisture level, water activity, particle size, growth medium supplementation, temperature, $\mathrm{pH}$, agitation and aeration (Singh nee' Nigam and Pandey 2009). The advantages of SSF over submerged fermentation $(\mathrm{SmF})$ are a consequence of the different physiology shown by fungi and other microorganisms on a solid substrate. In SSF, for instance, final yields of various extracellular enzymes of filamentous fungi are significantly higher than in SmF (Barrios-González 2012). The production yield of a heterologous chymosin by Aspergillus oryzae was 500-fold higher in wheat bran based SSF systems than in SmF conditions (Tsuchiya et al. 1994). In a comparative study, the economic yield of cellulase production in SSF was higher compared to SmF (Tengerdy 1998). Several studies reported that antibiotics, organic acids, polyunsaturated fatty acids, biopesticides and biofuels can be produced under SSF conditions in high yield. From biochemical engineering point of view, the temperature, oxygen limitation and moisture content are the main factors during the fermentation (Bhargav et al. 2008).

\subsubsection{Microorganisms applied in solid-state fermentation}

Microorganisms that grow naturally on solid substrates, e.g. pieces of wood, stems, roots, etc., are the most suitable for the bioconversion of agro-industrial wastes. Filamentous fungi are important microorganisms in the SSF processes owing to their physiological, enzymological and biochemical properties. The hyphal growth of filamentous fungi gives them a great advantage to penetrate and use the nutrients of solid substrates. The contact of hyphae with the substrate surface is enabled and the mycelium synthesizes hydrolytic exoenzymes in high yield (Raimbault 1998). Table 3 shows some examples of fungi used in SSF with the appropriate solid substrates to produce bioactive compounds and enzymes. 
Table 3. Some SSF studies applying fungi as fermenting microorganism for bioactive compound production.

\begin{tabular}{|c|c|c|c|}
\hline Filamentous fungi & Substrate & Product & References \\
\hline Aspergillus niger & Cassava bagasse & Citric acid & $\begin{array}{l}\text { Vandenberghe } \text { et al. } \\
(2000)\end{array}$ \\
\hline Aspergillus niger & $\begin{array}{l}\text { Wheat bran, soybean meal, } \\
\text { cottonseed meal, orange peel }\end{array}$ & Protease & de Castro et al. (2015) \\
\hline Aspergillus niger & Sugarcane bagasse & Citric acid & Yadegary et al. (2013) \\
\hline Aspergillus fumigatus & Wheat bran, rice straw & Cellulase & Das et al. (2013) \\
\hline Aspergillus oryzae & Wheat bran+coconut oil cake & $\begin{array}{l}\text { Neutral } \\
\text { metalloprotease }\end{array}$ & Sumantha et al. (2006) \\
\hline Fusarium oxysporium & $\begin{array}{l}\text { Groundnut cake, soybean cake, } \\
\text { and cottonseed cake }\end{array}$ & Protease & $\begin{array}{l}\text { Apastambh and Baig } \\
(2017)\end{array}$ \\
\hline Monascus purpureus & Jack fruit seed & Pigment & Babitha et al. (2007) \\
\hline Mortierella alpina & Rice bran & $\begin{array}{l}\text { Polyunsaturated } \\
\text { fatty acid }\end{array}$ & Jang and Yang (2008) \\
\hline $\begin{array}{l}\text { Mucor corticolus, } \\
\text { Rhizomucor miehei, } \\
\text { Gilbertella persicaria, } \\
\text { Rhizopus niveus }\end{array}$ & Corn residues, wheat bran & $\begin{array}{l}\text { Cellulase, } \\
\text { lipase, protease }\end{array}$ & Takó et al. (2015) \\
\hline $\begin{array}{l}\text { Penicillium } \\
\text { simplicissimum }\end{array}$ & Soybean cake & Lipase & Di Luccio et al. (2004) \\
\hline Rhizopus arrhizus & $\begin{array}{l}\text { Corn flour, wheat bran, rice } \\
\text { bran, wheat flour, sunflower } \\
\text { meal, sunflower cake, oat bran }\end{array}$ & Lipase & Dobrev et al. (2018) \\
\hline Rhizopus oryzae & $\begin{array}{l}\text { Coconut oil cake + sesame oil } \\
\text { cake }(1: 1, \mathrm{w} / \mathrm{w})\end{array}$ & Phytase & $\begin{array}{l}\text { Ramachandran et al. } \\
\text { (2005) }\end{array}$ \\
\hline Trichoderma reesei & Wheat bran & Cellulase & Singhania et al. (2007) \\
\hline Trichoderma harzianum & Colloidal chitin & Chitobiase & Binod et al. (2007) \\
\hline
\end{tabular}

\subsection{Rhizomucor miehei}

The genus Rhizomucor has two well characterized species, Rhizomucor miehei and Rhizomucor pusillus. The saprotrophic $R$. miehei is a thermophilic homothallic fungus that produces numerous colored sporangiospores, therefore, its colony has dark gray color. The optimum growth temperature of $R$. miehei is between 35 and $45{ }^{\circ} \mathrm{C}$, and the maximum is about $58{ }^{\circ} \mathrm{C}$. It is an excellent producer of industrial enzymes, especially aspartic protease, lipase, $\beta$-1,3-glucanase, $\beta$-glucosidase and xylanase (Maheshwari et al. 2000, Ferreira et al. 2013). The aspartic proteases have been widely used as substitute for calf chymosin in the cheese production (Rao et al. 1998). Lipases of $R$. miehei are commercialized in soluble and immobilized forms; those have a very high activity and good stability (Rodrigues and Fernandez-Lafuente 2010, Takó et al. 2017). Other extracellular enzymes have also been 
characterized from $R$. miehei including fibrinolytic enzymes and xylanases (Ali and Ibrahim 2008, Fawzi 2010).

\subsection{Application of enzymes to produce plant bioactives}

Enzymes are frequently used in industrial processes. These are mainly hydrolytic enzymes that are utilized in the textile-, pulp- and paper-, and food- and feed industries in large quantities (Li et al. 2012). In the last decades, the use of enzymes has gained relevance in the ecofriendly enrichment of polyphenols from plant cell-wall structures (Soto-Maldonado and Zúñiga-Hansen 2018). Namely, the carbohydrate cleaving enzymes can hydrolyze the phenolic glycosides releasing the aglycone phenols, thus, improving their bioavailability (Madeira Jr et al. 2015). Enzymes such as pectinase, cellulase, hemicellulase and glucanase are used in the extraction of complex polyphenols. Other enzymes can also be associated with the liberation of phenolic aglycone moieties. For instance, tannin acyl hydrolase (known as tannase) catalyzes the hydrolysis of the galloyl ester bond of hydrolysable tannins (mainly tannic acid). Tannins are present in a variety of plants processed in food industry (Sagar et al. 2018); therefore, their amount in byproducts is considerable. The released gallic acid then can be utilized as intermediate compounds in various organic synthesis processes and food industrial applications (Zhang et al. 2015).

Enzymatic extraction of phenolic compounds from food wastes has many advantages over the physical and solvent based methods, such as the high efficiency, large scale application and eco-friendly reaction conditions (Shahidi and Yeo 2016). Furthermore, as a non-denaturing condition, the enzyme treatment can preserve the antioxidant activity of the extracted phenolic compounds (Laroze et al. 2010). In addition, low-cost enzyme preparations with high carbohydrase activity can be obtained via fermentation of various agro-industrial wastes (Behera and Ray 2016), then, the produced cocktails can be used for efficient phenolic extraction. In most studies, however, commercially available enzyme preparations are applied as extraction biocatalysts (SotoMaldonado and Zúñiga-Hansen 2018).

The operating condition of the enzyme treatment affects the release of phenolic compounds. The most important factors are composition, particle size and porosity of the raw material; type of enzyme and its activity (Hong et al. 2013); the method used for quantifying antioxidant capacity (Laroze et al. 2010); enzyme/substrate ratio and the reaction time; temperature of the treatment and the solid-liquid ratio in the reaction 
environment (Azmir et al. 2013). For instance, reaction temperatures between 45 and 55 ${ }^{\circ} \mathrm{C}$ proved to be optimal to achieve the highest phenolic yield during the enzyme assisted extraction of pomegranate husk (Mushtaq et al. 2015). High temperatures could cause a decrease in phenolic yield because of the enzyme inactivation and phenolic degradation. Chandini et al. (2011) studied the recovery of antioxidants from tea extract by applying pectinase or tannase at different concentrations. Concerning pectinase, only the enzyme concentration of $20 \mathrm{U} / \mathrm{g}$ black tea caused significant increase in the free phenolic content. However, the higher the tannase concentration, the higher the phenolic yield was in the extract. In the study of Laroze et al. (2010), the highest Grindamyl CA 150 (pectinase) concentration used (10\% enzyme/substrate ratio) caused a significant increase in the free phenolic yield and antioxidant activity of raspberry residues. Type of carbohydrases, enzyme-substrate ratio and temperature were the most relevant variables in the enzymatic extraction of polyphenols from grape residues (Kammerer et al. 2005).

\subsection{Importance of pretreatment of fruit byproducts}

Prior to fermentation and enzyme treatment, the byproduct residues are subjected to drying and subsequent grinding in most studies. Frequently used pretreatment methods are the heat treatment (vaporization), drying and grinding. First step could be wet grinding of the byproduct to decrease the particle size of wet residue for further actions (Galanakis 2012). To avoid the degradation of phytochemical compounds during storage, stabilization of the byproducts is needed. The reduction of free water in the substrate is essential to inactivate the enzymes responsible for the degradation of biologically active compounds and to decrease the microbial growth rate. Enzymatic browning could occur by the result of enzymatic oxidation of phenolic compounds in the presence of oxygen (Pirovani et al. 2015). For example, apple pomace without drying process could quickly suffer from brown discoloration thanks to polyphenol oxidase activities, and microbial spoilage (Kammerer et al. 2014). Due to the moisture content of the pomace, the risk that unwanted microorganisms populate fruit and vegetable pomace is high. However, if the pomace is dried immediately after harvesting, microbial contamination can be decreased, thereby, the shelf life of the pomace is expanded (Kruczek et al. 2016). Hot air drying (oven-drying) and freeze-drying (lyophilization) are frequently used drying procedures (Vashisth et al. 2011). 
Heating has impact on activation or de-activation of some key enzymes (e.g., pectin methyl esterase or polyphenol oxidases), which determines the final amount and quality of bioactive compounds in the residues (Galanakis 2012). However, some bioactive phenolics are sensitive to heat. Temperatures higher than $50{ }^{\circ} \mathrm{C}$ often cause their chemical degradation, isomerization or polymerization affecting the antioxidant capacity of the byproduct (Sadilova et al. 2007, Yu and Ahmedna 2013). Drying procedures in oven use a temperature of about $60{ }^{\circ} \mathrm{C}$ for a few hours. This technique has low operating cost, but the risk of degradation of the phenolic compounds is relatively high. Alternatively, ohmic heating, also called as electro-conductive heating, could be applied for avoiding the thermal damage of heat sensitive substances, such as vitamins and pigments (Aggarwal and Jain 2019).

The freeze-drying procedure is based on sublimating the water from a previously frozen sample. As it needs vacuum, and the process could take several days to reduce the moisture content to the desired level, lyophilization is a costly and time-consuming technique compared to oven-drying (Galanakis 2012). Using lyophilization, however, high quality products could be obtained with minimal loss in their nutritional and organoleptic (e.g., content of volatile components) properties (Vashisth et al. 2011). This pretreatment method could preserve the physical and chemical structures of the byproduct thanks to the low temperature (Michalczyk et al. 2009). The study of Khanal et al. (2010) showed that the heating above $60{ }^{\circ} \mathrm{C}$ significantly decreased the concentrations of procyanidins and anthocyanins in blueberry and grape pomace. The authors concluded that drying at low temperature for three days may not be detrimental compared to heating at higher temperatures for more than eight hours. In another research, freeze-dried mango husk and seed retained phenolic compounds in higher percentage than the oven-dried samples, which could be a result of the lack of heat-related damage (Sogi et al. 2013). Lyophilization also proved to be a suitable pretreatment to stabilize the bioactive compounds in onion (De Ancos et al. 2015) and apple byproducts (Wolfe and Liu 2003).

For high yield recovery of phytochemicals from byproducts, grinding is needed before or/and after the drying process to get the appropriate particle size. Grinding supports the degradation of the lignin-cellulose network, thereby, can increase the surface contact area for enzyme treatment. Grinded particles could facilitate the accessibility of hydrolytic enzymes to degrade cellulose and improve the bio-digestibility and the porosity of the solid residues. When solvent extraction is applied, grinding provides higher diffusion of solvents into the byproduct matrix as well (Hendriks and Zeeman 2009, Galanakis 2012). 


\subsection{Foodborne pathogens and spoilage bacteria}

Foodborne diseases frequently occur worldwide. The infection is caused by the consumption of food or water contaminated with a pathogen and/or microbial toxin. The pathogenesis varies according to the host's health condition, the type of food consumed, the type of microorganism and the number of microbes, to which the host is initially exposed. Foodborne pathogens can live in adverse environments such as cold, warm, acidic and high salt conditions and have the capacity to form biofilms on biotic or abiotic surfaces. Therefore, they could become tolerant against many food processing and conservation methods (Gyawali and Ibrahim 2014, Begley and Hill 2015). QS, as a mechanism of bacterial communication, plays an important role in the development, resistance and proliferation of bacterial biofilms, accordingly, its inhibition can contribute to the elimination of pathogenic and spoilage organisms (Alvarez et al. 2012). The risk of foodborne illnesses is enhanced by the contamination of foods before consumption and by the increased consumption of raw products, such as fruits and vegetables, packaged salads and ready-to-eat products (King et al. 2000). Another problem is the selective pressure generated by the use, misuse and overuse of antimicrobial drugs, which can lead to resistance of microorganisms against clinical antibiotic therapy (Ngwoke et al. 2011, Daglia 2012). Nevertheless, despite the high worldwide food demand and progresses in conservation techniques, the food losses due to microbial deterioration are large. Many synthetic antimicrobials are used successfully for shelf life extension; however, growing concern of consumers against such preservatives in foods encourages researchers to screen for natural alternatives.

A variety of natural antimicrobials is known that can be used against foodborne pathogens. These are obtained from animal, plant, bacterial, algal and fungal sources (Gyawali and Ibrahim 2014). Antimicrobial activity of plant extracts can be attributed to secondary metabolites (Ngwoke et al. 2011); of which polyphenolics is one of the largest groups (Daglia 2012). Besides the in vitro activity (see section 2.2.3), many studies have demonstrated the in situ efficacy of antimicrobial plant phenolic compounds as well (Stojković et al. 2013, Papuc et al. 2017).

The US Centers of Disease Control and Prevention has reported a list of selected multistate foodborne outbreak investigations from 2006 until date (www.cdc.gov/foodsafety/outbreaks/multistate-outbreaks/outbreaks-list.html) and found that the strains of E. coli and Listeria monocytogenes and various Salmonella serovars are 
the main causes of foodborne disease outbreaks. In addition, other food-related bacteria such as Shigella, Clostridium, Campylobacter, Staphylococcus and Bacillus species may also be responsible for food and waterborne illnesses and/or toxic symptoms (Addis and Sisay 2015). In the present work, several representatives from the above genera were selected to test the antimicrobial capacity of phenolic extracts produced. 


\section{AIMS}

There is a growing interest in the application of phenolic antioxidants as natural additives in functional foods. Fruit residues are excellent substrates to produce such phenolics, however, most of them occur in conjugated forms with sugar residues reducing their bioavailability. Carbohydrate-cleaving enzymes, i.e. cellulases and pectinases, can hydrolyze these glycosides releasing the phenolic aglycones. Foodborne pathogens and spoilage bacteria cause serious problems in the food industry despite preservation methods are applied. Because synthetic preservatives in foods provoke serious concern in consumers, there is a need to identify and produce novel preservatives. The abovementioned phenolic compounds can enhance the stability and shelf life of food products, increase their antioxidant capacity, and inhibit the growth of a range of bacteria and fungi.

In previous studies, the Rhizomucor miehei NRRL 5282 was identified as a high yield cellulase producer fungus (Takó et al. 2010, 2015). Therefore, the main objective of our work was to mobilize bioactive phenolic compounds from fruit byproducts via in vivo SSF with the $R$. miehei NRRL 5282 isolate and in vitro substrate treatment using $R$. miehei cellulolytic enzyme cocktail. The extraction efficiency of the phenolic compounds can be improved by pectinases, thus, addition of commercial Aspergillus niger pectinase to the $R$. miehei enzyme cocktail was also planned. We expect to show that the obtained phenolic rich extracts can be used as sources of natural antimicrobial agents.

For this purpose, our specific objectives were the followings:

1. Selection, preparation and pretreatment of residue substrates rich in polyphenolic compounds.

2. Completion of SSF studies using the R. miehei NRRL 5282 as the fermenting organism.

3. Direct enzyme treatment of the residues using a crude cellulolytic extract produced by $R$. miehei NRRL 5282 and/or a pectinase preparation from A. niger.

4. Analysis and comparison of the total phenolic content and the phenolic profile of the extracts before and after fermentation and enzyme treatment using spectrophotometric and chromatographic methods.

5. Evaluation of the bioactive properties of the extracts before and after fermentation and enzyme treatment by: 
- antioxidant capacity studies,

- antimicrobial activity assays against foodborne pathogens and spoilage bacteria,

- investigation of the anti-QS capacity with the model organism Chromobacterium violaceum,

- study of the inhibitory effect of bioactive extracts on the biofilm formation of foodborne pathogens and spoilage bacteria. 


\section{MATERIALS AND METHODS}

\subsection{Substrates}

Othello black grape (Vitis vinifera $x$ (Vitis labrusca $x$ Vitis riparia)), Saszla white grape (Vitis vinifera) and Jonagold apple (Malus domestica cv. Jonagold) were purchased at a local market in Szeged, Hungary. Yellow pitahaya (Hylocereus megalanthus), Tommy Atkins mango (Mangifera indica L.) and naranjilla (Solanum quitoense) were purchased at a local market in Guayaquil, Ecuador.

\subsection{Media}

The composition of the used media is presented in Table 4. Solid media were prepared by addition of $2 \%$ agar-agar.

Table 4. Composition of the media used during the experiments.

\begin{tabular}{llll}
\hline \multicolumn{1}{c}{$\begin{array}{c}\text { Malt extract } \\
\text { medium }(\text { ME) }\end{array}$} & \multicolumn{1}{c}{$\begin{array}{c}\text { Tryptone glucose } \\
\text { yeast extract (TGE) }\end{array}$} & \multicolumn{1}{c}{$\begin{array}{c}\text { Tryptic soy broth } \\
\text { (TSB) }\end{array}$} & $\begin{array}{c}\text { Lysogeny broth } \\
(\mathbf{L B})\end{array}$ \\
\hline $20 \%(\mathrm{v} / \mathrm{v}) \mathrm{malt}$ & glucose, $1 \mathrm{~g} / \mathrm{L} ;$ yeast & casein peptone, $17 \mathrm{~g} / \mathrm{L} ;$ & tryptone, $10 \mathrm{~g} / \mathrm{L} ;$ \\
extract*, $50 \mathrm{~mL} / \mathrm{L} ;$ & extract, $3 \mathrm{~g} / \mathrm{L} ;$ & $\mathrm{K}_{2} \mathrm{HPO}_{4}, 2.5 \mathrm{~g} / \mathrm{L} ;$ glucose, & yeast extract, $5 \mathrm{~g} / \mathrm{L} ;$ \\
yeast extract, $5 \mathrm{~g} / \mathrm{L} ;$ & tryptone, $5 \mathrm{~g} / \mathrm{L}$ & $2.5 \mathrm{~g} / \mathrm{L} ; \mathrm{NaCl}, 5 \mathrm{~g} / \mathrm{L} ;$ soya & $\mathrm{NaCl}, 5 \mathrm{~g} / \mathrm{L}$ \\
glucose, $5 \mathrm{~g} / \mathrm{L}$ & & peptone, $3 \mathrm{~g} / \mathrm{L}$ & \\
\hline
\end{tabular}

*All ingredients were purchased from VWR International (USA).

\subsection{Microorganisms}

The fungal and bacterial strains used for the experiments are listed in Table 5. The microorganisms were subcultured every four weeks on the corresponding solid medium and stored at $4{ }^{\circ} \mathrm{C}$. Before use, fresh bacterial cultures were prepared by picking a colony from a 24-h old culture, suspended in $30 \mathrm{~mL}$ medium and incubated for $18 \mathrm{~h}$ at 30 or $37^{\circ} \mathrm{C}$ depending on the requirements of the applied strain. At the end of the incubation period, the growth of each bacterium was in the stationary phase. Cell number was set by serial dilution in the respective growth medium followed by counting in a Bürker-chamber under a light microscope (Carl Zeiss Jena, LABOVAL 4, Germany). 
Table 5. Fungal and bacterial strains used in the experiments.

\begin{tabular}{lccc}
\hline Microorganism & Code & $\begin{array}{c}\text { Growth } \\
\text { medium }\end{array}$ & $\begin{array}{c}\text { Growth } \\
\text { temperature }\left({ }^{\circ} \mathbf{C}\right)\end{array}$ \\
\hline Rhizomucor miehei NRRL 5282* & SZMC 11005 & ME & 37 \\
Bacillus subtilis & SZMC 0209 & TGE & 30 \\
Bacillus cereus & SZMC 0042 & TGE & 30 \\
Listeria monocytogenes & SZMC 21307 & TSB & 37 \\
Staphylococcus aureus & SZMC 0579 & LB & 37 \\
Methicillin-resistant Staphylococcus aureus & SZMC 6270 & LB & 37 \\
Escherichia coli & SZMC 0582 & LB & 37 \\
Salmonella enterica subsp. enterica serovar & SZMC 23289 & LB & 37 \\
Typhimurium ATCC 13311 & SZMC 6010 & LB & 30 \\
Pseudomonas putida & SZMC 0568 & LB & 30 \\
Pseudomonas aeruginosa & SZMC 6269 & LB & 30 \\
Chromobacterium violaceum 85WT & Cun Coll
\end{tabular}

*Abbreviations: NRRL, Agricultural Research Service Culture Collection; SZMC, Szeged Microbiological Collection; ATCC, American Type Culture Collection; ME, malt extract medium; TGE, tryptone glucose yeast extract; TSB, tryptic soy broth; LB, lysogeny broth.

\subsection{Reagents, solvents and standards}

Unless otherwise stated, all materials were purchased from VWR International (USA). All solutions were prepared freshly before use.

$\underline{\text { Solutions and reagents for the cellulase activity assays }}$

- Dinitrosalicylic acid reagent: 1\% dinitrosalicylic acid (Sigma-Aldrich, Germany), $1 \% \mathrm{NaOH}, 0.2 \%$ phenol, $0.05 \% \mathrm{Na}_{2} \mathrm{SO}_{3}$,

- $4 \mathrm{mM} p$-nitrophenyl- $\beta$-D-cellobioside (Sigma-Aldrich) solution in distilled water,

- $7 \mathrm{mM}$ p-nitrophenyl- $\beta$-D-glucopyranoside (Sigma-Aldrich) solution in distilled water,

- Sodium acetate buffer (100 mM, pH 5.0) prepared by addition of $1.36 \mathrm{~g}$ sodium acetate $\times 3 \mathrm{H}_{2} \mathrm{O}$ to $100 \mathrm{~mL}$ distilled water supplemented with $85 \mathrm{mg}$ of $96 \%$ glacial acetic acid,

- $100 \mathrm{mM}$ sodium carbonate buffer solution in distilled water,

- $8 \mathrm{mM}$ glucose and $10 \mathrm{mM}$ p-nitrophenol (Sigma-Aldrich) standard solutions in acetate buffer (100 mM, pH 5.0) for preparation of calibration curves. 
$\underline{\text { Solutions for total phenolic concentration measurement }}$

- $50 \%$ Folin-Ciocalteu's reagent (Sigma-Aldrich) solution in distilled water,

- $5 \%$ sodium carbonate solution in distilled water,

- gallic acid (Sigma-Aldrich) solutions of various concentrations prepared in $96 \%$ ethanol for calibration curve establishment.

\section{$\underline{\text { Solutions for ferric reducing antioxidant power (FRAP) assay }}$}

- Sodium acetate buffer (300 mM, pH 3.6) prepared by addition of $4 \mathrm{~g}$ sodium acetate $\mathrm{x} 3 \mathrm{H}_{2} \mathrm{O}$ to $100 \mathrm{~mL}$ distilled water supplemented with $3 \mathrm{~mL}$ of $96 \%$ glacial acetic acid,

- $40 \mathrm{mM} \mathrm{HCl}$ solution,

- $10 \mathrm{mM}$ 2,4,6-Tri(2-pyridyl)-s-triazine (TPTZ; Sigma-Aldrich) solution prepared in $40 \mathrm{mM} \mathrm{HCl}$ by heating at $50{ }^{\circ} \mathrm{C}$,

- $20 \mathrm{mM}$ Iron (III) chloride solution in distilled water,

- $\quad$ FRAP reagent prepared by mixing $20 \mathrm{~mL}$ of $300 \mathrm{mM}$ acetate buffer (pH 3.6), $4 \mathrm{~mL}$ of $10 \mathrm{mM}$ TPTZ solution, $4 \mathrm{~mL}$ of $20 \mathrm{mM}$ Iron (III) chloride solution and $2.2 \mathrm{~mL}$ distilled water under $37{ }^{\circ} \mathrm{C}$ condition,

- $1 \mathrm{mM}$ Iron (II) sulfate solution for calibration curve preparation.

$\underline{\text { Solutions for free radical scavenging activity determination }}$

- $100 \mu \mathrm{M}$ 1,1-diphenyl-2-picrylhydrazyl (DPPH; Sigma-Aldrich) solution prepared in $96 \%$ ethanol. The solution was stored in the dark.

$\underline{\text { Solutions for high-performance liquid chromatography (HPLC) analysis }}$

- Solvent A: $97 \mathrm{~mL}$ of distilled water, $3 \mathrm{~mL} 96 \%$ acetic acid

- Solvent B: $97 \mathrm{~mL}$ acetonitrile, $3 \mathrm{~mL}$ 96\% acetic acid

$\underline{\text { Phenolic standards }}$

- Gallic acid, vanillic acid, syringic acid, p-coumaric acid, 4-hydroxybenzoic acid, cinnamic acid, (+)-catechin, (-)-epicatechin, polydatin, quercetin and resveratrol were purchased from Sigma-Aldrich. Stock solutions $(1 \mathrm{mg} / \mathrm{mL})$ of pure phenolic compounds were prepared in $10 \%(\mathrm{v} / \mathrm{v})$ ethanol. 
$\underline{\text { Control solution in antimicrobial tests }}$

- $100 \mu \mathrm{g} / \mathrm{mL}$ streptomycin (Sigma-Aldrich) solution prepared in distilled water. The solution was sterilized by filtration using $0.45 \mu \mathrm{m}$ Millex-HV syringe filter (PVDF, Millipore).

\subsection{Substrate preparation}

The grapes and apple substrates were processed at the Institute of Food Engineering, University of Szeged, Hungary, while the pitahaya, mango and naranjilla residues at the Faculty of Food Engineering, Escuela Superior Politécnica del Litoral, Ecuador. In the case of grapes and naranjilla, the skin, stem, and seeds were obtained after juice pressing. The apple, pitahaya and mango fruits were peeled, and the flesh was separated from the other parts of the fruits. A mixture of peels, cores, peduncles and seeds was subjected to substrate pretreatment. These byproducts constitute the bulk of the pomace remained after wine, juice and jam production, therefore, the substrates used were close to those generated at industrial level. To pretreat the substrates, the residues were dried immediately in an oven or frozen at $-20^{\circ} \mathrm{C}$ and subsequently lyophilized. Time of drying processes varied depending on humidity, fruit sugar content and the used equipment (Table 6). Then, both types of samples were ground in a commercial mill into particles of 3 $\mathrm{mm}$ mean diameter. The ground samples were stored in dark at room temperature and used for subsequent experiments.

Table 6. Conditions of oven-drying and lyophilization processes.

\begin{tabular}{lccccc}
\hline \multirow{2}{*}{ Fruits } & $\begin{array}{c}\text { Weight of initial } \\
\text { biomass }(\mathbf{g})\end{array}$ & $\begin{array}{c}\text { Temperature } \\
\left({ }^{\circ} \mathbf{C}\right)\end{array}$ & $\begin{array}{c}\text { Time } \\
(\mathbf{h})\end{array}$ & $\begin{array}{c}\text { Humidity } \\
(\boldsymbol{\%})\end{array}$ & Tyophilization \\
\hline Grapes & 30 & 65 & 18 & 10.3 & 24 \\
Apple & 25 & 65 & 18 & 12.2 & 24 \\
Pitahaya* & 20 & 65 & 5 & 13.1 & $24-32$ \\
Mango* & 25 & 65 & 4 & 10.8 & 24 \\
Naranjilla* & 30 & 65 & 4 & 11.1 & 24 \\
\hline
\end{tabular}




\subsection{Solid-state fermentation conditions}

For SSF, $2 \mathrm{~g}$ of ground sample, $0.5 \mathrm{~g}$ of soy flour as a nitrogen source and $5 \mathrm{~mL}$ distilled water were mixed in 100-mL Erlenmeyer flasks and autoclaved at $121{ }^{\circ} \mathrm{C}$ for 25 min. The flasks were then inoculated with $5 \times 10^{6}$ spores of $R$. miehei NRRL 5282 and incubated at $37{ }^{\circ} \mathrm{C}$ for 18 days. Four parallel fermentation tests were carried out, two for distilled water extraction and two for $50 \%(\mathrm{v} / \mathrm{v})$ ethanol extraction. During incubation, four flasks were taken on every second day for subsequent analytical measurements, and the remaining flasks were hydrated with $2 \mathrm{~mL}$ of sterile distilled water to ensure the humidity conditions until the end of fermentation.

\subsection{Extraction processes after solid-state fermentation}

The fungus-byproduct ferments were extracted with $30 \mathrm{~mL}$ of distilled water or a solution of $50 \%(\mathrm{v} / \mathrm{v})$ ethanol macerating them with a spatula and incubated at $4{ }^{\circ} \mathrm{C}$ for 24 h. After the extraction, the samples were filtered through gauze and centrifuged at $16,200 \times g$ for $20 \mathrm{~min}$ at $4{ }^{\circ} \mathrm{C}$. The supernatant was stored at $-20{ }^{\circ} \mathrm{C}$ until analytical measurements. To avoid the inhibition effect of ethanol (Takó et al. 2010), aqueous extracts were used to measure the $\beta$-glucosidase activity in the samples, while crude extracts made with $50 \%(\mathrm{v} / \mathrm{v})$ ethanol solution were utilized for total phenolic content (TPC), antioxidant activity and HPLC measurements.

\subsection{Production of cellulolytic cocktail}

To produce crude cellulolytic enzyme cocktail, $20 \mathrm{~g}$ of wheat bran was mixed with $20 \mathrm{~mL}$ of distilled water, then, the flask was sterilized at $121{ }^{\circ} \mathrm{C}$ for $25 \mathrm{~min}$. After cooling to room temperature, the flask was inoculated with $800 \mu \mathrm{L}$ of $10^{6}$ spore suspension of $R$. miehei and incubated at $37{ }^{\circ} \mathrm{C}$ for 6 days (Takó et al. 2010). After incubation, the ferment was extracted with $120 \mathrm{~mL}$ of sodium acetate buffer $(100 \mathrm{mM}, \mathrm{pH} 5.0)$ and incubated at 4 ${ }^{\circ} \mathrm{C}$ for $12 \mathrm{~h}$. The extracted ferment was filtered through gauze and centrifuged at $5,040 \times \mathrm{g}$ for $20 \mathrm{~min}$ at $4{ }^{\circ} \mathrm{C}$. The supernatant was sterilized using $3.0 \mu \mathrm{m}$ and $0.45 \mu \mathrm{m}$ pore-size filters (PVDF; Millipore) and after cellulase activity measurements, the filtrate was stored at $-20^{\circ} \mathrm{C}$ until use. 


\subsection{Cellulolytic activity assays}

To determine the cellulolytic property of the crude enzyme extract used for enzymeassisted extraction tests, filter paper degrading (FPase), endoglucanase, cellobiohydrolase and $\beta$-glucosidase activity measurements were carried out. During SSF on fruit residue substrates, only the $\beta$-glucosidase activity was monitored. In case of the FPase and endoglucanase assays, one enzyme activity unit was defined as the amount of enzyme that released $1 \mu \mathrm{M}$ of glucose from the treated substrate per minute under the assay conditions. One unit of cellobiohydrolase or $\beta$-glucosidase activity was defined as the activity of the enzyme that released $1 \mu \mathrm{M} p$-nitrophenol per minute under the conditions of the assay. Standard curves were established using stock solution of $8 \mathrm{mM}$ glucose or $10 \mathrm{mM}$ nitrophenol in sodium acetate buffer (100 mM, pH 5.0).

\section{FPase activity}

FPase activity was determined using Whatman No. 1 filter paper as a substrate. The reaction mixture consisted of $200 \mu \mathrm{L}$ sodium acetate buffer $(100 \mathrm{mM}, \mathrm{pH} 5.0), 50 \mu \mathrm{L}$ crude enzyme extract and $2.5 \mathrm{mg}$ filter paper. After incubation at $50{ }^{\circ} \mathrm{C}$ for $1 \mathrm{~h}, 250 \mu \mathrm{L}$ of dinitrosalicylic acid was added and the mixture was incubated in hot water bath for 15 minutes. Then, absorbance was measured at $570 \mathrm{~nm}$ using a SPECTROstar Nano spectrophotometer (BMG Labtech, Germany).

\section{Endoglucanase activity}

To determine the endoglucanase activity, a reaction mixture was composed from $200 \mu \mathrm{L}$ sodium acetate buffer (100 mM, pH 5.5), $50 \mu \mathrm{L}$ crude enzyme extract and $1 \%$ carboxymethyl cellulose (Sigma-Aldrich). The mixture was incubated at $50{ }^{\circ} \mathrm{C}$ for $30 \mathrm{~min}$, then, $250 \mu \mathrm{L}$ of dinitrosalicylic acid was added and the mixture was subjected to boiling for 15 minutes. After cooling to room temperature, absorbance was recorded at $570 \mathrm{~nm}$ (SPECTROstar Nano spectrophotometer, BMG Labtech).

\section{Cellobiohydrolase and $\beta$-glucosidase activities}

The cellobiohydrolase and $\beta$-glucosidase activities were determined by using $4 \mathrm{mM}$ $p$-nitrophenyl- $\beta$-D-cellobioside and $7 \mathrm{mM} \quad p$-nitrophenyl- $\beta$-D-glucopyranoside stock solutions, respectively. The reaction mixtures consisted of $20 \mu \mathrm{L}$ of appropriate substrate solution, $160 \mu \mathrm{L}$ of $100 \mathrm{mM}$ sodium acetate buffer $(\mathrm{pH}$ 5.0) and $20 \mu \mathrm{L}$ of extract diluted to 
10 -fold by distilled water. After 30 min incubation at $50{ }^{\circ} \mathrm{C}$, the reaction was stopped by addition of $50 \mu \mathrm{L}$ of $100 \mathrm{mM}$ sodium carbonate, and the $p$-nitrophenol release was measured at $405 \mathrm{~nm}$ using a SPECTROstar Nano spectrophotometer (BMG Labtech).

\subsection{Enzyme treatment of plant residues}

The $R$. miehei cellulolytic cocktail produced by wheat bran-based SSF and a commercial A. niger pectinase with $1.1 \mathrm{U} / \mathrm{mg}$ polygalacturonase activity (Sigma-Aldrich) were used for enzyme-assisted extraction of phenolics. For treatment 1 (designated as S1), $600 \mathrm{mg}$ of oven-dried or lyophilized fruit residue was mixed with $6 \mathrm{~mL}$ of $R$. miehei cellulase cocktail. In the case of treatment 2 (designated as S2), this reaction mixture was supplemented with $0.6 \mathrm{mg}$ of $A$. niger pectinase $(1 \mathrm{mg} / \mathrm{g} \mathrm{DM})$. For treatment 3 (designated as C2) $600 \mathrm{mg}$ of fruit residue was mixed with $6 \mathrm{~mL}$ of acetate buffer $(50 \mathrm{mM}, \mathrm{pH} 5.0)$ and $0.6 \mathrm{mg}$ A. niger pectinase. Enzyme-free acetate buffer $(50 \mathrm{mM}, \mathrm{pH} 5.0) /$ fruit residue mixture was used as control (designated as $\mathrm{C} 1$ ). The reaction mixtures were then incubated at $50{ }^{\circ} \mathrm{C}$ for $5 \mathrm{~h}$ under constant stirring (200 rpm), and the reaction was stopped by boiling $\left(100{ }^{\circ} \mathrm{C}\right)$ for $3 \mathrm{~min}$. After centrifugation at $16,200 \times \mathrm{g}$ for $10 \mathrm{~min}$, the resulted clear supernatant was collected and used for TPC, antioxidant activity and HPLC measurements, and to prepare stock solutions for subsequent bioactivity tests. The reaction conditions $(\mathrm{pH}$ 5.0, $50{ }^{\circ} \mathrm{C}$ and $5 \mathrm{~h}$ incubation time) were selected according to the studies of Krisch et al. (2012) and Xu et al. (2014). All enzyme treatments were carried out in three independent experiments.

\subsection{Extract stock solution preparation for microbiological tests}

Clear supernatant of S1-2 and C1-2 treatments was placed to a 50-mL Falcon centrifuge tube and frozen overnight at $-20{ }^{\circ} \mathrm{C}$. Then, these samples were lyophilized until the water content was completely displaced. The remained DM of each sample was weighted and subsequently diluted in $10 \%(\mathrm{v} / \mathrm{v})$ ethanol solution to reach the concentration of $200 \mathrm{mg} / \mathrm{mL}$. After vortexing, this concentrated stock solution was sterilized by syringe filtration (Millex-HV, PVDF, pore size: $0.45 \mu \mathrm{m}$; Millipore). 


\subsection{Determination of total phenolics}

TPC was measured using a reaction mixture containing $20 \mu \mathrm{L}$ of ethanol (96\%), $100 \mu \mathrm{L}$ of distilled water, $10 \mu \mathrm{L}$ of $50 \%$ Folin-Ciocalteu's phenol reagent and $20 \mu \mathrm{L}$ of extract diluted 10-fold in ethanol (96\%). The mixture was left at room temperature for 5 min, then, the reaction was initiated by the addition of $20 \mu \mathrm{L}$ of sodium carbonate $(5 \%)$, and incubated in dark condition for $60 \mathrm{~min}$. After incubation, absorbance was measured at $725 \mathrm{~nm}$ (SPECTROstar Nano spectrophotometer, BMG Labtech). The standard curve was established using gallic acid in the concentration range of $0-100 \mu \mathrm{g} / \mathrm{mL}$. The content of total phenolics was expressed as mg of gallic acid equivalent (GAE) in $100 \mathrm{~g}$ DM. The following equation was used to calculate the TPC:

$$
\text { TPC }(m g G A E / 100 g D M)=\frac{P(\mu g / m L) * D * E S(m L) * 1000}{\text { amount of pomace }(g)} * 100
$$

where $\mathrm{P}$ is the phenol concentration determined from the calibration curve, $\mathrm{D}$ is the dilution factor, and ES is the volume of the extraction solvent.

\subsection{Antioxidant activity assays}

\subsubsection{Determination of free radical scavenging activity}

The free radical scavenging activity of the extracts and phenolic compounds was determined using DPPH solution in $100 \mu \mathrm{M}$ concentration prepared freshly before the measurement. The mixture was shaken vigorously until complete dissolution and left in the dark at room temperature until use. The reaction mixture contained $150 \mu \mathrm{L}$ of $100 \mu \mathrm{M}$ DPPH and $25 \mu \mathrm{L}$ of extract diluted in $50 \%$ (v/v) ethanol (10-fold dilution), or $25 \mu \mathrm{L}$ of phenolic standard solution $(1 \mathrm{mg} / \mathrm{mL})$. The control sample contained $150 \mu \mathrm{L}$ of $100 \mu \mathrm{M}$ $\mathrm{DPPH}$ and $25 \mu \mathrm{L}$ of $50 \%(\mathrm{v} / \mathrm{v})$ ethanol. Absorption was measured at $517 \mathrm{~nm}$ (SPECTROstar Nano spectrophotometer, BMG Labtech), and the results were plotted as percent DPPH radical scavenging capacity against the control. The following equation was used to calculate the DPPH inhibition:

$$
D P P H(\%)=\frac{\text { control } A-\text { extract } A}{\text { control } A} * 100
$$

where $A$ is the absorbance at $517 \mathrm{~nm}$. 


\subsubsection{Ferric reducing antioxidant power assay}

The reagent solution prepared for FRAP analysis contained $80 \mathrm{~mL}$ of $300 \mathrm{mM}$ acetate buffer ( $\mathrm{pH} 3.6$ ), $8 \mathrm{~mL}$ of $10 \mathrm{mM}$ TPTZ diluted in $40 \mathrm{mM} \mathrm{HCl}, 8 \mathrm{~mL}$ of $20 \mathrm{mM}$ iron(III) chloride and $4.8 \mathrm{~mL}$ of distilled water. The power of phenolic extracts and compounds on ferric reducing was determined by mixing $200 \mu \mathrm{L}$ FRAP reagent with $6 \mu \mathrm{L}$ of extract diluted in $50 \%(\mathrm{v} / \mathrm{v})$ ethanol (10-fold dilution), or $6 \mu \mathrm{L}$ of phenolic standard solution $(1 \mathrm{mg} / \mathrm{mL})$. The reaction mixture was incubated at $37{ }^{\circ} \mathrm{C}$ for $30 \mathrm{~min}$ and then absorbance was measured at $593 \mathrm{~nm}$ (SPECTROstar Nano spectrophotometer, BMG Labtech). The standard curve was established using $1 \mathrm{mM}$ iron(II) sulfate solution in the concentration range of $0.1-1.0 \mathrm{mM}$. The FRAP of the crude extracts and phenolics was expressed as $\mathrm{mM} \mathrm{Fe}(\mathrm{II}) / 100 \mathrm{~g}$ DM. The following equation was used to calculate the reducing power:

$$
\operatorname{FRAP}(\mathrm{mM} F e(\mathrm{II}) / 100 \mathrm{~g} \mathrm{DM})=\frac{C(m M) * \text { extraction solvent }(\mathrm{mL}) * \text { dilution }}{1000 \mathrm{ml} * \text { amount of pomace }(\mathrm{g})}
$$

where $\mathrm{C}$ is the $\mathrm{Fe}(\mathrm{II})$ concentration determined from the calibration curve.

\subsection{Antimicrobial activity tests}

\subsubsection{Agar disk-diffusion assay}

Agar disk-diffusion method was used to screen the antimicrobial activity of the extracts and individual phenolic compounds. A volume of $1 \mathrm{~mL}$ of each bacterial suspension $\left(10^{6}\right.$ colony forming unit $\left.(\mathrm{CFU}) / \mathrm{mL}\right)$ was uniformly spread on the surface of the corresponding solid medium prepared in Petri-dishes. After removing the excess suspension, plates were dried and six sterile paper disks $(5 \mathrm{~mm}$ in diameter) were placed equidistantly on the surface of each agar plate. Then, stock solution of extracts was diluted to $100 \mathrm{mg} / \mathrm{mL}$ concentration using $10 \%$ (v/v) ethanol. A volume of $10 \mu \mathrm{L}$ of fruit extract solution (1 mg per disk) or phenolic compound stock solution (10 $\mu \mathrm{g}$ per disk) was pipetted to the surface of the disks. Then, the cultures were incubated for $24 \mathrm{~h}$ under the condition appropriate for the bacteria tested. The antibacterial activity was estimated from the diameter of the growth inhibition zone (in $\mathrm{mm}$ ) formed around the disks. Paper disks impregnated with $10 \%(\mathrm{v} / \mathrm{v})$ ethanol and $100 \mu \mathrm{g} / \mathrm{mL}$ of streptomycin served as negative 
and positive control, respectively. Three biological replicates were performed with each enzyme-treated sample and phenolic compound.

\subsubsection{Determination of minimum inhibitory concentration}

The minimum inhibitory concentration (MIC) of the extracts and individual phenolics was determined by microplate assay. Using the corresponding stock solution, diluted samples were prepared in $10 \%(\mathrm{v} / \mathrm{v})$ ethanol to the concentrations of $12.5,25,50$ and $100 \mathrm{mg} / \mathrm{mL}$ for the fruit extracts and 250 and $500 \mu \mathrm{g} / \mathrm{mL}$ for the phenolic compounds. After $18 \mathrm{~h}$ incubation, the bacterial cells were collected $(16,200 \times \mathrm{g}, 10 \mathrm{~min})$ and a $10^{5}$ $\mathrm{CFU} / \mathrm{ml}$ suspension was prepared using double concentrated growth medium appropriate for the specific bacterium. A volume of $100 \mu \mathrm{L}$ from this bacterial suspension was added to each well of a sterile 96-well polystyrene microtiter plate (Sarstedt, Germany), followed by adding $100 \mu \mathrm{L}$ of the stock or diluted fruit extract and phenolic compound samples, giving a final concentration from 6.25 to $100 \mathrm{mg} / \mathrm{mL}$ and 125 to $500 \mu \mathrm{g} / \mathrm{mL}$, respectively. A volume of $100 \mu \mathrm{L}$ of bacterial suspension supplemented with $100 \mu \mathrm{L}$ of $10 \%(\mathrm{v} / \mathrm{v})$ ethanol solution was considered as positive control, while the negative controls contained $100 \mu \mathrm{L}$ of sterile double concentrated growth medium and $100 \mu \mathrm{L}$ of diluted fruit extract or phenolic compound. Final volume of the reaction mixture was $200 \mu \mathrm{L}$. Subsequently, the optical density (OD) of the plates was measured at $600 \mathrm{~nm}$ (SPECTROstar Nano spectrophotometer, BMG Labtech) before and after the incubation (for $24 \mathrm{~h}$ under appropriate growth conditions). MIC was considered as the lowest concentration of fruit extract or phenolic compound where the absorbance was $10 \%$ or lower than the positive control, thus the growth inhibition was $90 \%$ or higher. Three biological replicates were performed with each enzyme-treated sample and phenolic compounds. The following equation was used to calculate the percentage of growth inhibition:

$$
M I C=\frac{A-B}{\mathrm{C}-\mathrm{D}} * 100
$$

where $\mathrm{A}$ and $\mathrm{B}$ are the absorbance of the sample after and before incubation, respectively, and $\mathrm{C}$ and $\mathrm{D}$ are the absorbance of the positive control after and before incubation, respectively. 


\subsubsection{Determination of minimum bactericidal concentration}

A volume of $10 \mu \mathrm{L}$ from the cultures where the MIC was recorded, and from the higher concentrations (up to $100 \mathrm{mg} / \mathrm{mL}$ for the fruit extracts or $500 \mu \mathrm{g} / \mathrm{mL}$ for the phenolic compounds), were inoculated equidistantly on solid medium appropriate for growth of the bacterium tested. Then, the plates were incubated for $24 \mathrm{~h}$ under different conditions depending on the bacterium used. The lowest concentration, at which no colonies were formed, was taken as the minimum bactericidal concentration (MBC). This value corresponds to at least $99.9 \%$ elimination of the cells from the inoculum.

\subsection{Quorum sensing inhibition assay}

Anti-QS activity of the extracts and individual phenolics was assessed through the inhibition of violacein synthesis in $C$. violaceum model organism, which uses N-acyl-Lhomoserine lactones as signaling molecules like many other Gram-negative bacteria (Morohoshi et al. 2008). In this assay, the violacein pigment produced in liquid culture was extracted and detected spectrophotometrically, according to the modified method of Choo et al. (2006). Falcon tubes containing $9.4 \mathrm{~mL}$ of $\mathrm{LB}$ medium and $100 \mu \mathrm{L}$ of fruit extract or phenolic compound stock solutions were inoculated with $500 \mu \mathrm{L}$ of 18 -h old bacterial culture with approximately $10^{8} \mathrm{CFU} / \mathrm{mL}$ density. A single tube consisting $9.5 \mathrm{~mL}$ of $\mathrm{LB}$ medium and $500 \mu \mathrm{L}$ of bacterial suspension $\left(10^{8} \mathrm{CFU} / \mathrm{mL}\right)$ was used as positive control, and tubes consisting $9.9 \mathrm{~mL}$ of growth medium and $100 \mu \mathrm{L}$ of extract and phenolic compound stock solutions were the negative controls. Final concentrations of the fruit extracts and the phenolic compounds during the test were $2 \mathrm{mg} / \mathrm{mL}$ and $10 \mu \mathrm{g} / \mathrm{mL}$, respectively. After the inoculation, culturing tubes were incubated at $30{ }^{\circ} \mathrm{C}$ for $24 \mathrm{~h}$ under continuous shaking at $150 \mathrm{rpm}$. The samples were then vortexed and 2-mL aliquots were transferred to sterile Eppendorf tubes and centrifuged at $16,200 \times g$ for 20 minutes to precipitate the insoluble violacein pigment and the bacterial cells. The supernatant was discarded, and the pellet was solubilized in $1 \mathrm{~mL}$ of dimethyl sulfoxide by vigorous vortexing for $20 \mathrm{~min}$. Finally, cellular debris was removed by centrifugation $(16,200 \times g, 20$ $\min$ ), and $200 \mu \mathrm{L}$ of supernatant was transferred into the wells of a 96 -well polystyrene microtiter plate. Absorption was measured at $585 \mathrm{~nm}$ via SPECTROstar Nano microplate reader (BMG Labtech), and the percentage inhibition of violacein production was calculated by using the following equation: 
Inhibition of violacein production $(\%)=\frac{a-b}{a} * 100$

where "a" and "b" are the absorbance of the control and the sample, respectively.

The CFU was determined in each tube after the incubation, to make sure that the tested extracts and phenolic compounds did not inhibit the growth of C. violaceum, at the applied concentration. Three replicates were performed in case of each enzyme-treated sample and phenolic compound.

\subsection{Biofilm formation assay}

Effect of extracts and individual phenolics on the biofilm formation was determined by the crystal violet staining method. Following the procedure of Kerekes et al. (2013), $200 \mu \mathrm{L}$ of 24 -h old bacterial culture (approximately $10^{8} \mathrm{CFU} / \mathrm{ml}$ ) was pipetted into the wells of a sterile 96-well polystyrene microtiter plate and the cells were allowed to adhere for $4 \mathrm{~h}$ at temperatures appropriate for the bacteria tested. After removing the planktonic cells, the plate was rinsed with physiological saline solution and left to dry for $10 \mathrm{~min}$ under sterile conditions. A volume of $200 \mu \mathrm{L}$ of medium containing fruit extracts or phenolic compounds in $50 \mathrm{mg} / \mathrm{mL}$ or $100 \mu \mathrm{g} / \mathrm{mL}$ concentrations, respectively, were then added to each treated well. The positive control was made by addition of $200 \mu \mathrm{L}$ of growth medium to treated wells, while the negative controls contained fruit extracts or phenolic compounds in the growth medium. The plates were incubated for $24 \mathrm{~h}$, then, the supernatant was removed, and the wells were rinsed with physiological saline. To fix the biofilm, $200 \mu \mathrm{L}$ of methanol was added to each well and the plate was left to stand for 15 min at room temperature. The methanol was removed, and $200 \mu \mathrm{L}$ of $0.1 \%$ crystal violet solution was added to each well. After incubation for 20 minutes at room temperature, the excess dye was removed by rinsing each well twice with distilled water. To release the bounded dye, $200 \mu \mathrm{L}$ of $33 \%$ acetic acid solution was added to the wells followed by 10 min incubation at room temperature. Finally, the absorbance was measured at $590 \mathrm{~nm}$ (SPECTROstar Nano microplate reader, BMG Labtech), and the percentage of biofilm formation was calculated. Optical density of the positive control was considered as $100 \%$. Three biological replicates were performed with each enzyme-treated sample and phenolic compounds. The percent biofilm formation was calculated according to the following equation: 


$$
\text { Biofilm formation }(\%)=\frac{b}{a} * 100
$$

where "a" and "b" are the absorbance of the positive control and the sample, respectively.

\subsection{HPLC analysis of phenolic compounds}

Phenolic compounds were separated on Prodigy ODS 3 C18 $(250$ x $4.6 \mathrm{~mm}, 5 \mu$; Phenomenex, USA) column using the mixture of solvent A (distilled water:acetic acid, 97:3) and solvent B (acetonitrile:acetic acid, 97:3) as mobile phase at a flow rate of 1 $\mathrm{mL} / \mathrm{min}$; detection was carried out at $280 \mathrm{~nm}$ with an SPD-20AVP UV-VIS detector (Shimadzu, Germany). The following gradient program was used during the separation: 0 $\min 8 \%$ B, $20 \min 25 \%$ B, $25 \min 25 \%$ B, $40 \min 60 \%$ B, $45 \min 60 \%$ B, $46 \min 8 \%$ B, and $60 \mathrm{~min} 8 \% \mathrm{~B}$. The oven temperature and injection volume were $40{ }^{\circ} \mathrm{C}$ and $3 \mu \mathrm{L}$, respectively. The detector response was linear for all examined phenolic compounds (gallic, vanillic, syringic, p-coumaric, 4-hydroxybenzoic and cinnamic acids, and (+)catechin, (-)-epicatechin, polydatin, resveratrol and quercetin) with correlation coefficients greater than 0.995. Recording of data and evaluation was carried out using the ClassVP v5.1 chromatography software.

\subsection{Statistical analysis}

Assays were performed in three independent experiments and data were expressed as an average of the replicates \pm standard deviation. Two-way analysis of variance (ANOVA) was used for pairwise multiple comparisons. The independent variables considered for each study are given in the figure captions or table footnotes. One-way ANOVA was applied for the individual phenolic compounds in the antimicrobial activity tests. Significant differences between the means were further analyzed by Tukey's Multiple Comparison Test using the program GraphPad Prism version 6.00 (GraphPad Software Inc., San Diego, USA). A p value of $<0.05$ was considered as statistically significant. Pearson's correlation coefficients were calculated using Microsoft Office Excel 2016 function. 


\section{RESULTS AND DISCUSSION}

\subsection{Selection of fruit residue samples}

Pomace, peel, seed and/or stem residues of grape, apple, mango, pitahaya and naranjilla fruits contain substantial amounts of polyphenolic compounds; therefore, they could be a good basis to test the in vivo fermentative and in vitro enzyme-assisted production of bioactive phytochemicals using cellulolytic microorganisms and their carbohydrases. For our experiments, the antioxidative Othello black grape, (Vitis vinifera $x$ (Vitis labrusca $x$ Vitis riparia)), Saszla white grape (Vitis vinifera), Jonagold apple (Malus domestica cv. Jonagold), yellow pitahaya (Hylocereus megalanthus), Tommy Atkins mango (Mangifera indica L.) and naranjilla (Solanum quitoense) fruits have been selected. Pomace and/or different parts of the fruits were prepared according to the method described in subsection 4.5. Two pretreatment methods were used and compared to prepare the residues for fermentation and enzyme treatment assays: drying at $65{ }^{\circ} \mathrm{C}$ in a conventional oven (oven-dried sample) and freeze drying (lyophilized sample).

\subsection{Solid-state fermentation on oven-dried and lyophilized fruit residues}

A previous study pointed out the potential of Rhizomucor miehei NRRL $5282 \beta$ glucosidase to enrich free, extractable and bioavailable phenolic compounds from fruit samples by liberating them from the glycosidic form (Krisch et al. 2012). Generally, plant wastes contain enough polysaccharides that can induce the fungal $\beta$-glucosidase production in solid cultures. The solid-state bioprocessing is a useful technique to test the fungusmediated liberation of phenolics from plant wastes (Martins et al. 2011), by using the cellulolytic fungus $R$. miehei NRRL 5282 that grows well under such conditions (Takó et al. 2015).

\subsubsection{Black grape pomaces}

Weak negative associations were found between $\beta$-glucosidase activity and FRAP for both oven-dried (DBG) $(r=-0.477)$ and lyophilized black grape (LBG) $(r=-0.111)$ pomaces. $\beta$-Glucosidase activity showed a slow increase from the 7 th day of the fermentation and reached maximal yields at the 15th day (Figure 4). The slow increase in 
the activity may be due to the high glucose content of the medium. Namely, glucose in the growth medium represses the cellulase production at the beginning of the fermentation (Adnan et al. 2018). Another explanation could be that sugar compounds, for example cellobiose and glucose, can bind to the active site of the $\beta$-glucosidase inhibiting its activity if they are present in excess (Srivastava et al. 2019). Additionally, interaction of polyphenols and free aglycones with glucosidases may also reduce the enzyme activity (Cairns and Esen 2010, Ximenes et al. 2010, Yu and Ahmedna 2013).

The high phenolic content observed at the beginning of the fermentation (Figure 4) is related to the flavanol, stilbene and proanthocyanin content of the crude pomace (Ali et al. 2010). Polyphenol concentration in DBG samples decreased from $1236 \pm 74$ to $875 \pm$ $50 \mathrm{mg}$ GAE/100 g DM, while it reached $1956 \pm 31 \mathrm{mg} \mathrm{GAE} / 100 \mathrm{~g} \mathrm{DM}$ TPC at the 7th day on the LBG residue. The decrease in TPC may be due to degradation and/or enzymatic polymerization of the released phenolics by the fermenting fungus. Phenolic compound degradation and polymerization have been documented for other filamentous fungi as well (Correia et al. 2004, Mendonça et al. 2004, Santos and Linardi 2004).

In black grape pomaces, the main phenolic compounds are gallic acid, catechin and epicatechin (Makris et al. 2007). HPLC analysis detected an increase in the concentration of these components when LBG pomace was used as a fermenting medium. The highest gallic acid, (+)-catechin and (-)-epicatechin yields, i.e. $0.79 \pm 0.12,3.49 \pm 0.52$ and $1.37 \pm$ $0.08 \mathrm{mg} / 100 \mathrm{~g} \mathrm{DM}$, respectively, were determined at the 7th day of fermentation. In case of the DBG samples, only the gallic acid content improved reaching $1.27 \pm 0.03 \mathrm{mg} / 100 \mathrm{~g}$ DM at the 7th day of incubation.
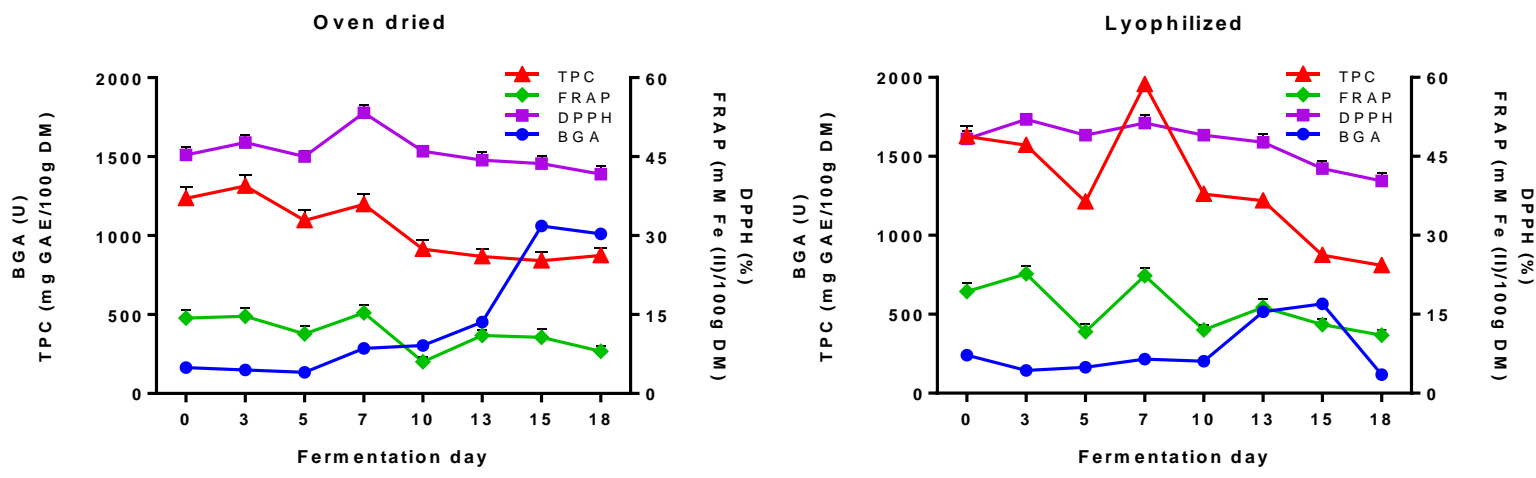

Figure 4. $\beta$-Glucosidase activity (BGA), total phenolic content (TPC), antioxidant power (FRAP) and free radical scavenging activity (DPPH) of oven-dried and lyophilized black grape byproducts during solid-state fermentation by $R$. miehei NRRL 5282. Error bars represent SD values of replicates. 
Antioxidant potential in the fermented samples varied depending on the incubation time. FRAP for the DBG and LBG samples was the highest at the 3rd day (14.6 \pm 0.9 and $22.5 \pm 1.1 \mathrm{mM} \mathrm{Fe}(\mathrm{II}) / 100 \mathrm{~g} \mathrm{DM}$, respectively) and 7 th day $(15.0 \pm 1.0$ and $22.4 \pm 1.1 \mathrm{mM}$ $\mathrm{Fe}(\mathrm{II}) / 100 \mathrm{~g} \mathrm{DM}$, respectively). The ability of polyphenolics to inhibit DPPH was $53 \pm 1$ and $51 \pm 1 \%$ for $\mathrm{DBG}$ and $\mathrm{LBG}$, respectively, in the 7th day extracts (Figure 4). Fermentation on LBG resulted in higher free phenolic yield compared to DBG $(\mathrm{p}<0.05)$, which is directly related to the increased FRAP.

\subsubsection{White grape pomaces}

The $\beta$-glucosidase activity was low during fermentation on both oven-dried (DWG) and lyophilized (LWG) white grape residues (Figure 5). There was no association between the total phenolic content and the antioxidant potential on DWG residues, whereas LWG displayed a sharp positive correlation $(r=0.7)$. The initial $\beta$-glucosidase activity obtained on DWG and LWG was $108 \pm 1$ and $90 \pm 1 \mathrm{U}$, respectively, and remained constant around these values until the end of the fermentation process. The TPC displayed an increase on the 3rd, 10th and 13rd days (DWG), and on the 5th and 7th days (LWG) of fermentation compared to initial data. The maximum TPC yields were $1118 \pm 11$ (DWG) and $1102 \pm 10$ mg GAE/100 g DM (LWG) at the 13th and 7th day, respectively. The FRAP was maximum at the 5 th fermentation day reaching $183 \pm 2$ and $163 \pm 2 \mu \mathrm{M} \mathrm{Fe}(\mathrm{II}) / \mathrm{g} \mathrm{DM}$ for DWG and LWG samples, respectively, while the highest scavenging capacity was $45 \pm 0.3$ and $50 \pm 0.3 \%$ detected at the 10th and 13th day in DWG and LWG pomaces, respectively (Figure 5).
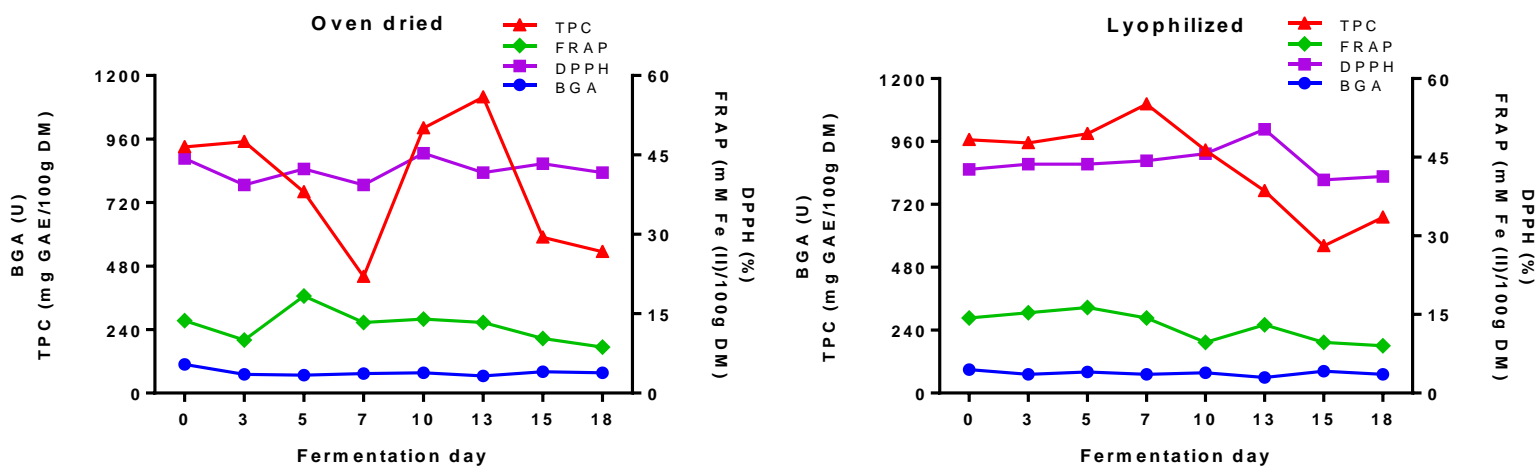

Figure 5. $\beta$-Glucosidase activity (BGA), total phenolic content (TPC), antioxidant power (FRAP) and free radical scavenging activity (DPPH) of oven-dried and lyophilized white grape byproducts during solid-state fermentation by $R$. miehei NRRL 5282. Error bars represent SD values of replicates. 
Overall, fermentation on DWG substrate resulted in slightly higher free phenolic yield and FRAP than LWG. Although the white grape and black grape have different phenolic composition (Rodríguez Montealegre et al. 2006), results of the current study didn't show a big difference in antioxidant activity between the two types of grape variety tested.

\subsubsection{Apple residues}

$\beta$-Glucosidase activity of the oven-dried (DA) and the lyophilized (LA) apple substrates showed a considerable increase from the 7th to the 10th day of bioconversion (Figure 6). TPC of DA continuously decreased during the fermentation, while TPC of LA increased for 5 days reaching a maximum value of $477 \pm 37 \mathrm{mg} \mathrm{GAE} / 100 \mathrm{~g}$ DM (Figure 6). Similarly, Ajila et al. (2012) described an increase in the free phenolic content after bioconversion of apple samples by Phanerochaete chrysosporium. $\beta$-Glucosidase activity reached its maximum by the 6th to 8th day, which coincided with the liberation of phenolic compounds. In the current study on LA, however, TPC increased slowly and reached a maximum on the 5 th fermentation day before the $\beta$-glucosidase activity increased.

Hydroxybenzoic acids are one of the major polyphenolic compounds of apple residues (Watkins and Liu 2011). Interestingly, among hydroxybenzoic acids analyzed by HPLC, only the gallic acid content of LA samples demonstrated an increase during the fermentation. The highest gallic acid concentration was $0.79 \pm 0.06 \mathrm{mg} / 100 \mathrm{~g} \mathrm{DM}$ at the 5th sampling day. However, free gallic acid may be formed not only from its glucosidic derivatives but by hydrolysis of the gallic acid esters of flavan-3-ol (Rentzsch et al. 2009).
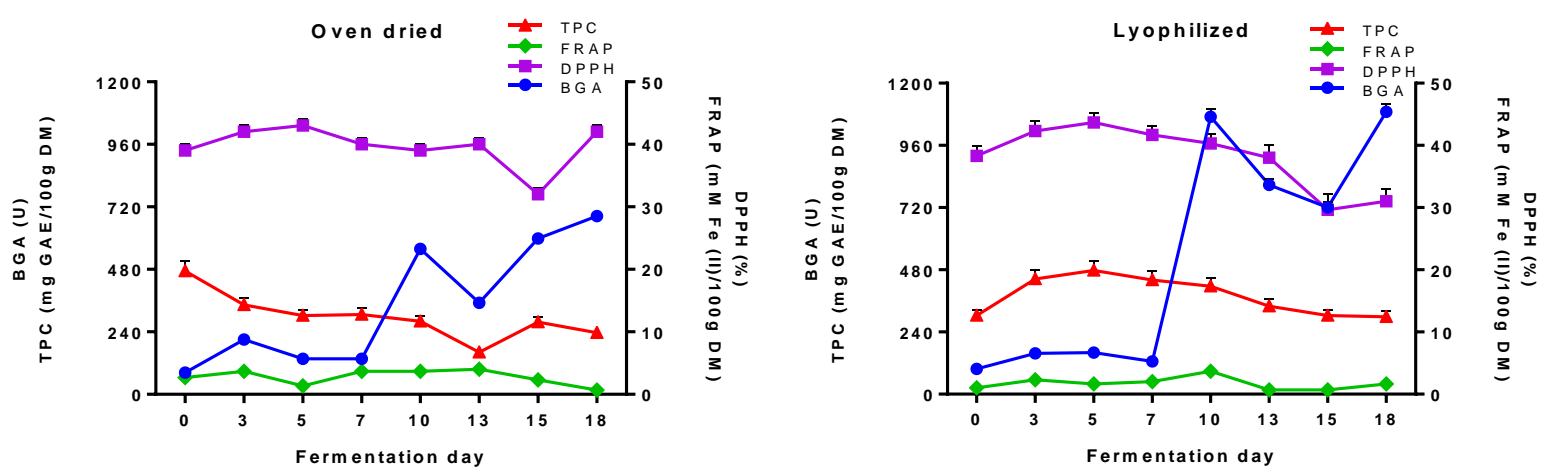

Figure 6. $\beta$-Glucosidase activity (BGA), total phenolic content (TPC), antioxidant power (FRAP) and free radical scavenging activity (DPPH) of oven-dried and lyophilized apple byproducts during solid-state fermentation by $R$. miehei NRRL 5282. Error bars represent SD values of replicates. 
FRAP was the highest at the 13th and 10th days for DA and LA, respectively, and subsequently reduced during later course of fermentation (Figure 6). In this context, the phenolic compound stability and antioxidant activity might be affected by a number of factors including enzymatic degradation (Santos and Linardi 2004), oxidation of phenolics and storage conditions of the extracts (Heras-Ramírez et al. 2012, Shah et al. 2015). It is remarkable that the FRAP increased in parallel to the $\beta$-glucosidase activity in both fermentation systems. Furthermore, the DPPH radical scavenging activity showed a slight increase up to the 5th day of fermentation (Figure 6). In the case of LA-based fermentation, this may be related to the TPC increase during the first phase of fermentation.

\subsubsection{Yellow pitahaya residues}

Despite the large antioxidant compound content of the fruit, fermentative production of bioactive phenolics from pitahaya residues has not been studied so far. In case of the lyophilized pitahaya (LP) sample, $\beta$-glucosidase activity found to be correlating with TPC $(r=0.866)$ and FRAP $(r=0.41)$ suggesting that the $R$. miehei $\beta$-glucosidase has an important role in the liberation of phenolics with reducing power (Figure 7). A similar trend has been reported during the bioconversion of cranberry and pineapple pomaces by Lentinus edodes and Rhizopus oligosporus, respectively (Zheng and Shetty 2000, Correia et al. 2004). $\beta$-Glucosidase activity on LP was maximal at the 10th day, while it was the highest at the 13th day in the case of oven-dried pitahaya (DP) residue. TPC of DP substrate exhibited a decrease up to the 13th fermentation day, then, a moderate increase was observed, potentially due to the $\beta$-glucosidase action (Figure 7). In contrast, TPC of LP did not decrease during the fermentation, moreover, it increased in parallel to the $\beta$ glucosidase activity. Concerning antioxidant properties, FRAP was $7.8 \pm 0.3 \mathrm{mM}$ $\mathrm{Fe}(\mathrm{II}) / 100 \mathrm{~g} \mathrm{DM}$ at the 10th fermentation day when LP was used as substrate, while it was $5.8 \pm 0.2 \mu \mathrm{M} \mathrm{Fe}(\mathrm{II}) / 100 \mathrm{~g}$ at the 3rd day on DP. The DPPH radical scavenging activity of DP residues showed an increase in parallel to the $\beta$-glucosidase activity (Figure 7). 

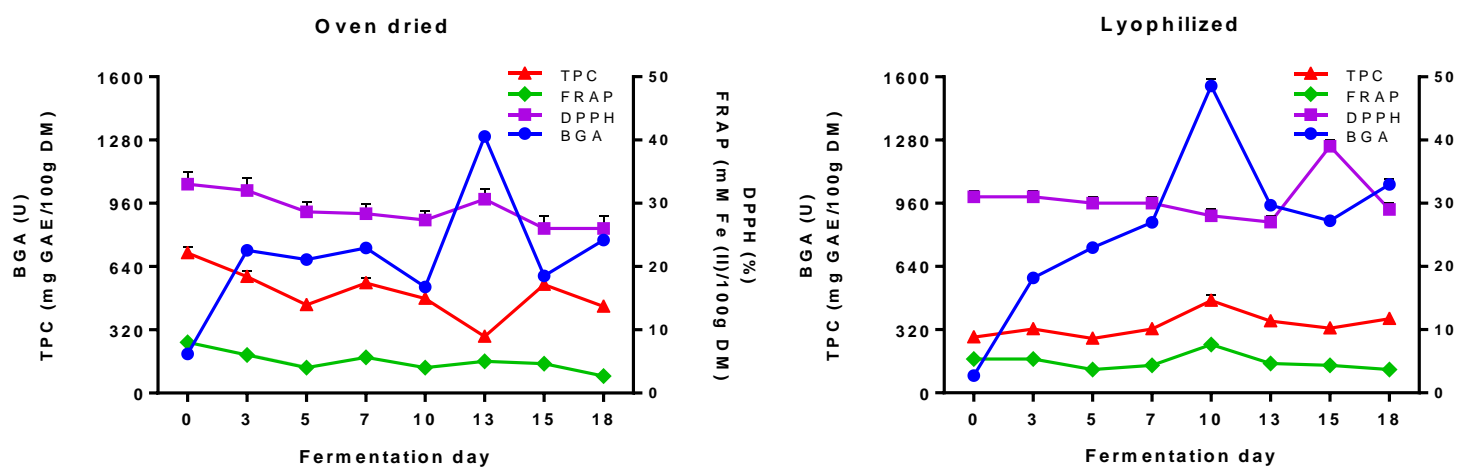

Figure 7. $\beta$-Glucosidase activity (BGA), total phenolic content (TPC), antioxidant power (FRAP) and free radical scavenging activity (DPPH) of oven-dried and lyophilized pitahaya byproducts during solid-state fermentation by $R$. miehei NRRL 5282. Error bars represent SD values of replicates.

Gallic acid, 4-hydroxybenzoic acid, (+)-catechin and (-)-epicatechin content of DP samples increased during the fermentation (Table 7). Concentration of vanillic acid, syringic acid, cinnamic acid, quercetin, polydatin and resveratrol compounds were below the detection limit. The quantity of gallic acid and (-)-epicatechin increased considerably and hydroxycinnamate $p$-coumaric acid was also detected after 15 days (Table 7). Hydroxycinnamates were previously identified in large quantities in red and white pitahaya varieties (Mahattanatawee et al. 2006). The initial concentration of gallic acid in LP samples was $2.46 \pm 0.11 \mathrm{mg} / 100 \mathrm{~g}$ DM. After fermenting for 15 days, it increased to 10.38 $\pm 0.34 \mathrm{mg} / 100 \mathrm{~g} \mathrm{DM}$. The content of 4-hydroxybenzoic acid, vanillic acid, syringic acid, (+)-catechin, quercetin and polydatin decreased, while the content of $p$-coumaric acid, cinnamic acid, (-)-epicatechin and resveratrol did not change after fermentation.

Table 7. Liberation of phenolic substances $(\mathrm{mg} / 100 \mathrm{~g} \mathrm{DM})$ from oven-dried pitahaya residues fermented with $R$. miehei NRRL 5282. Data were obtained from $50 \%(\mathrm{v} / \mathrm{v})$ ethanol solution.

\begin{tabular}{lccccc}
\hline $\begin{array}{l}\text { Fermentation } \\
\text { time (day) }\end{array}$ & Gallic acid & $\begin{array}{c}\text { 4-Hydroxybenzoic } \\
\text { acid }\end{array}$ & $\begin{array}{c}\boldsymbol{p} \text {-Coumaric } \\
\text { acid }\end{array}$ & $\begin{array}{c}(+)- \\
\text { Catechin }\end{array}$ & $\begin{array}{c}(-)- \\
\text { Epicatechin }\end{array}$ \\
\hline 0 & $<\mathrm{DL}^{*}$ & $<\mathrm{DL}$ & $<\mathrm{DL}$ & $<\mathrm{DL}$ & $<\mathrm{DL}$ \\
3 & $1.24 \pm 0.09$ & $<\mathrm{DL}$ & $<\mathrm{DL}$ & $<\mathrm{DL}$ & $1.88 \pm 0.30$ \\
7 & $7.88 \pm 1.00$ & $2.06 \pm 0.38$ & $<\mathrm{DL}$ & $4.49 \pm 0.19$ & $14.32 \pm 0.49$ \\
15 & $37.93 \pm 2.19$ & $3.33 \pm 0.31$ & $0.77 \pm 0.01$ & $6.77 \pm 0.29$ & $25.49 \pm 1.21$ \\
\hline$*<\mathrm{DL}$, below detection limit; detection limit values were 1.95 and $0.98 \mathrm{mg} / \mathrm{L}$ for $(+)$-catechin and quercetin, \\
respectively, and $0.49 \mathrm{mg} / \mathrm{L}$ for the other phenolics tested. Values are averages from measurements \\
performed in triplicates \pm standard deviation.
\end{tabular}

There is little information in the literature regarding to the phenolic content and antioxidant activity of pitahaya samples. The study of $\mathrm{Wu}$ et al. (2006) detected 42.4 and 
$39.7 \mathrm{mg} \mathrm{GAE} / 100 \mathrm{~g}$ TPC of red pitahaya flesh and peel, respectively. They also concluded that this variety was rich in polyphenols and was a good source of antioxidants, for instance gallic acid, which acted as a strong inhibitor of the growth of B16F10 melanoma cancer cells. In addition, the antioxidant activity of the peel extracts was significantly higher than in fruit flesh (Wu et al. 2006) which may be attributed to the considerable amount of betalain and betacyanin in the peel (Harivaindaran et al. 2008). In another studies, 52.3 and $17.25 \mathrm{mg}$ GAE/100 g TPC have been reported for white pitahaya flesh samples (Mahattanatawee et al. 2006, Chen et al. 2014).

\subsubsection{Mango residues}

Concerning mango, surprisingly, $R$. miehei did not grow on the lyophilized residue (LM), while it grew on oven-dried mango (DMG) sample. In DMG, a moderate negative correlation $(r=-0.5)$ was identified between the $\beta$-glucosidase activity and the antioxidant potential. The $\beta$-glucosidase activity significantly increased $(\mathrm{p}<0.05)$ during the fermentation process while the antioxidant parameters decreased (Figure 8 ). $\beta$-Glucosidase activity was maximal at the 18th day reaching $1734 \pm 14 \mathrm{U}$ activity. The highest total phenolic content, antioxidant power and scavenging capacity decreased during the course of the fermentation. Ajila et al. (2007) reported 54.7 - $109.7 \mathrm{mg}$ GAE/g DM TPC for Indian Raspuri and Badami (ripe and raw) mango peel extracts. In another study, it was found that bound polyphenolic acids (gallic, protocatechuic and syringic) and flavonoid contents (kaempferol and quercetin) ranged from 8.1 to 29.5 and 0.101 to $0.392 \mathrm{mg} / \mathrm{g}$, respectively, in the mango peel (Ajila et al. 2013). In our experiments, the maximum TPC determined was about 10 times lower than those measured by Ajila et al (2007), which can be attributed to the different mango variety, maturity grade, sugar content, substrate pretreatment method and/or extraction procedure. Dorta et al. (2012) studied the effects of different drying methods on the polyphenol and antioxidant activity of mango peels and seeds. In their assays, a decrease in antioxidant capacity was detected after oven-drying of the samples, while this was not observed for the freeze-dried residues. The freeze-drying method could improve the antiradical and scavenge capacity of the mango peel against ABTS/ + and free radicals, respectively, and inhibit the lipid peroxidation in the seed (Dorta et al. 2012). 


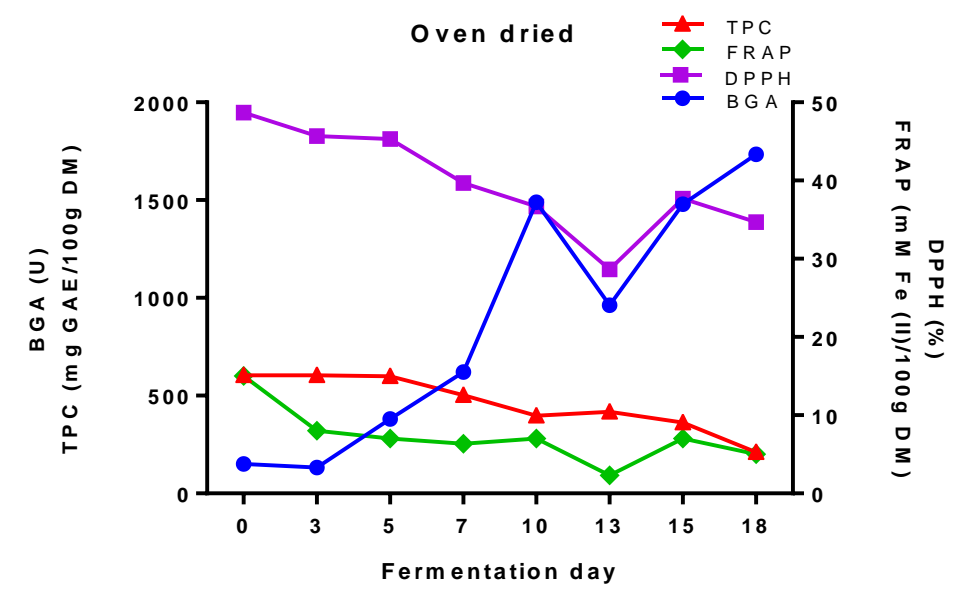

Figure 8. $\beta$-Glucosidase activity (BGA), total phenolic content (TPC), antioxidant power (FRAP) and free radical scavenging activity (DPPH) of oven-dried mango byproducts during solid-state fermentation by $R$. miehei NRRL 5282. Error bars represent SD values of replicates.

\subsubsection{Naranjilla residues}

There was no fungal growth on the oven-dried naranjilla (DN) samples probably due to the low $\mathrm{pH}$ condition generated by the substrate $(\mathrm{pH}=3.0 \pm 0.5)$. On lyophilized naranjilla (LN), the $\beta$-glucosidase activity and TPC significantly increased at the beginning of the fermentation (Figure 9) reaching the maximum activity at the 5th and 3rd day, respectively. Then, a significant drop in their yields was observed. The enzyme activity increased again at the 10th and 15th days followed by the increase of TPC at the 13th and 18 th days. Therefore, it seems that the $R$. miehei $\beta$-glucosidase plays an important role in the free phenolic liberation with antioxidant capacity from LN residues. In this experiment, the maximal $\beta$-glucosidase activity, TPC, antioxidant power and DPPH inhibition values were $1976 \pm 54 \mathrm{U}, 2118 \pm 100 \mathrm{mg}$ GAE/100 g DM, $7.1 \pm 1 \mathrm{mM} \mathrm{Fe}(\mathrm{II}) / 100 \mathrm{~g}$ DM and $34 \pm$ $2 \%$, respectively (Figure 9). In previous studies, the TPC and antioxidant properties of naranjilla samples from Ecuador (Gancel et al. 2008), Costa Rica (Acosta et al. 2009) and Colombia (Contreras-Calderón et al. 2011) were determined, and it was found that the TPC varied between $48 \pm 3$ and $505 \pm 63 \mathrm{mg}$ GAE$/ 100 \mathrm{~g}$ fresh fruit depending on the sample origin. In a comprehensive assay, the DPPH radical inhibition activity of the Ecuadorian naranjilla was measured about 23\% (Vasco et al. 2008), which is agreed with the overall values determined here during the fermentation process (Figure 9). 


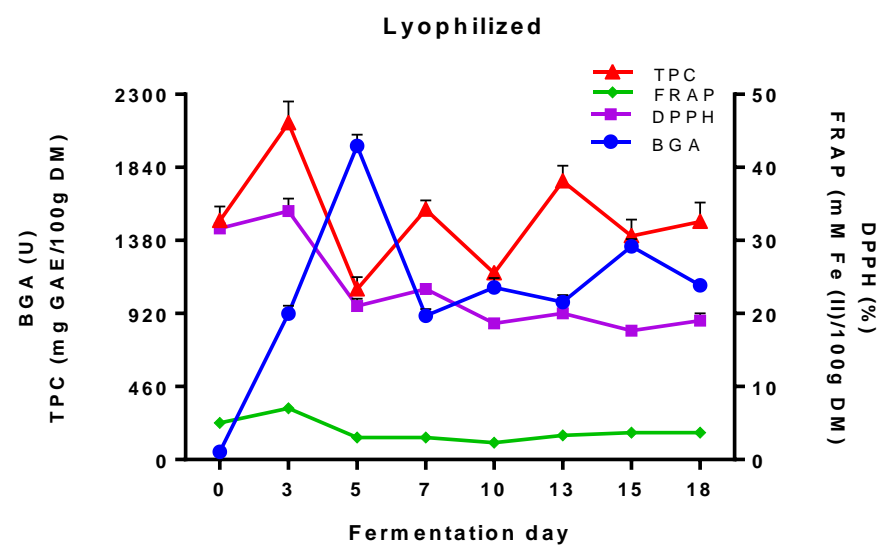

Figure 9. $\beta$-Glucosidase activity (BGA), total phenolic content (TPC), antioxidant power (FRAP) and free radical scavenging activity (DPPH) of lyophilized naranjilla byproducts during solid-state fermentation by $R$. miehei NRRL 5282. Error bars represent SD values of replicates.

\subsubsection{Effect of substrate pretreatment on free phenolics enrichment}

Proper selection of the sample preparation technique is important to achieve high phenolic yield during the fermentation. It influences not only the growth of fermenting fungus but affects the stability of the fruit byproducts and phenolics (Tseng and Zhao 2012). The $\beta$-glucosidase activities were higher when lyophilized substrates were used except for both grape residues (Figure 10A). However, the fermentation on DP sample resulted higher maximum TPC compared to the yield obtained on the lyophilized residue (Figure 10B). In the case of apple, pitahaya and white grape samples, there were no significant differences in the FRAP between the two pretreatments (Figure 10C). The DPPH scavenging activity obtained was not remarkable different between pretreatments except for the pitahaya and white grape samples that showed the highest activity on lyophilized substrate (Figure 10D).

In general, some bioactive compounds in fruit byproducts were sensitive to heat and may undergo chemical degradation, isomerization or polymerization when subjected to elevated temperature (Yu and Ahmedna 2013). Freeze-drying at low temperature and vacuum conditions is a more gently process preventing the bioactive compounds, especially the heat sensitive polyphenolics, from thermal degradation (Michalczyk et al. 2009). 


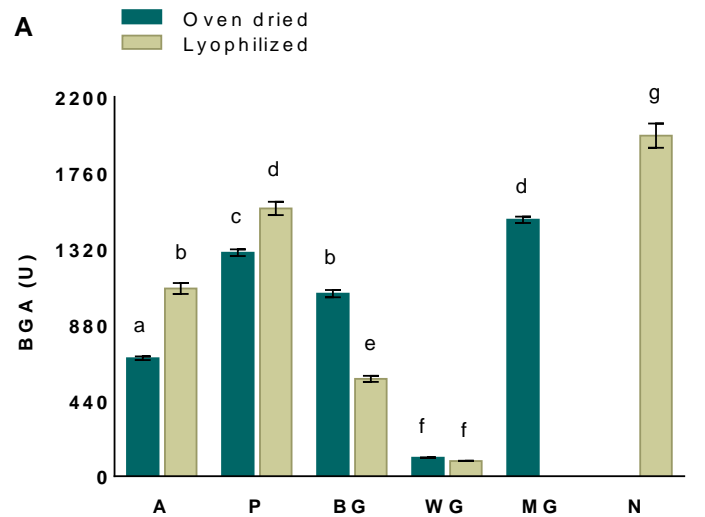

B

C

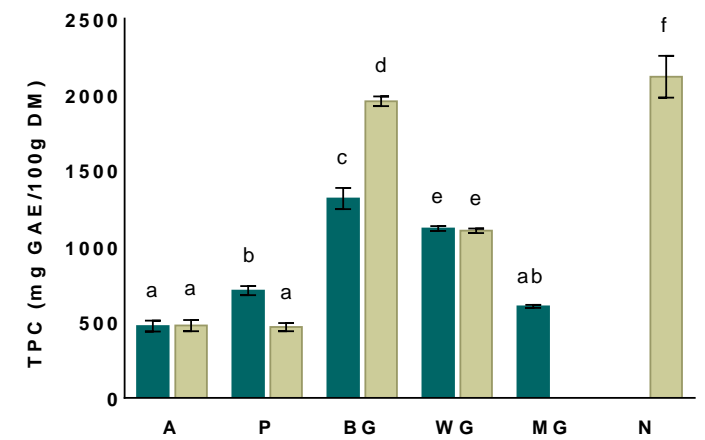

D
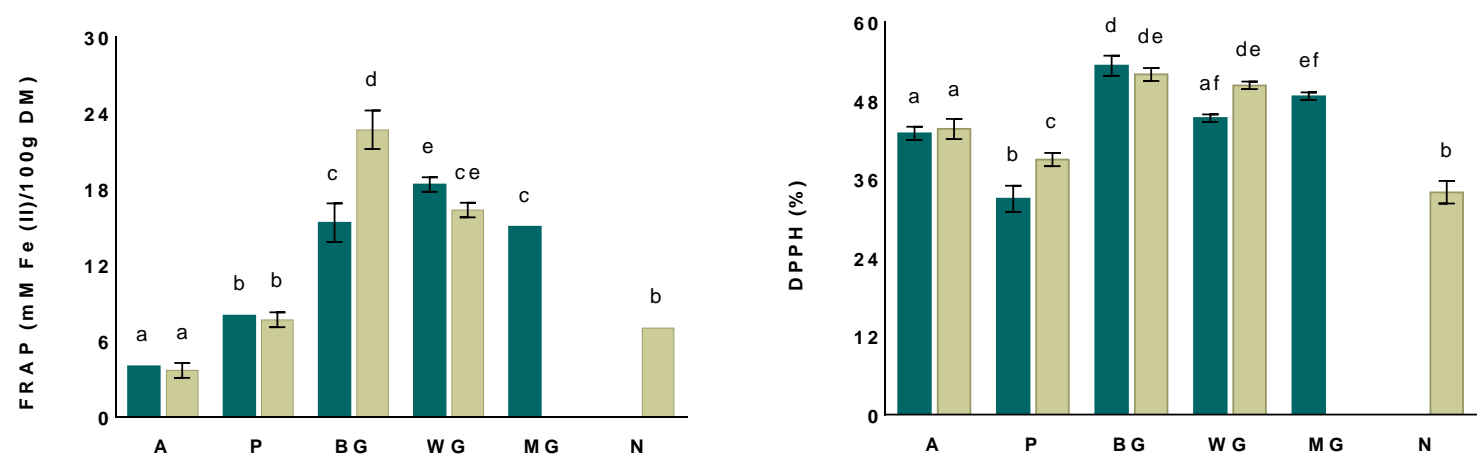

Figure 10. Comparison between pretreatment methods and fruit residue types according to the best $\beta$ glucosidase activity (A), total phenolic content (B) and antioxidant activity (C and D) data achieved on ovendried and lyophilized residues during solid-state $R$. miehei NRRL 5282 bioconversion. A: apple, P: pitahaya, BG: black grape, WG: white grape, MG: mango, N: naranjilla. Different letters on the bars show significant differences according to two-way ANOVA followed by Tukey's Multiple Comparison Test ( $p<0.05$; independent variables: pretreatment and the fruit residue).

The optimal fermentation day to achieve the highest $\beta$-glucosidase and antioxidant activities and TPC yield depended on the type of fruit and was found to be different for the $\beta$-glucosidase activity and the antioxidant potential. Highest $\beta$-glucosidase activity yields were achieved at 5th day for naranjilla, 10th day for pitahaya, 15th day for white and black grapes and 18th day for apple and mango. On the other hand, the FRAP exposed the maximum values at the 3rd day for black grape, mango and naranjilla, 5th day for white grape, 10th day for pitahaya and 13th day for apple. The highest TPC for DA, and the highest TPC, FRAP and DPPH radical scavenging activity for DP and DMG substrates presented on Figure 10 were obtained at the initial phase of fermentation. Then, a decrease was observed in these values. This may be caused by the action of phenolics-degrading and/or stress induced polymerizing enzymes of the fermenting fungus, similar to that observed for black grape substrates (see 5.2.1.), and reported in other studies (Vattem et al. 
2004, Dulf et al. 2016). However, the recovery of some small phenolics of DP sample was increased during the fermentation (see Table 7), which may be explained by the hydrolysis of total phenolic compounds.

\subsection{Enzyme treatment of oven-dried and lyophilized fruit residues}

Carbohydrate cleaving enzymes can rapidly and totally hydrolyze plant tissue polymers, and some studies pointed out that these enzymes can mobilize free phenolics during the hydrolysis (see 2.8.). Therefore, in the following experiments, both oven-dried and lyophilized fruit residues were treated with a cellulolytic enzyme cocktail produced by R. miehei NRRL 5282 on wheat bran substrate (S1 samples). The cellulase cocktail exhibited 75, 203, 35 and 1727 U/g DM of FPase, endoglucanase, cellobiohydrolase and $\beta$ glucosidase activities, respectively. To loosen the cell wall matrix in the fruit residues, the reaction mixture was supplemented by Aspergillus niger produced pectinase (S2 samples). The TPC and antioxidant activities (FRAP and DPPH radical scavenging) were determined after 5-h treatments, and data were compared to those measured in enzyme-free samples (C1 samples) and samples treated with pectinase exclusively (C2 samples).

\subsubsection{Total phenolics and antioxidant activity after enzyme hydrolysis}

\section{Black grape pomace}

TPC and FRAP of LBG pomace showed significant $(\mathrm{p}<0.05)$ increase after cellulase and cellulase-pectinase treatments (Figures 11A and B). For DBG samples, cellulase treatment also improved the TPC and FRAP compared to the enzyme-free control, however, interestingly, this was not observed when the reaction mixture was supplemented with pectinase. The highest TPCs, $5221 \mathrm{mg}$ and $5393 \mathrm{mg}$ GAE/100 g substrate, were obtained on LBG sample after cellulase and cellulase-pectinase treatments, respectively. In parallel, the FRAP of the lyophilized sample displayed about 1.5 -fold and 1.3-fold increment, respectively. Considering enzyme-free samples, the DPPH radical scavenging activity was slightly higher in DBG than in LBG (Figure 11C). However, the pectinase treatment of DBG and the cellulase-pectinase treatment of LBG caused an increase in the DPPH radical scavenging activity compared to the ezyme-free control. Overall, the $R$. miehei cellulase-pectinase combined treatment was effective to liberate free phenolics and increase the antioxidant activities of the LBG samples. In a previous study 
testing tannase treatment of grape pomace, the TPC increased by six-fold, and it was observed that tannase combined with pectinase could release gallic acid from galloylated catechins and thus, increased the antioxidant activity of the extracts (Chamorro et al. 2012).

A

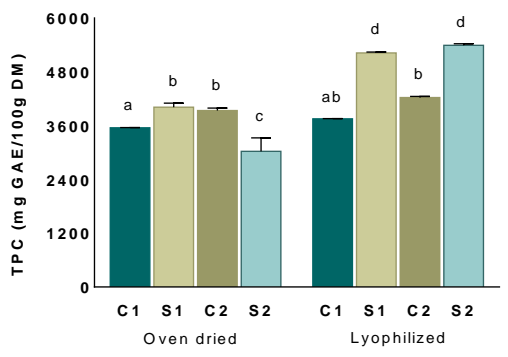

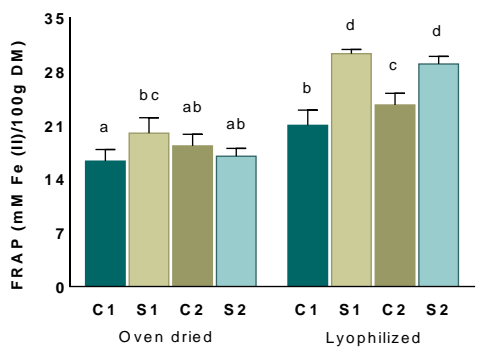

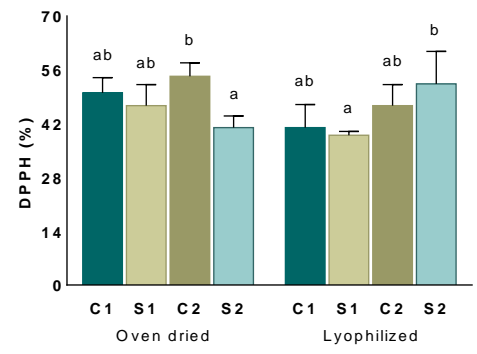

Figure 11. Effect of R. miehei NRRL 5282 cellulolytic cocktail (S1), A. niger pectinase (C2) and R. miehei cellulase-A. niger pectinase (S2) treatments on the TPC (A) and FRAP (B) and DPPH scavenging activity

(C) of oven-dried and lyophilized black grape pomaces. Enzyme-free (C1) mixture was used as control.

Different letters above the columns indicate significant differences according to two-way ANOVA followed by Tukey's Multiple Comparison Test ( $\mathrm{p}<0.05$; independent variables: pretreatment and the type of the enzyme treatment).

\section{White grape pomace}

The LWG residue displayed significantly higher $(\mathrm{p}<0.05)$ TPC and FRAP compared to DWG sample (Figures 12A and B). All three types of enzyme treatments increased $(\mathrm{p}<0.05)$ the TPC of LWG sample, while none of the enzymes used affected the TPC in DWG residue.

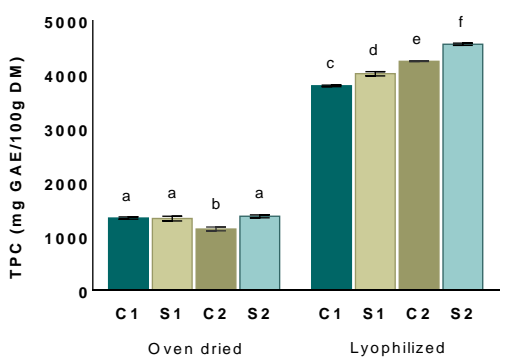

B

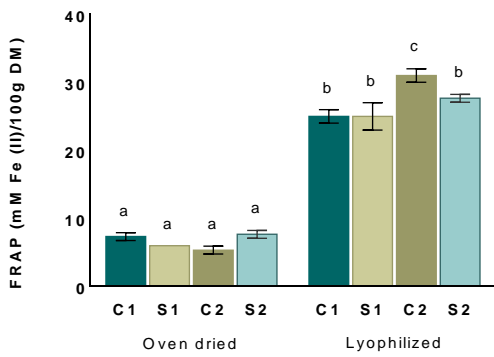

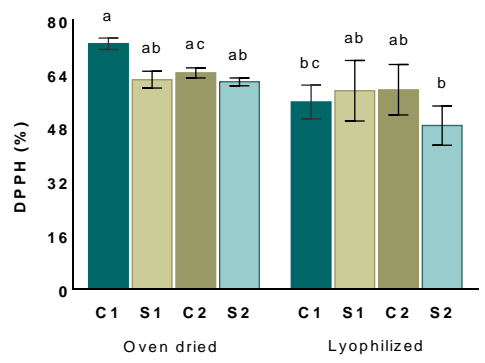

Figure 12. Effect of R. miehei NRRL 5282 cellulolytic cocktail (S1), A. niger pectinase (C2) and R. miehei cellulase-A. niger pectinase (S2) treatments on the TPC (A) and FRAP (B) and DPPH scavenging activity (C) of oven-dried and lyophilized white grape pomaces. Enzyme-free (C1) mixture was used as control. Different letters above the columns indicate significant differences according to two-way ANOVA followed by Tukey's Multiple Comparison Test ( $\mathrm{p}<0.05$; independent variables: pretreatment and the type of the enzyme treatment). 
The a maximum TPC yield was $4564 \pm 14.3 \mathrm{mg}$ GAE/100 g DM obtained after the cellulase-pectinase combined treatment of LWG sample. Compared to enzyme-free sample, only the pectinase treatment caused a significant $(\mathrm{p}<0.05)$ increase in FRAP of LWG residue achieving a $30.8 \mathrm{mM} \mathrm{Fe}$ (II)/100 g DM maximum yield. However, the DPPH radical scavenging activity of enzyme treated samples did not change significantly compared to the corresponding enzyme-free control (Figure 12C).

\section{Apple residues}

For apple residues, both cellulase and cellulase-pectinase treatments positively affected the TPC yield. After $5 \mathrm{~h}$ incubation, the overall TPC showed 1.7 and 1.3 times increase $(\mathrm{p}<0.05)$ in cellulase treated DA and LA samples, respectively, compared to that of untreated samples (Figure 13A). Furthermore, statistically significant $(\mathrm{p}<0.05)$ increase in the phenolics yield was also observed for the samples treated with pectinase supplemented cellulolytic enzymes. Oven-dried and lyophilized samples subjected to combined cellulase-pectinase treatment resulted in the maximum phenolic contents (1521 \pm 90 and $1732 \pm 17 \mathrm{mg} \mathrm{GAE} / 100 \mathrm{~g}$, respectively). This could be attributed to the cell wall depolymerization by pectinases, which is responsible for releasing soluble compounds, including phenolic substances, from the residues (Will et al. 2000).
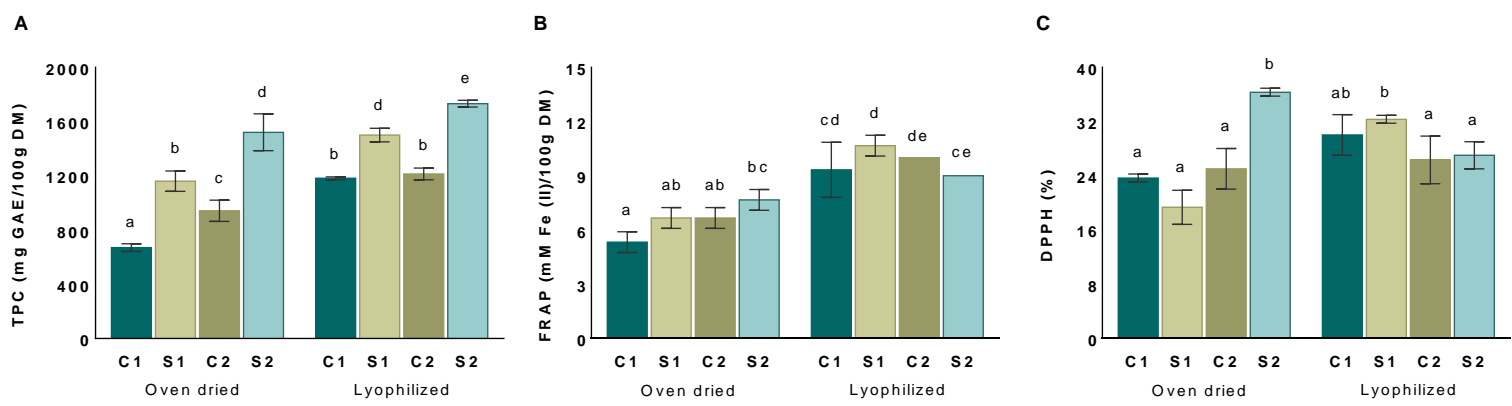

Figure 13. Effect of $R$. miehei NRRL 5282 cellulolytic cocktail (S1), A. niger pectinase (C2) and R. miehei cellulase-A. niger pectinase (S2) treatments on the TPC (A) and FRAP (B) and DPPH scavenging activity (C) of oven-dried and lyophilized apple residues. Enzyme-free $(\mathrm{C} 1)$ mixture was used as control. Different letters above the columns indicate significant differences according to two-way ANOVA followed by Tukey's Multiple Comparison Test ( $\mathrm{p}$ < 0.05; independent variables: pretreatment and the type of the enzyme treatment).

In most studies, the optimal pectinase concentration for liberation of phenolics is different, which variation is due to the variations of enzyme spectrum and -activities between the commercially distibuted enzyme products. The Pectinex AFP L-4, Pectinex Yield Mash and Pectinex XXL, for example, proved to be strong biocatalysts for the 
liberation of phenolics from apple residues, while the Pectinex Ultra SPL has no effect on the free phenolics yield (Oszmiański et al. 2011). The TPC of LA substrate was higher in enzyme treated and untreated systems compared to those detected in the corresponding DA samples. The antioxidant activity followed this trend (Figures 13B and C); however, DPPH radical scavenging activity detected in cellulase-pectinase treated DA residues was slightly superior compared to the other samples. The DPPH radical scavenging activity of enzyme treated LA samples did not differ from that of untreated control.

\section{$\underline{\text { Pitahaya residues }}$}

TPC and FRAP of the DP and the LP samples exhibited an increase after a 5-h incubation with the cellulase and cellulase-pectinase cocktails (Figures 14A and B). Since the pectin content of the pitahaya residues is relatively low $(0.12-0.27 \mathrm{~g} / 100 \mathrm{~g}$ fruit) compared to those of grapes $(0.7-0.8 \mathrm{~g} / 100 \mathrm{~g})$ and apple $(0.25-0.63 \mathrm{~g} / 100 \mathrm{~g})$ (Mahattanatawee et al. 2006), the pectinase treatment was expected to have insignificant effect on the extractable phenolic content. Remarkably, the added pectinase resulted in about 1.4- and 1.2-fold increase in the TPC yield on DP and LP, respectively, compared to the non-treated sample. The cellulase-pectinase cocktail further enhanced the TPC by 1.1and 2.2-fold reaching maximum yields of $2207 \pm 43$ and $1314 \pm 19 \mathrm{mg}$ GAE/100 $\mathrm{g}$ for DP and LP, respectively. Furthermore, the cellulase-pectinase combined treatment affected positively the DPPH radical scavenging activity of the DP substrate (Figure 14C). To our knowledge, TPC and antioxidant activity of cellulolytic and pectinolytic enzyme treated pitahaya residues have not been reported so far.
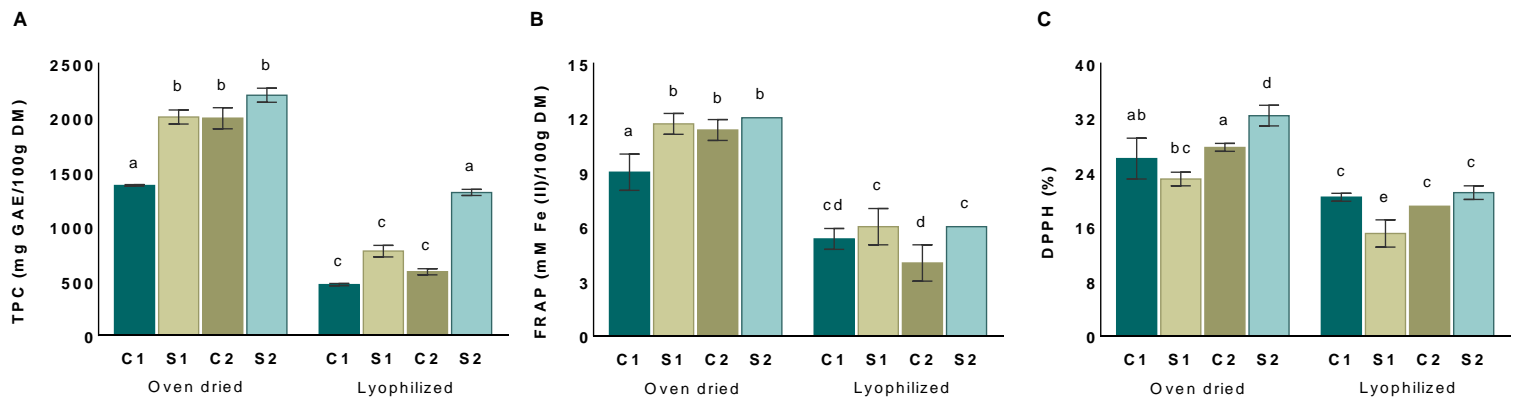

Figure 14. Effect of $R$. miehei NRRL 5282 cellulolytic cocktail (S1), A. niger pectinase (C2) and R. miehei cellulase- $A$. niger pectinase (S2) treatments on the TPC (A) and FRAP (B) and DPPH scavenging activity

(C) of oven-dried and lyophilized pitahaya residues. Enzyme-free (C1) mixture was used as control. Different letters above the columns indicate significant differences according to two-way ANOVA followed by Tukey's Multiple Comparison Test ( $\mathrm{p}<0.05$; independent variables: pretreatment and the type of the enzyme treatment). 


\section{Mango residues}

Concerning mango, only the oven-dried residue (DMG) was subjected to enzyme treatment. All three types of enzyme treatments increased the TPC yields significantly $(\mathrm{p}<$ 0.05) (Figure 15A), while only the pectinase and the cellulase-pectinase treatments improved the FRAP values (Figure 15B) The highest TPC yield (2350 $\pm 38 \mathrm{mg} \mathrm{GAE} / 100 \mathrm{~g}$ DM) and DPPH scavenging activity $(47 \pm 6 \%)$ were in the extract obtained by cellulasepectinase treatment (Figures 15A and C). FRAP was maximum in cellulase-pectinase treated samples $(20.1 \pm 0.8 \mathrm{mM}$ Fe(II)/100 g DM).
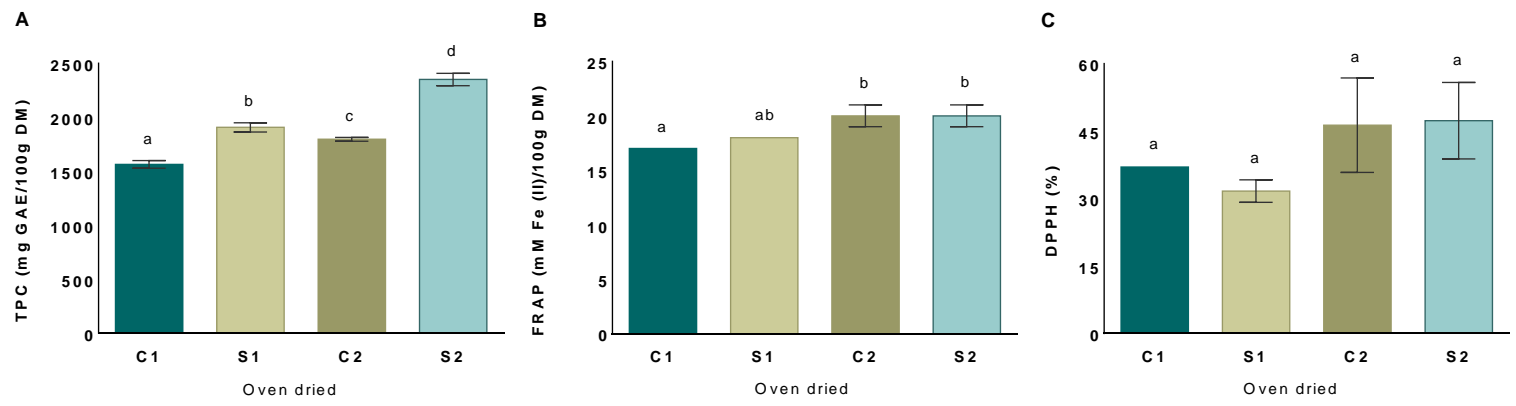

Figure 15. Effect of $R$. miehei NRRL 5282 cellulolytic cocktail (S1), A. niger pectinase (C2) and R. miehei cellulase-A. niger pectinase (S2) treatments on the TPC (A) and FRAP (B) and DPPH scavenging activity

(C) of oven-dried mango residues. Enzyme-free (C1) mixture was used as control. Different letters above the columns indicate significant differences according to two-way ANOVA followed by Tukey's Multiple Comparison Test ( $p<0.05$; independent variables: pretreatment and the type of the enzyme treatment).

\section{$\underline{\text { Naranjilla residues }}$}

The TPC and the FRAP of the LN showed a significant increase $(\mathrm{p}<0.05)$ in the cellulase treated sample compared to the untreated one. The DPPH radical scavenging activity improved only for the oven-dried residue (Figure 16). Among all naranjilla extracts analyzed, the highest TPC and FRAP yields were in the oven-dried enzyme-free extract, however, the values decreased after the cellulase treatment. In contrast, LN sample exhibited improved phenolics yield and reducing power after the cellulase-assisted extraction: the TPC and FRAP values increased to 1.5 and 1.3 times, respectively, compared to enzyme-free sample. The maximum TPC and FRAP in cellulase treated LN sample were $1654 \pm 69 \mathrm{mg}$ GAE/100 $\mathrm{g} \mathrm{DM}$ and $10 \pm 0.5 \mathrm{mM} \mathrm{Fe(II)/100} \mathrm{g} \mathrm{DM}$, respectively. 


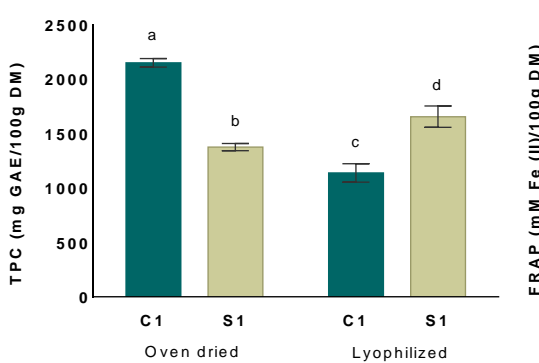

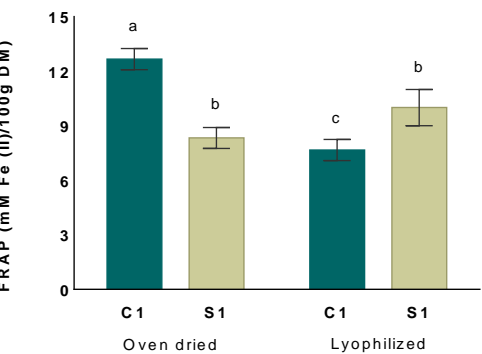

C

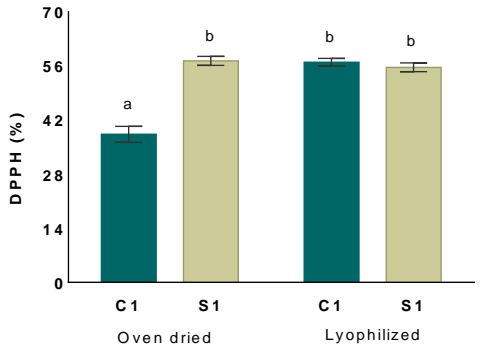

Figure 16. Effect of $R$. miehei NRRL 5282 cellulolytic cocktail (S1) treatment on the TPC (A) and FRAP (B) and DPPH scavenging activity (C) of oven-dried and lyophilized naranjilla residues. Enzyme-free (C1) mixtures were used as controls. Different letters above the columns indicate significant differences according to two-way ANOVA followed by Tukey's Multiple Comparison Test $(\mathrm{p}<0.05$; independent variables: pretreatment and the enzyme treatment).

\subsubsection{Analysis of individual phenolic compounds after enzyme treatments}

Tables 8, 9 and 10 summarize the concentrations of distinct phenolic compounds belonging to the groups of hydroxybenzoates, hydroxycinnamates, flavan-3-ols, flavonols and stilbenoids in black grape, apple, pitahaya and mango samples before and after enzyme treatments. Analytical HPLC data indicate that total yield of the tested individual phenolics increased after enzyme treatments, which agrees with the TPC results. However, it is worth to note that the Folin-Ciocalteu's phenol reagent used for the TPC assay reacts not only with phenolic compounds but also with amino acids, sugars and other reducing substances present in the extracts (Rapisarda et al. 1999). Therefore, differences between the degree of phenolic content determined by Folin-Ciocalteu's phenol reagent and analytical HPLC method are expected.

With regards to the cellulase-pectinase treatments, chromatographic measurements showed a decrease in the amount of some individual phenolics. This was most obvious for the data of the DBG and DMG extracts (Tables 8 and 10). A probable reason for this phenomenon can be the transformation of the phenolics into volatile compounds during incubation (Sandri et al. 2011, Shah et al. 2015) and the release of additional phenolic acid derivatives from their ester linkages by the action of the enzyme. 
Table 8. Concentration of phenolic compounds (mg/100 g DM) detected in oven-dried black grape, apple and yellow pitahaya extracts pre- and post-enzyme treatment. Data were obtained from the supernatant of the reaction mixture.

\begin{tabular}{|c|c|c|c|c|c|c|c|c|c|}
\hline \multirow[b]{3}{*}{ Compounds } & \multicolumn{9}{|l|}{ Fruit residues } \\
\hline & \multicolumn{3}{|l|}{ Black grape } & \multicolumn{3}{|l|}{ Apple } & \multicolumn{3}{|l|}{ Pitahaya } \\
\hline & Control* & $\begin{array}{l}R \text {. miehei } \\
\text { cellulase }\end{array}$ & $\begin{array}{l}R . \text { miehei } \\
\text { cellulase + } \\
\text { A. niger } \\
\text { pectinase }\end{array}$ & Control & $\begin{array}{l}R \text {. miehei } \\
\text { cellulase }\end{array}$ & $\begin{array}{l}R . \text { miehei } \\
\text { cellulase + } \\
\text { A. niger } \\
\text { pectinase }\end{array}$ & Control & $\begin{array}{l}R . \text { miehei } \\
\text { cellulase }\end{array}$ & $\begin{array}{l}R . \text { miehei } \\
\text { cellulase + } \\
\text { A. niger } \\
\text { pectinase }\end{array}$ \\
\hline Gallic acid & $2.28 \pm 0.32 \mathrm{a}$ & $6.21 \pm 0.46 \mathrm{~b}$ & $3.61 \pm 0.26 \mathrm{ab}$ & $2.17 \pm 0.24 \mathrm{a}$ & $<\mathrm{DL}$ & $0.58 \pm 0.06 \mathrm{a}$ & $19.68 \pm 1.31 \mathrm{c}$ & $27.53 \pm 2.02 \mathrm{~d}$ & $34.16 \pm 2.95 \mathrm{e}$ \\
\hline Vanillic acid & $2.11 \pm 0.21 \mathrm{a}$ & $12.61 \pm 0.93 b$ & $11.27 \pm 0.39 b$ & $<\mathrm{DL}$ & $3.56 \pm 0.34 \mathrm{a}$ & $3.18 \pm 0.31 \mathrm{a}$ & $5.16 \pm 0.35 \mathrm{a}$ & $11.99 \pm 1.13 b$ & $15.86 \pm 1.35 \mathrm{c}$ \\
\hline Syringic acid & $2.27 \pm 0.31 \mathrm{a}$ & $7.97 \pm 0.80 \mathrm{~b}$ & $14.58 \pm 0.81 \mathrm{c}$ & $<\mathrm{DL}$ & $2.09 \pm 0.21 \mathrm{a}$ & $2.29 \pm 0.33 \mathrm{a}$ & $5.94 \pm 0.66 b$ & $6.19 \pm 0.93 b$ & $7.69 \pm 0.77 b$ \\
\hline$p$-Coumaric acid & $<\mathrm{DL}$ & $2.56 \pm 0.16 \mathrm{a}$ & $10.35 \pm 0.35 b$ & $<\mathrm{DL}$ & $<\mathrm{DL}$ & $1.78 \pm 0.37 \mathrm{a}$ & $2.61 \pm 0.28 \mathrm{a}$ & $3.21 \pm 0.60 \mathrm{ac}$ & $4.41 \pm 0.84 \mathrm{c}$ \\
\hline Cinnamic acid & $<\mathrm{DL}$ & $<\mathrm{DL}$ & $<\mathrm{DL}$ & $<\mathrm{DL}$ & $<\mathrm{DL}$ & $<\mathrm{DL}$ & $1.59 \pm 0.18 \mathrm{a}$ & $1.66 \pm 0.37 \mathrm{a}$ & $1.73 \pm 0.35 \mathrm{a}$ \\
\hline$(+)$-Catechin & $3.59 \pm 0.42 \mathrm{a}$ & $22.14 \pm 1.42 \mathrm{~b}$ & $7.67 \pm 0.52 \mathrm{c}$ & $<\mathrm{DL}$ & $8.93 \pm 0.55 \mathrm{c}$ & $6.22 \pm 0.57 \mathrm{c}$ & $22.86 \pm 2.08 b$ & $18.03 \pm 0.78 \mathrm{~d}$ & $3.74 \pm 0.51 \mathrm{a}$ \\
\hline$(-)$-Epicatechin & $3.44 \pm 0.38 \mathrm{a}$ & $21.73 \pm 0.91 b$ & $7.82 \pm 0.42 \mathrm{c}$ & $<\mathrm{DL}$ & $2.59 \pm 0.26 \mathrm{a}$ & $3.35 \pm 0.41 \mathrm{a}$ & $14.02 \pm 0.93 \mathrm{~d}$ & $6.95 \pm 0.84 \mathrm{c}$ & $10.87 \pm 1.21 \mathrm{e}$ \\
\hline Polydatin & $<\mathrm{DL}$ & $3.97 \pm 0.34 \mathrm{a}$ & $<\mathrm{DL}$ & $<\mathrm{DL}$ & $<\mathrm{DL}$ & $<\mathrm{DL}$ & $22.56 \pm 1.17 \mathrm{~b}$ & $28.56 \pm 1.11 \mathrm{c}$ & $36.56 \pm 3.15 \mathrm{~d}$ \\
\hline Resveratrol & $<\mathrm{DL}$ & $<\mathrm{DL}$ & $<\mathrm{DL}$ & $<\mathrm{DL}$ & $1.99 \pm 0.24 \mathrm{a}$ & $<\mathrm{DL}$ & $2.46 \pm 0.44 \mathrm{a}$ & $2.82 \pm 0.62 \mathrm{a}$ & $<\mathrm{DL}$ \\
\hline Total & 13.69 & 89.61 & 58.18 & 2.17 & 21.15 & 19.18 & 102.32 & 111.98 & 120.95 \\
\hline
\end{tabular}

* without enzyme treatment; ** $<\mathrm{DL}$, below detection limit; detection limit values were 1.95 and $0.98 \mathrm{mg} / \mathrm{L}$ for (+)-catechin and quercetin, respectively, and $0.49 \mathrm{mg} / \mathrm{L}$ for the other phenolics tested. Values are the average of measurements performed in triplicates \pm standard deviation; mean values within a row with different letters are significantly differ according to two-way ANOVA followed by Tukey’s Multiple Comparison Test $(p<0.05$; independent variables: fruit residue and type of the enzyme treatment). 
Table 9. Concentration of phenolic compounds (mg/100 g DM) detected in lyophilized black grape, apple and yellow pitahaya extracts pre- and post-enzyme treatment. Data were obtained from the supernatant of the reaction mixture.

\begin{tabular}{|c|c|c|c|c|c|c|c|c|c|}
\hline \multirow[b]{3}{*}{ Compounds } & \multicolumn{9}{|l|}{ Fruit residues } \\
\hline & \multicolumn{3}{|l|}{ Black grape } & \multicolumn{3}{|l|}{ Apple } & \multicolumn{3}{|l|}{ Pitahaya } \\
\hline & Control* & $\begin{array}{l}R . \text { miehei } \\
\text { cellulase }\end{array}$ & $\begin{array}{l}R \text {. miehei } \\
\text { cellulase }+ \\
\text { A. niger pectinase }\end{array}$ & Control & $\begin{array}{l}R . \text { miehei } \\
\text { cellulase }\end{array}$ & $\begin{array}{l}R \text {. miehei } \\
\text { cellulase }+ \\
\text { A. niger } \\
\text { pectinase } \\
\end{array}$ & Control & $\begin{array}{l}R \text {. miehei } \\
\text { cellulase }\end{array}$ & $\begin{array}{l}R \text {. miehei } \\
\text { cellulase }+ \\
\text { A. niger } \\
\text { pectinase } \\
\end{array}$ \\
\hline Gallic acid & $3.05 \pm 0.59 \mathrm{a}$ & $43.77 \pm 4.10 \mathrm{~b}$ & $37.23 \pm 3.10 \mathrm{~b}$ & $<\mathrm{DL}$ & $5.11 \pm 0.74 \mathrm{a}$ & $3.91 \pm 0.86 \mathrm{a}$ & $2.24 \pm 0.35 \mathrm{a}$ & $2.61 \pm 0.34 \mathrm{a}$ & $2.56 \pm 0.24 \mathrm{a}$ \\
\hline $\begin{array}{l}\text { 4-Hydroxybenzoic } \\
\text { acid }\end{array}$ & $4.21 \pm 0.66 \mathrm{a}$ & $68.23 \pm 4.27 \mathrm{~b}$ & $67.45 \pm 6.11 b$ & $2.35 \pm 0.41 \mathrm{a}$ & $8.32 \pm 0.98 \mathrm{c}$ & $7.30 \pm 0.92 \mathrm{c}$ & $1.53 \pm 0.21 \mathrm{a}$ & $1.67 \pm 0.38 \mathrm{a}$ & $1.61 \pm 0.25 \mathrm{a}$ \\
\hline Vanillic acid & $2.75 \pm 0.37 \mathrm{a}$ & $60.26 \pm 6.11 \mathrm{~b}$ & $60.27 \pm 6.64 b$ & $1.52 \pm 0.35 \mathrm{a}$ & $14.64 \pm 1.42 \mathrm{c}$ & $12.49 \pm 0.57 \mathrm{c}$ & $<\mathrm{DL}$ & $2.87 \pm 0.34 \mathrm{a}$ & $2.84 \pm 0.36 \mathrm{a}$ \\
\hline Syringic acid & $2.45 \pm 0.48 \mathrm{a}$ & $33.06 \pm 2.68 \mathrm{~b}$ & $35.46 \pm 3.47 \mathrm{~b}$ & $0.76 \pm 0.15 \mathrm{a}$ & $3.23 \pm 0.44 \mathrm{a}$ & $3.92 \pm 0.49 \mathrm{a}$ & $2.08 \pm 0.18 \mathrm{a}$ & $2.29 \pm 0.24 \mathrm{a}$ & $2.22 \pm 0.16 \mathrm{a}$ \\
\hline$p$-Coumaric acid & $1.83 \pm 0.36 \mathrm{a}$ & $10.35 \pm 1.16 \mathrm{~b}$ & $15.36 \pm 2.11 \mathrm{c}$ & $0.89 \pm 0.09 \mathrm{a}$ & $0.95 \pm 0.11 \mathrm{a}$ & $2.97 \pm 0.67 \mathrm{a}$ & $<\mathrm{DL}$ & $1.80 \pm 0.19 \mathrm{a}$ & $1.81 \pm 0.18 \mathrm{a}$ \\
\hline Cinnamic acid & $<\mathrm{DL}^{* *}$ & $1.51 \pm 0.36 \mathrm{a}$ & $1.49 \pm 0.35 \mathrm{a}$ & $<\mathrm{DL}$ & $<\mathrm{DL}$ & $<\mathrm{DL}$ & $<\mathrm{DL}$ & $<\mathrm{DL}$ & $<\mathrm{DL}$ \\
\hline$(+)$-Catechin & $7.48 \pm 0.89 \mathrm{a}$ & $209.83 \pm 22.31 b$ & $200.51 \pm 20.33 b$ & $<\mathrm{DL}$ & $33.23 \pm 3.62 \mathrm{c}$ & $2.81 \pm 0.55 \mathrm{a}$ & $<\mathrm{DL}$ & $<\mathrm{DL}$ & $<\mathrm{DL}$ \\
\hline (-)-Epicatechin & $8.75 \pm 0.82 \mathrm{a}$ & $215.81 \pm 17.17 b$ & $188.13 \pm 19.93 b$ & $6.71 \pm 0.84 \mathrm{a}$ & $10.05 \pm 1.22 \mathrm{a}$ & $99.92 \pm 9.68 \mathrm{c}$ & $2.79 \pm 0.34 \mathrm{a}$ & $2.83 \pm 0.28 \mathrm{a}$ & $2.77 \pm 0.34 \mathrm{a}$ \\
\hline Quercetin & $<\mathrm{DL}$ & $8.54 \pm 0.81 \mathrm{a}$ & $7.61 \pm 0.71 \mathrm{a}$ & $<\mathrm{DL}$ & $<\mathrm{DL}$ & $6.49 \pm 0.75 \mathrm{a}$ & $<\mathrm{DL}$ & $<\mathrm{DL}$ & $<\mathrm{DL}$ \\
\hline Polydatin & $2.63 \pm 0.43 \mathrm{a}$ & $<\mathrm{DL}$ & $<\mathrm{DL}$ & $<\mathrm{DL}$ & $<\mathrm{DL}$ & $<\mathrm{DL}$ & $3.35 \pm 0.41 \mathrm{a}$ & $3.51 \pm 0.37 \mathrm{a}$ & $3.49 \pm 0.36 \mathrm{a}$ \\
\hline Resveratrol & $<\mathrm{DL}$ & $4.28 \pm 0.61 \mathrm{a}$ & $4.67 \pm 0.53 \mathrm{a}$ & $<\mathrm{DL}$ & $0.51 \pm 0.02 \mathrm{~b}$ & $<\mathrm{DL}$ & $<\mathrm{DL}$ & $2.17 \pm 0.19 \mathrm{c}$ & $2.12 \pm 0.17 \mathrm{c}$ \\
\hline Total & 33.15 & 655.64 & 618.18 & 12.23 & 76.04 & 139.81 & 11.99 & 19.75 & 19.42 \\
\hline
\end{tabular}

* without enzyme treatment; ** $<\mathrm{DL}$, below detection limit; detection limit values were 1.95 and $0.98 \mathrm{mg} / \mathrm{L}$ for $(+)$-catechin and quercetin, respectively, and $0.49 \mathrm{mg} / \mathrm{L}$ for the other phenolics tested. Values are the average of measurements performed in triplicates \pm standard deviation; mean values within a row with different letters are significantly differ according to two-way ANOVA followed by Tukey's Multiple Comparison Test $(\mathrm{p}<0.05$; independent variables: fruit residue and type of the enzyme treatment). 
Table 10. Concentration of phenolic compounds (mg/100 g DM) detected in oven-dried mango extract preand post-enzyme treatment. Data were obtained from the supernatant of the reaction mixture.

\begin{tabular}{llll}
\hline Compounds & Control* & $\begin{array}{l}\text { R. miehei } \\
\text { cellulase }\end{array}$ & $\begin{array}{l}\text { R. miehei } \\
\text { cellulase }+ \\
\text { A.niger pectinase }\end{array}$ \\
\hline Gallic acid & $3.29 \pm 0.48 \mathrm{a}$ & $80.25 \pm 5.10 \mathrm{~b}$ & $6.98 \pm 0.10 \mathrm{a}$ \\
4-Hydroxybenzoic acid & $<\mathrm{DL} * *$ & $33.39 \pm 2.77 \mathrm{a}$ & $3.24 \pm 0.11 \mathrm{~b}$ \\
Vanillic acid & $<\mathrm{DL}$ & $21.61 \pm 2.11 \mathrm{a}$ & $2.94 \pm 0.64 \mathrm{~b}$ \\
Syringic acid & $<\mathrm{DL}$ & $10.48 \pm 1.68 \mathrm{a}$ & $2.2 \pm 0.47 \mathrm{~b}$ \\
$p$-Coumaric acid & $<\mathrm{DL}$ & $3.84 \pm 0.16 \mathrm{a}$ & $1.8 \pm 0.11 \mathrm{~b}$ \\
Cinnamic acid & $<\mathrm{DL}$ & $<\mathrm{DL}$ & $<\mathrm{DL}$ \\
$(+)$-Catechin & $<\mathrm{DL}$ & $2.67 \pm 0.31 \mathrm{a}$ & $2.98 \pm 0.33 \mathrm{a}$ \\
$(-)$-Epicatechin & $6.29 \pm 0.89 \mathrm{a}$ & $163.75 \pm 12.17 \mathrm{~b}$ & $13.41 \pm 2.93 \mathrm{a}$ \\
Quercetin & $<\mathrm{DL}$ & $10.35 \pm 0.83 \mathrm{a}$ & $5.93 \pm 0.61 \mathrm{~b}$ \\
Polydatin & $<\mathrm{DL}$ & $<\mathrm{DL}$ & $2.27 \pm 0.21 \mathrm{a}$ \\
Resveratrol & $<\mathrm{DL}$ & $<\mathrm{DL}$ & $<\mathrm{DL}$ \\
Total & 9.58 & 326.34 & 41.75 \\
\hline
\end{tabular}

* without enzyme treatment; $* *<\mathrm{DL}$, below detection limit; detection limit values were 1.95 and $0.98 \mathrm{mg} / \mathrm{L}$ for (+)-catechin and quercetin, respectively, and $0.49 \mathrm{mg} / \mathrm{L}$ for the other phenolics tested. Values are the average of measurements performed in triplicates \pm standard deviation; mean values within a row with different letters are significantly differ according to one-way ANOVA followed by Tukey's Multiple Comparison Test $(\mathrm{p}<0.05)$.

After the cellulase treatment, (+)-catechin was found in the largest concentration in DBG and LBG pomaces (Tables 8 and 9), while (-)-epicatechin content was the highest in LBG and DMG samples (Tables 9 and 10). Compared to the control treatment, the quantities of (+)-catechin and (-)-epicatechin in the DBG and LBG residues had increased about 6 and 26 times, respectively, while the amount of (-)-epicatechin enhanced by 27 fold in DMG samples $(\mathrm{p}<0.05)$. The enzyme treatments increased the $(+)$-catechin content in DMG residues as well, although it remained in low concentration (Table 10). The contents of these flavan-3-ols also increased when apple residues were incubated with the cellulase cocktail. Furthermore, chromatography detected an about 10 times increase $(p<$ $0.05)$ in the (-)-epicatechin content of LA after addition of pectinase (Table 9). This could ascribe to the decomposition of apple pectin fiber, supporting the liberation of epicatechin from its insoluble, fiber- and pectin bounded form. The bioavailability of the entrapped apple epicatechin is limited (Hollands et al. 2013), which could be enhanced by the $R$. miehei cellulase-A. niger pectinase combined treatment. However, a decrease in the flavan3-ol content was detected in some samples after pectinase addition, which may be due to both oxidation and several polymerization reactions (Ye et al. 2014). 
As a result of enzyme treatments, the content of hydroxybenzoates (gallic, 4hydroxybenzoic, vanillic and syringic acids) and hydroxycinnamates ( $p$-coumaric and cinnamic acids) increased by different degrees in both oven-dried and lyophilized pomaces. From DMG samples, for instance, the cellulase treatment markedly supported the mobilization of most of these molecules (Table 10). The LBG residues contained the highest level of the hydroxybenzoates and hydroxycinnamates analyzed, with concentrations from 1.49 to $68.19 \mathrm{mg} / \mathrm{L}$, respectively. Except for cinnamic acid, the content of these above phenolics increased by about 10 to 20 times $(\mathrm{p}<0.05)$ after the enzyme treatments (Table 9). The same trend was reported during the treatment of grape pomace from red wine using Novoferm 106 pectinolytic and Cellubrix ${ }^{\circledR} \mathrm{L}$ cellulolytic enzyme mixtures (Maier et al. 2008). The DP samples showed the highest initial gallic acid concentration among the fruit residues studied. Moreover, its content increased to 1.7 times $(\mathrm{p}<0.05)$ after cellulase-pectinase treatment (Table 8). The gallic acid is the major contributor to hydroxybenzoates and has attracted considerable interests because of its antioxidant properties (Strlič et al. 2002).

The detected stilbenoids during enzyme treatment were the resveratrol and its glycosidic form, the polydatin. These compounds are the major stilbenoids found in foods of plant origin and display a broad variety of beneficial effects on human health (Ravagnan et al. 2013). Except for DP samples, the initial content of resveratrol in residues was below the detection limit (Tables 8, 9 and 10). This low level may be due to the poor extractability of resveratrol from the residues in the applied aqueous environment. However, the resveratrol yield increased in all lyophilized and the DA samples after cellulase treatment. Polydatin, was found in the largest concentration in the DP samples. Compared to the initial content, it showed an about 1.6 times increase $(\mathrm{p}<0.05)$ during enzyme treatments (Table 8). The amount of polydatin in DP residues was higher than that of the resveratrol, which finding is consistent with the results of studies on grape samples (Romero-Pérez et al. 1999).

Quercetin was observed after cellulase treatment in DBG $(6.11 \mathrm{mg} / 100 \mathrm{~g} \mathrm{DM})$, LBG (8.54 mg/100 g DM) and DMG (10.35 mg/100 g DM) pomace extracts (Tables 8, 9 and 10), and after cellulase-pectinase treatment of LBG (7.61 mg/100 g DM), LA (6.49 $\mathrm{mg} / 100 \mathrm{~g} \mathrm{DM}$ ) and DBG (5.93 mg/100 g DM) samples (Tables 9 and 10). In line with our previous study testing sour cherry pomace (Krisch et al. 2012), it could be a result of the hydrolysis of the quercetin aglycone from quercetin glycosides by the $R$. miehei cellulase. No quercetin was detected in the pitahaya samples. 
After HPLC analysis of phenolic compounds of the fruit extracts, their antioxidant activity was also determined by FRAP and DPPH methods. In this assay, the syringic and gallic acids and the flavonoid (+)-catechin exhibited the highest antioxidant capacity among the tested phenolic compounds $(\mathrm{p}<0.05)$ (Figure 17). After evaluation of results, correlation could be observed between the antioxidant activity and concentration of some individual phenolics after enzyme treatments. The above phenolics could be responsible for the increase of antioxidant potential in the samples after enzyme treatment.

A

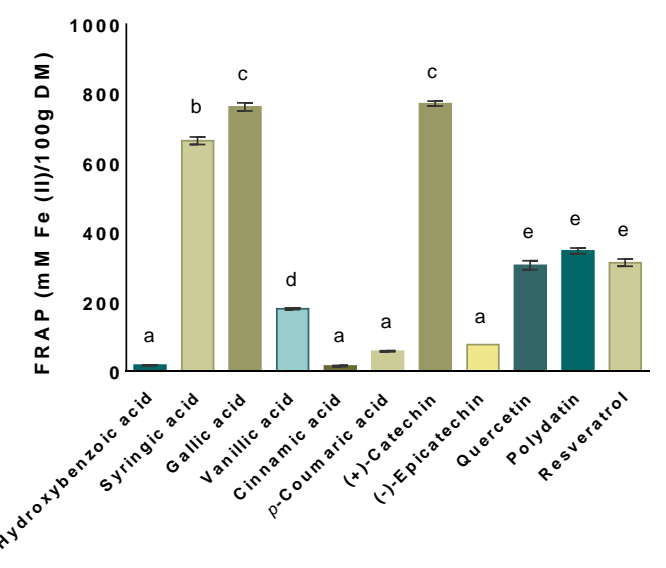

B

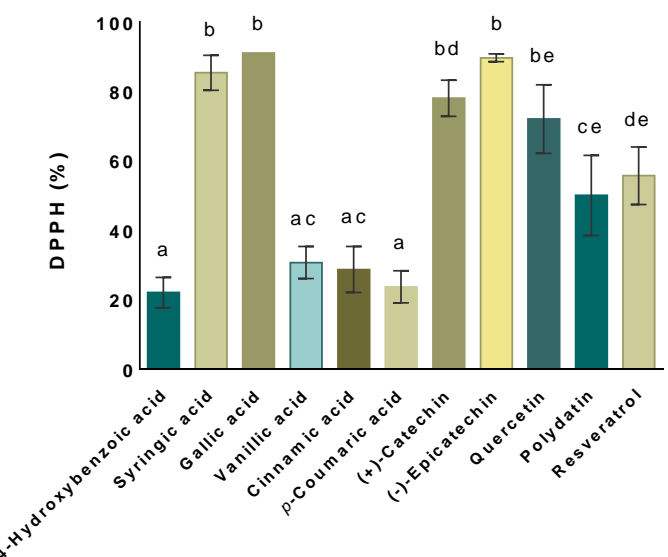

Figure 17. FRAP (A) and DPPH scavenging (B) activity of phenolic compounds. Different letters above the columns indicate significant differences according to one-way ANOVA followed by Tukey's Multiple Comparison Test $(\mathrm{p}<0.05)$.

\subsection{Antimicrobial activity of selected phenolic extracts}

In these studies, additional bioactive properties, i.e. the antimicrobial, anti-QS and anti-biofilm forming activities of selected enzyme-free and enzyme-treated fruit extracts were screened and compared. In addition, the above examined 4-hydroxybenzoic acid, syringic acid, gallic acid, vanillic acid, cinnamic acid, $p$-coumaric acid, (+)-catechin, (-)epicatechin, quercetin, polydatin and resveratrol compounds were also subjected to bioactivity analyses in order to study the possible correlation between the activity changes in the extracts and the increase in the phenolic compound concentrations after the enzyme treatments. The foodborne pathogen and/or spoilage Bacillus subtilis, Bacillus cereus, Listeria monocytogenes, Staphylococcus aureus, methicillin-resistant Staphylococcus aureus (MRSA), Escherichia coli, Salmonella enterica subsp. enterica serovar Typhimurium, Pseudomonas putida and Pseudomonas aeruginosa bacteria were involved 
in the antimicrobial and anti-biofilm forming activity tests. The model organism Chromobacterium violaceum was used in the anti-QS activity assays.

\subsubsection{Screening of antimicrobial capacity on solid medium}

In this experiment, antimicrobial activity of enzyme-free and treated fruit extracts and individual phenolics was screened and compared by using a disk-diffusion method. Majority of the fruit residue extracts inhibited the growth of the bacteria studied (Table 11). Overall, B. subtilis, S. aureus and S. enterica were the most sensitive bacteria to all extracts investigated. The lowest growth inhibition effect was detected against $L$. monocytogenes and the Pseudomonas strains. By comparing the fruit samples, in general, extracts made from enzyme treated and untreated grape pomaces presented slightly stronger antimicrobial effect against the tested bacteria than those observed for apple, pitahaya, mango and naranjilla residues (Table 11). Most grape samples resulted in inhibition zones between 4 and $8 \mathrm{~mm}$, whereas this was mainly between 1 to $5 \mathrm{~mm}$ for the other fruits tested. Grapes were effective growth inhibitors of S. aureus, S. enterica and both Bacillus strains; for instance, the cellulase treated DBG and DWG samples presented 8- and 9-mm inhibition zone, respectively, against the $S$. enterica. The white grape extracts exhibited stronger inhibition against the growth of B. subtilis and B. cereus than the black grape ones. Apple extracts were the most effective against B. subtilis and S. enterica, while the B. subtilis, B. cereus, S. aureus and S. enterica were the most sensitive bacteria to pitahaya extracts. In the case of many residues, the cellulase and/or the cellulase-pectinase combined treatments enhanced the antimicrobial activity. For instance, the cellulase and cellulase-pectinase treatments enhanced the inhibitory effect of the DP extracts against $B$. cereus and S. aureus, respectively. All three enzyme treatments supported the inhibition potential of DP residue against $P$. aeruginosa. Both the pectinase treated DP and LP samples considerably suppressed the growth of S. enterica, and the pectinase increased the activity of LP samples against $B$. cereus and $S$. aureus as well. The cellulase treatment remarkably increased the growth inhibitory effect of DMG samples against $L$. monocytogenes and S. aureus as compared to enzyme-free extract (Table 11). And the cellulase-pectinase treatment positively affected the inhibitory potential of both the DA and LA samples against S. aureus, MRSA and E. coli (Table 11). 
Table 11. Antimicrobial activity of fruit residue extracts against pathogenic and spoilage bacteria before and after treatment with $R$. miehei cellulase and/or $A$. niger pectinase. Results were calculated from the growth inhibition zone $(\mathrm{mm})$ measured around the paper disk.

\begin{tabular}{|c|c|c|c|c|c|c|c|c|c|c|}
\hline \multirow{2}{*}{ Fruit residues } & & \multicolumn{9}{|c|}{ Growth inhibition* } \\
\hline & & B. subtilis & B. cereus & L. monocytogenes & S. aureus & MRSA & E. coli & S. enterica & P. putida & P. aeruginosa \\
\hline & $\begin{array}{r}\text { Antibiotic control } \\
\text { Streptomycin }(100 \mu \mathrm{g} / \mathrm{mL})\end{array}$ & ++++ & ++++ & ++++ & ++++ & ++++ & ++++ & ++++ & ++++ & ++++ \\
\hline \multicolumn{11}{|c|}{ Black grape } \\
\hline \multirow[t]{4}{*}{ Oven-dried } & Enzyme-free & ++ & + & + & ++ & + & + & ++ & $\mathrm{NI}$ & + \\
\hline & Cellulase & ++ & + & ++ & ++ & + & ++ & +++ & + & + \\
\hline & Pectinase & + & + & + & ++ & + & + & + & $\mathrm{NI}$ & + \\
\hline & Cellulase + Pectinase & ++ & ++ & NI & +++ & ++ & + & + & + & + \\
\hline \multirow[t]{4}{*}{ Lyophilized } & Enzyme-free & ++ & + & + & + & + & + & ++ & + & + \\
\hline & Cellulase & ++ & +++ & + & ++ & + & + & + & + & NI \\
\hline & Pectinase & + & ++ & + & ++ & + & + & ++ & + & + \\
\hline & Cellulase + Pectinase & ++ & + & + & ++ & ++ & ++ & +++ & + & + \\
\hline \multicolumn{11}{|l|}{ White grape } \\
\hline \multirow[t]{4}{*}{ Oven-dried } & Enzyme-free & +++ & + & ++ & ++ & + & ++ & + & + & $\mathrm{NI}$ \\
\hline & Cellulase & ++ & NI & ++ & ++ & ++ & +++ & ++++ & + & + \\
\hline & Pectinase & +++ & +++ & ++ & + & + & + & NI & NI & $\mathrm{NI}$ \\
\hline & Cellulase + Pectinase & ++ & +++ & + & ++ & + & + & + & + & + \\
\hline \multirow[t]{4}{*}{ Lyophilized } & Enzyme-free & +++ & + & ++ & + & + & + & + & + & NI \\
\hline & Cellulase & ++ & ++ & + & ++ & ++ & ++ & ++ & + & + \\
\hline & Pectinase & +++ & +++ & + & + & + & + & + & + & NI \\
\hline & Cellulase + Pectinase & +++ & ++ & ++ & ++ & ++ & ++ & ++ & + & + \\
\hline \multicolumn{11}{|l|}{ Apple } \\
\hline \multirow[t]{4}{*}{ Oven-dried } & Enzyme-free & ++ & + & NI & + & + & + & ++ & NI & NI \\
\hline & Cellulase & ++ & ++ & NI & ++ & + & + & +++ & + & + \\
\hline & Pectinase & ++ & + & NI & + & + & + & ++ & NI & NI \\
\hline & Cellulase + Pectinase & NI & ++ & + & ++ & ++ & ++ & ++ & + & + \\
\hline \multirow[t]{4}{*}{ Lyophilized } & Enzyme-free & + & + & + & + & + & + & + & $\mathrm{NI}$ & $\mathrm{NI}$ \\
\hline & Cellulase & +++ & + & + & + & + & + & ++ & + & + \\
\hline & Pectinase & + & + & + & + & + & + & ++ & + & $\mathrm{NI}$ \\
\hline & Cellulase + Pectinase & ++ & + & + & ++ & +++ & ++ & + & + & + \\
\hline
\end{tabular}


Table 11. Continued.

\begin{tabular}{|c|c|c|c|c|c|c|c|c|c|c|}
\hline \multirow{2}{*}{ Fruit residues } & & \multicolumn{9}{|c|}{ Growth inhibition* } \\
\hline & & B. subtilis & B. cereus & L. monocytogenes & S. aureus & MRSA & E. coli & S. enterica & P. putida & P. aeruginosa \\
\hline \multicolumn{11}{|l|}{ Pitahaya } \\
\hline \multirow[t]{4}{*}{ Oven-dried } & Enzyme-free & +++ & + & + & ++ & + & + & ++ & + & NI \\
\hline & Cellulase & ++ & +++ & + & ++ & + & + & ++ & + & + \\
\hline & Pectinase & +++ & + & NI & ++ & + & + & +++ & + & + \\
\hline & Cellulase + Pectinase & + & + & + & +++ & + & + & + & + & + \\
\hline \multirow[t]{4}{*}{ Lyophilized } & Enzyme-free & +++ & + & + & + & + & + & + & $\mathrm{NI}$ & + \\
\hline & Cellulase & +++ & + & + & + & + & + & + & NI & NI \\
\hline & Pectinase & + & ++ & + & ++ & + & + & +++ & NI & + \\
\hline & Cellulase + Pectinase & +++ & + & + & + & + & + & + & NI & + \\
\hline \multicolumn{11}{|l|}{ Mango } \\
\hline \multirow[t]{4}{*}{ Oven-dried } & Enzyme-free & + & + & + & + & + & + & NI & $\mathrm{NI}$ & $\mathrm{NI}$ \\
\hline & Cellulase & ++ & + & +++ & +++ & + & + & + & + & + \\
\hline & Pectinase & ++ & + & + & + & + & ++ & NI & NI & NI \\
\hline & Cellulase + Pectinase & ++ & + & ++ & ++ & + & + & + & + & NI \\
\hline \multicolumn{11}{|l|}{ Naranjilla } \\
\hline \multirow[t]{2}{*}{ Oven-dried } & Enzyme-free & + & + & NI & + & NI & NI & NI & NI & NI \\
\hline & Cellulase & ++ & + & NI & + & NI & NI & NI & NI & NI \\
\hline \multirow[t]{2}{*}{ Lyophilized } & Enzyme-free & ++ & ++ & $\mathrm{NI}$ & NI & + & + & + & $\mathrm{NI}$ & $\mathrm{NI}$ \\
\hline & Cellulase & ++ & + & $\mathrm{NI}$ & NI & + & + & $\mathrm{NI}$ & NI & $\mathrm{NI}$ \\
\hline
\end{tabular}

* Slight antimicrobial activity (+), inhibition zone: $1-3 \mathrm{~mm}$; moderate antimicrobial activity (++), inhibition zone: 4-5 mm; high antimicrobial activity (+++), inhibition zone: $6-8$; strong antimicrobial activity $(++++)$, inhibition zone $>8 \mathrm{~mm}$; NI: No inhibition. There was no bacterial growth inhibition around the disks contained the negative control (10\% (v/v) ethanol). 
Although there were significant differences between the oven-dried and lyophilized samples in terms of their TPC and antioxidant capacity (see 5.3.1.), antimicrobial activity of both types of pretreatment was generally comparable. However, a strong positive correlation $(r>0.900)$ was observed between the TPC (see 5.3.1.) and the antimicrobial activities (Table 11) of the extracts against certain pathogens (Appendix 1), except for the LP residue. These findings suggested that the higher the TPC in those samples, the better their antimicrobial activity against the corresponding bacteria.

There are some reports in which the antimicrobial capacity of various grape, apple and pitahaya residue extracts were screened against microorganisms in agar diffusion systems (Özkan et al. 2004, Fratianni et al. 2011, Cheng et al. 2012, Nurmahani et al. 2012, Oliveira et al. 2013, Jahurul et al. 2015, Xu et al. 2016, Zhang et al. 2016). However, comparison of the results is quite difficult because the inhibitory potential of each residue sample strongly depends on the mode of extraction, the microorganism tested, and the fruit cultivar involved in the study.

There was no detectable growth inhibition by the individual phenolic compounds with the disk-diffusion method applied, at a phenolic quantity of $10 \mu \mathrm{g}$ per disk. Therefore, antimicrobial activity of the compounds was further analyzed at higher concentrations in broth microdilution antimicrobial susceptibility tests.

\subsubsection{Minimum inhibitory and minimum bactericidal concentrations}

Complementing the results on the inhibitory potential of the enzyme-free and treated fruit residue extracts, MICs against the pathogenic and spoilage bacteria were determined via broth microdilution assay. As it can be seen in Table 12, majority of the samples had MIC value within the tested concentration range against all bacteria studied, with the exemption of DWG that did not exhibit MIC against both Bacillus isolates. 
Table 12. Minimum inhibitory concentration (MIC) of fruit residue extracts against pathogenic and spoilage bacteria before and after treatment with $R$. miehei cellulase and/or A. niger pectinase.

\begin{tabular}{|c|c|c|c|c|c|c|c|c|c|c|}
\hline \multirow{2}{*}{ Fruit residues } & & \multicolumn{9}{|c|}{$\mathrm{MIC}(\mathrm{mg} / \mathrm{mL})$} \\
\hline & & B. subtilis & B. cereus & L. monocytogenes & S. aureus & MRSA & E. coli & S. enterica & P. putida & P. aeruginosa \\
\hline \multicolumn{11}{|l|}{ Black grape } \\
\hline \multirow[t]{4}{*}{ Oven-dried } & Enzyme-free & 25 & 25 & 100 & 50 & 100 & 100 & 100 & 50 & 50 \\
\hline & Cellulase & 12.5 & 12.5 & 100 & 50 & 50 & 50 & 50 & 25 & 50 \\
\hline & Pectinase & 12.5 & $>100 *$ & 100 & 50 & 50 & 100 & $>100$ & 50 & 25 \\
\hline & Cellulase + Pectinase & 25 & 25 & 50 & 50 & 50 & 100 & 50 & 25 & 25 \\
\hline \multirow[t]{4}{*}{ Lyophilized } & Enzyme-free & 12.5 & 25 & 50 & 50 & 50 & 50 & 100 & 25 & 25 \\
\hline & Cellulase & 12.5 & 12.5 & $>100$ & 25 & 50 & 50 & 50 & 50 & 25 \\
\hline & Pectinase & 12.5 & 12.5 & 50 & 50 & 50 & 50 & 50 & 25 & 25 \\
\hline & Cellulase + Pectinase & 50 & 25 & 100 & 25 & 50 & 100 & 50 & 25 & 25 \\
\hline \multicolumn{11}{|l|}{ White grape } \\
\hline \multirow[t]{4}{*}{ Oven-dried } & Enzyme-free & $>100$ & $>100$ & 50 & 25 & 100 & 50 & 50 & 25 & 25 \\
\hline & Cellulase & $>100$ & $>100$ & $>100$ & 50 & $>100$ & 50 & 50 & 25 & 25 \\
\hline & Pectinase & $>100$ & $>100$ & $>100$ & $>100$ & $>100$ & $>100$ & $>100$ & $>100$ & $>100$ \\
\hline & Cellulase + Pectinase & $>100$ & $>100$ & $>100$ & $>100$ & $>100$ & $>100$ & $>100$ & $>100$ & $>100$ \\
\hline \multirow[t]{4}{*}{ Lyophilized } & Enzyme-free & 100 & 100 & 50 & 50 & $>100$ & $>100$ & 50 & $>100$ & 100 \\
\hline & Cellulase & $>100$ & $>100$ & 50 & 50 & $>100$ & $>100$ & $>100$ & 100 & 100 \\
\hline & Pectinase & $>100$ & $>100$ & 50 & 25 & 50 & 50 & 25 & 50 & 25 \\
\hline & Cellulase + Pectinase & $>100$ & $>100$ & $>100$ & $>100$ & $>100$ & $>100$ & $>100$ & $>100$ & 100 \\
\hline \multicolumn{11}{|l|}{ Apple } \\
\hline \multirow[t]{4}{*}{ Oven-dried } & Enzyme-free & 50 & 50 & $>100$ & 100 & $>100$ & $>100$ & $>100$ & 100 & 100 \\
\hline & Cellulase & 50 & 25 & $>100$ & 50 & 100 & 100 & $>100$ & 50 & 50 \\
\hline & Pectinase & 100 & 50 & 25 & 100 & $>100$ & 100 & 100 & 50 & 50 \\
\hline & Cellulase + Pectinase & 25 & 25 & $>100$ & 50 & 100 & 100 & $>100$ & 25 & 25 \\
\hline \multirow[t]{4}{*}{ Lyophilized } & Enzyme-free & 100 & 100 & 50 & $>100$ & $>100$ & $>100$ & $>100$ & 50 & 100 \\
\hline & Cellulase & 25 & 25 & $>100$ & 50 & 100 & $>100$ & 100 & 12.5 & 25 \\
\hline & Pectinase & 100 & 100 & 100 & 100 & $>100$ & $>100$ & 100 & 100 & 50 \\
\hline & Cellulase + Pectinase & 25 & 25 & 50 & 50 & 100 & 50 & 50 & 50 & 25 \\
\hline
\end{tabular}


Table 12. Continued.

\begin{tabular}{|c|c|c|c|c|c|c|c|c|c|c|}
\hline \multirow{2}{*}{ Fruit residues } & & \multicolumn{9}{|c|}{$\mathrm{MIC}(\mathrm{mg} / \mathrm{mL})$} \\
\hline & & B. subtilis & B. cereus & L. monocytogenes & S. aureus & MRSA & E. coli & S. enterica & P. putida & P. aeruginosa \\
\hline \multicolumn{11}{|l|}{ Pitahaya } \\
\hline \multirow[t]{4}{*}{ Oven-dried } & Enzyme-free & 100 & 50 & 100 & 100 & $>100$ & 100 & 100 & 50 & 100 \\
\hline & Cellulase & 50 & 50 & $>100$ & 100 & 100 & $>100$ & 100 & 12.5 & 50 \\
\hline & Pectinase & 50 & 50 & 100 & 100 & $>100$ & $>100$ & 100 & 12.5 & 50 \\
\hline & Cellulase + Pectinase & 50 & 50 & 50 & 50 & $>100$ & 100 & 100 & 25 & 50 \\
\hline \multirow[t]{4}{*}{ Lyophilized } & Enzyme-free & 50 & 100 & 100 & 100 & 100 & 100 & 100 & 12.5 & 50 \\
\hline & Cellulase & 50 & 25 & 100 & $>100$ & 100 & $>100$ & 100 & 25 & 50 \\
\hline & Pectinase & 50 & 50 & 100 & 100 & 100 & 100 & 100 & 12.5 & 50 \\
\hline & Cellulase + Pectinase & 50 & 25 & 50 & 100 & 50 & 100 & 50 & 12.5 & 25 \\
\hline \multicolumn{11}{|l|}{ Mango } \\
\hline \multirow{4}{*}{ Oven-dried } & Enzyme-free & 50 & 50 & $>100$ & 100 & $>100$ & $>100$ & 100 & $>100$ & $>100$ \\
\hline & Cellulase & 12.5 & 12.5 & 100 & $>100$ & $>100$ & $>100$ & 50 & $>100$ & 50 \\
\hline & Pectinase & 12.5 & 12.5 & 100 & 50 & 50 & 25 & 25 & 25 & 25 \\
\hline & Cellulase + Pectinase & 12.5 & 12.5 & 100 & 50 & $>100$ & $>100$ & 50 & 50 & 50 \\
\hline \multicolumn{11}{|l|}{ Naranjilla } \\
\hline \multirow{2}{*}{ Oven-dried } & Enzyme-free & $>100$ & 100 & $>100$ & $>100$ & $>100$ & $>100$ & $>100$ & $>100$ & 100 \\
\hline & Cellulase & 12.5 & $>100$ & $>100$ & 12.5 & 25 & 12.5 & 25 & 25 & 25 \\
\hline \multirow{2}{*}{ Lyophilized } & Enzyme-free & $>100$ & $>100$ & $>100$ & $>100$ & $>100$ & 100 & $>100$ & $>100$ & $>100$ \\
\hline & Cellulase & 12.5 & 25 & 25 & 12.5 & 12.5 & 12.5 & 12.5 & 12.5 & 25 \\
\hline
\end{tabular}

* MIC is higher than $100 \mathrm{mg} / \mathrm{mL}$. 
The most sensitive bacteria were the Bacillus and Pseudomonas strains, while sensitivity of the other strains varied depending on the type of the fruit residue involved. Amongst the enzyme-free extracts, grape samples showed higher inhibitory effect against most of the bacteria to that observed for apple, pitahaya, mango and naranjilla samples, which correlated with the results of the disk diffusion test. Irrespectively of the residue pretreatment and enzyme treatments, MICs of black grape extracts started from 12.5 $\mathrm{mg} / \mathrm{mL}$ against the Bacillus and from $25 \mathrm{mg} / \mathrm{mL}$ against the Pseudomonas and $S$. aureus strains. MICs against MRSA, L. monocytogenes, E. coli and S. enterica were found in a range of 50 to $100 \mathrm{mg} / \mathrm{mL}$. The white grape extracts did not display inhibitory activity against the Bacillus and MRSA bacteria. On the other hand, the oven-dried enzyme-free and cellulase treated white grape extracts showed clear antibacterial effect against $S$. aureus, E. coli, S. enterica, P. putida and P. aeruginosa (the MIC ranged from 25 to 100 $\mathrm{mg} / \mathrm{mL}$ ). In addition, the pectinase treated $\mathrm{LWG}$ extract exhibited a remarkable inhibition against most of the tested bacteria (Table 12).

Literature describes various MICs to different grape extracts depending on the variety of grape, the mode of extraction and the waste fraction and microorganism applied for the test (Cheng et al. 2012). For instance, Dias et al. (2015) reported MICs from 66.7 to $133.3 \mathrm{mg} / \mathrm{mL}$ for stem phenolic extracts derived from different grape varieties against digestive pathogens. Their results are comparable to those reported here as the grape pomace subjected to enzyme treatments contained stem residues in high amount as well. Furthermore, in a recent study, MIC ranges from 4.69 to 18.8 and 40.6 to $250 \mathrm{mg} / \mathrm{mL}$ have been documented against L. monocytogenes and S. aureus, respectively, depending on the grape pomace extracts tested (Xu et al. 2016). The apple and pitahaya extracts were most effective against $P$. putida (MICs from $12.5 \mathrm{mg} / \mathrm{mL}$ ) followed by $P$. aeruginosa and both Bacillus strains (Table 12). Growth inhibition capacity of the yellow pitahaya extracts studied here were close to those reported by Yong et al. (2017) for red pitahaya pulp samples after methanol extraction. However, red and white pitahaya peel extracts, with slightly lower MIC ranges found in this study, also showed inhibitory effect against foodborne pathogenic bacteria (Nurmahani et al. 2012).

The carbohydrase treatment could decrease the initial MIC of some of the extracts (Table 12). Depending on the type of bacteria tested, the MIC values detected in many enzyme-free extracts could be reduced by using $R$. miehei cellulase and/or A. niger pectinase mixtures. This was most significant for the apple and mango samples reducing some MICs about 2 to 4 times; a decrease was also observed for many extracts where 
initial MIC was not found up to $100 \mathrm{mg} / \mathrm{mL}$. Furthermore, a considerable decrease in the inhibitory potential was also identified for the LP and DP extracts against B. cereus and $P$. putida, respectively (Table 12). All three enzyme treatments supported the inhibition potential of DMG extract against B. subtilis, B. cereus, L. monocytogenes, S. enterica and $P$. aeruginosa; the highest effect was found in case of the Bacillus isolates (MIC $=12.5$ $\mathrm{mg} / \mathrm{mL}$ ) (Table 12). The study of Gupta et al. (2010) reported that the MIC of ethanolic extract of dried unripe pulp of Mangifera indica was $250 \mathrm{mg} / \mathrm{mL}$ against $B$. subtilis, $B$. cereus, L. monocytogenes and E. coli, and $125 \mathrm{mg} / \mathrm{mL}$ for $S$. aureus and P. aeruginosa. The cellulase treated LN extract displayed strong inhibitory effect against all the bacteria tested. Studies showing the antimicrobial activity of enzyme-treated fruit extracts are scarce. In the work of Mandalari et al. (2007), the pectinase treatment efficiently increased the antimicrobial activity of flavonoids extracted from bergamot peel. Other papers reported effective carbohydrase-assisted extraction of phenolic antimicrobials from bilberry (pectinases; Puupponen-Pimiä et al. 2008), pumpkin and flaxseed ( $\alpha$-amylase, $\beta$ glucosidase and $\beta$-glucanase; Ratz-Łyko and Arct 2015) and Sargassum (Viscozyme ${ }^{\circledR}$ carbohydrase mix; Puspita et al. 2017) samples.

Majority of the samples had no MBC against the pathogens within the concentration range studied (Appendix 2). Where MBC was identified, it was the same or at least double of the MIC determined for the corresponding sample. Interestingly, despite their high sensitivity exhibited during the MIC assays, the Bacillus strains were not killed by extract concentrations less than $100 \mathrm{mg} / \mathrm{mL}$. Similar trend was observed in the inhibitory effect of red and white flesh pitahaya extracts against a $B$. cereus isolate (Nurmahani et al. 2012).

MIC results obtained by individual phenolic compounds, i.e. 4-hydroxybenzoic acid, syringic acid, gallic acid, vanillic acid, cinnamic acid, $p$-coumaric acid, (+)-catechin, $(-)$-epicatechin, quercetin, polydatin and resveratrol quantified in the extracts are shown in Table 13. In this experiment, although it is lower than the MICs commonly found for most phenolic compounds against other pathogenic microorganisms (Mandalari et al. 2007, Cheng et al. 2012, Alves et al. 2013, Sabel et al. 2017), $500 \mu \mathrm{g} / \mathrm{mL}$ was applied as the maximum concentration of each phenolics because their yield in all residue extracts (see 5.3.2.) remained less than this value. For many phenolics, no inhibitory effect was recorded below $500 \mu \mathrm{g} / \mathrm{mL}$ concentration against most of the bacteria tested (Table 13). Hence, an elevated amount of these components after the enzyme treatments could not be responsible for the antimicrobial activity of the corresponding extract. However, it is worth pointing 
out that our investigations do not exclude the occurrence of other phenolic compounds in the extract, and/or a synergic work between some of the phenolics present in the mixture (Dias et al. 2015), which could contribute to the growth inhibitory effect against the tested pathogens as well. Nonetheless, the two Bacillus strains examined were quite sensitive to cinnamic acid and resveratrol ( $\mathrm{MIC}=125 \mu \mathrm{g} / \mathrm{mL}), p$-coumaric acid $(\mathrm{MIC}=250 \mu \mathrm{g} / \mathrm{mL})$ and quercetin $(\mathrm{MIC}=500 \mu \mathrm{g} / \mathrm{mL})$ (Table 13). Resveratrol inhibited the Pseudomonas strains as well (250 and $500 \mu \mathrm{g} / \mathrm{mL}$ MICs for P. aeruginosa and P. putida, respectively). The yield of some of the above phenolics increased after the enzyme treatments (see 5.3.2.), which could explain the high sensitivity of the Bacillus and Pseudomonas isolates towards many extracts. No MBC was found for the individual phenolics against any of the pathogens tested, at the concentration range used in this experiment (from 125 to 500 $\mu \mathrm{g} / \mathrm{mL})$.

Table 13. Minimum inhibitory concentration (MIC) of phenolic acids and other phenolic compounds against foodborne pathogenic and spoilage bacteria.

\begin{tabular}{|c|c|c|c|c|c|c|c|c|c|}
\hline \multirow{2}{*}{ Compounds } & \multicolumn{9}{|c|}{$\mathrm{MIC}(\mu \mathrm{g} / \mathrm{mL})$} \\
\hline & $\begin{array}{c}\text { B. } \\
\text { subtilis }\end{array}$ & $\begin{array}{c}B . \\
\text { cereus }\end{array}$ & $\begin{array}{c}\text { L. } \\
\text { monocyt. }\end{array}$ & $\begin{array}{c}S . \\
\text { aureus } \\
\end{array}$ & MRSA & $\begin{array}{c}E . \\
\text { coli } \\
\end{array}$ & $\begin{array}{c}S . \\
\text { enterica }\end{array}$ & $\begin{array}{c}P . \\
\text { putida } \\
\end{array}$ & $\begin{array}{c}P . \\
\text { aeruginosa }\end{array}$ \\
\hline $\begin{array}{l}\text { 4-Hydroxybenzoic } \\
\text { acid }\end{array}$ & 250 & $>500$ & $>500$ & $>500$ & $>500$ & $>500$ & $>500$ & $>500$ & $>500$ \\
\hline Syringic acid & 250 & $>500$ & $>500$ & $>500$ & $>500$ & $>500$ & $>500$ & $>500$ & $>500$ \\
\hline Gallic acid & $>500 *$ & $>500$ & $>500$ & $>500$ & $>500$ & $>500$ & $>500$ & $>500$ & $>500$ \\
\hline Vanillic acid & 500 & $>500$ & $>500$ & $>500$ & $>500$ & $>500$ & $>500$ & $>500$ & $>500$ \\
\hline Cinnamic acid & 125 & 125 & $>500$ & $>500$ & $>500$ & $>500$ & $>500$ & $>500$ & $>500$ \\
\hline$p$-Coumaric acid & 250 & 250 & $>500$ & $>500$ & $>500$ & $>500$ & $>500$ & $>500$ & $>500$ \\
\hline$(+)$-Catechin & $>500$ & $>500$ & $>500$ & $>500$ & $>500$ & $>500$ & $>500$ & $>500$ & $>500$ \\
\hline$(-)$-Epicatechin & $>500$ & $>500$ & $>500$ & $>500$ & $>500$ & $>500$ & $>500$ & $>500$ & $>500$ \\
\hline Quercetin & 500 & 500 & $>500$ & $>500$ & $>500$ & $>500$ & $>500$ & $>500$ & $>500$ \\
\hline Polydatin & $>500$ & $>500$ & $>500$ & $>500$ & $>500$ & $>500$ & $>500$ & $>500$ & $>500$ \\
\hline Resveratrol & 125 & 125 & $>500$ & $>500$ & $>500$ & $>500$ & $>500$ & 500 & 250 \\
\hline
\end{tabular}

* MIC is higher than $500 \mu \mathrm{g} / \mathrm{mL}$.

\subsubsection{Quorum sensing inhibition}

It has been documented that certain phenol-rich plant extracts and phenolic compounds could inhibit the QS system of bacterial communities (Asfour 2018), which is responsible for many food deterioration phenotypes (Papuc et al. 2017). Therefore, we considered important to screen this potential of the enzyme treated and untreated extracts and the individual phenolics. From the extracts prepared, we selected the samples of black 
grape, apple and pitahaya residues for the analysis that was conducted by using the violacein pigment producer $C$. violaceum $85 \mathrm{WT}$ model strain. The synthesis of violacein in C. violaceum is under QS regulation, which property makes this bacterium suitable for screening of compounds with anti-QS capacity (Kerekes et al. 2013). The extracts and phenolic compounds at the applied concentrations did not inhibit the growth of $C$. violaceum according to the CFUs determined.

Based on the liquid-culture assays performed, all fruit extracts exhibited anti-QS activity at the studied concentration $(2 \mathrm{mg} / \mathrm{mL})$, irrespectively from the enzyme treatments (Figure 18). Percent inhibition of violacein production ranged from 9 to $36 \%, 15$ to $24 \%$ and 6 to $23 \%$ for black grape, apple and pitahaya extracts, respectively. Except for apple samples, there was no significant difference in the inhibitory effect of samples subjected to different substrate pretreatment methods (see the C1 column in Figure 18).
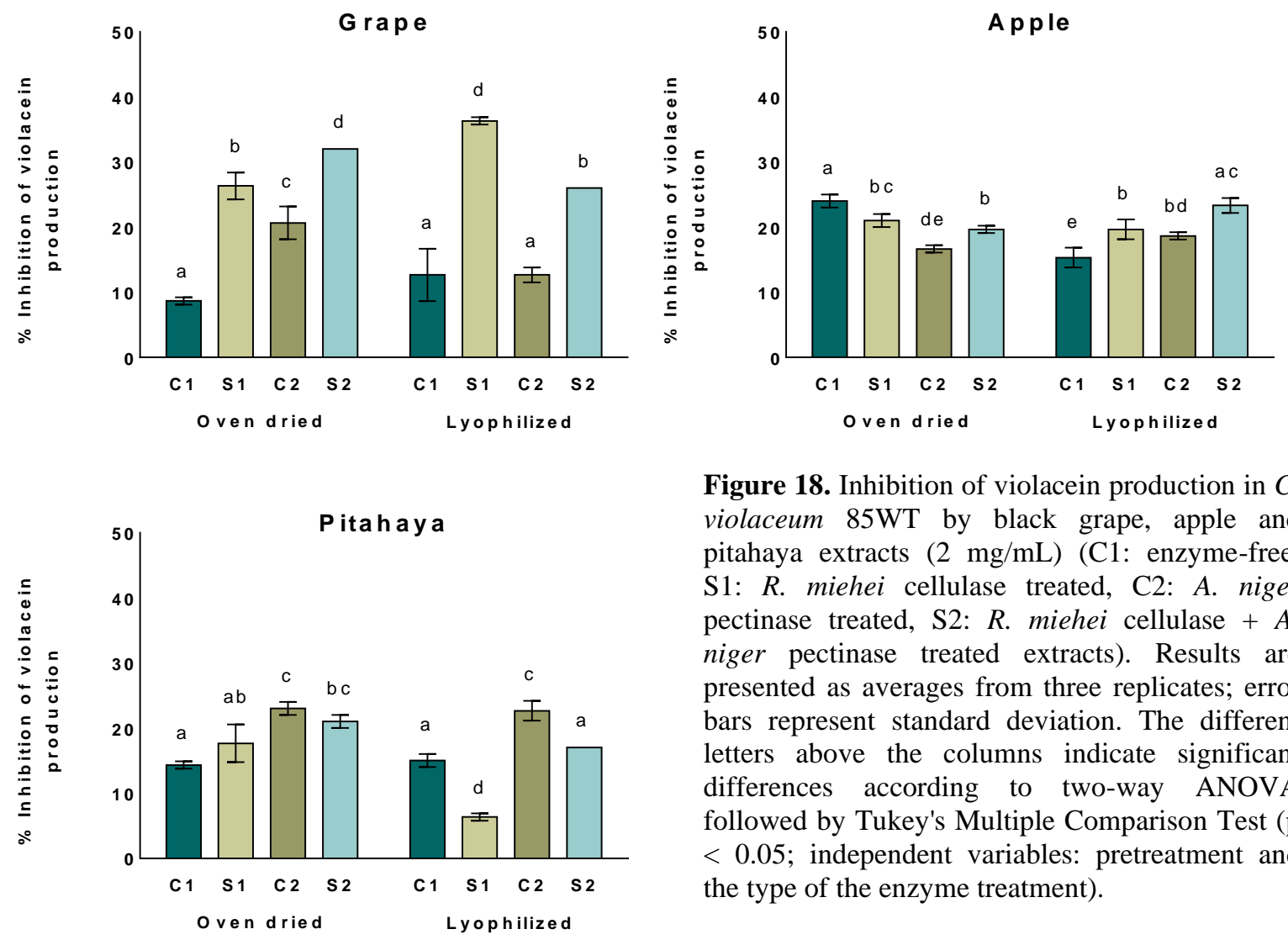

Figure 18. Inhibition of violacein production in $C$. violaceum $85 \mathrm{WT}$ by black grape, apple and pitahaya extracts $(2 \mathrm{mg} / \mathrm{mL})$ (C1: enzyme-free, $\mathrm{S} 1: R$. miehei cellulase treated, $\mathrm{C} 2: A$. niger pectinase treated, $\mathrm{S} 2: R$. miehei cellulase $+A$. niger pectinase treated extracts). Results are presented as averages from three replicates; error bars represent standard deviation. The different letters above the columns indicate significant differences according to two-way ANOVA followed by Tukey's Multiple Comparison Test ( $p$ $<0.05$; independent variables: pretreatment and the type of the enzyme treatment).

The cellulase and cellulase-pectinase treatments significantly stimulated $(\mathrm{p}<0.05)$ the anti-QS activity of both the LBG and the DBG grape samples compared to enzyme-free control (Figure 18). A moderate decrease in the violacein production could be detected for 
the LA and DP samples after carbohydrase treatments. In case of the LP sample, only the A. niger pectinase treated extract reduced the pigment production significantly compared to enzyme-free sample $(p<0.05)$ (Figure 18). In fact, no results have been published in the literature that the carbohydrase treatment could increase the anti-QS property of a fruit residue sample. Additionally, although many studies have been conducted so far with plant sources as potential QS inhibitors (Viswanathan et al. 2015), relatively few reports are available about grape and apple extracts in this regard (Vattem et al. 2007, Fratianni et al. 2011, Sheng et al. 2016), and no studies were found on the capacity of pitahaya samples.

Concerning the individual phenolics tested, the syringic acid, vanillic acid, (+)catechin and resveratrol compounds exhibited high inhibition against the violacein production compared to the control ( $\mathrm{p}<0.05$ ), at $10 \mu \mathrm{g} / \mathrm{mL}$ concentration used in this assay (Figure 19). More detailed analysis of the data, comparing with the individual phenolic concentrations (see 5.3.2.), revealed a correlation between the inhibition of violacein production by certain extracts and the yield of some of these phenolics after the enzyme treatments. This correlation was strong positive $(r>0.900)$ for syringic acid in DBG, LA and DP, for vanillic acid in DBG, LBG and DP and for (+)-catechin in LBG extracts (Appendix 3). Negative associations were found between the violacein inhibition values and the concentration of syringic and vanillic acids in DA and LP samples, (+)catechin in DA and DP samples and resveratrol in DA and both pitahaya extracts (Appendix 3). However, after enzyme treatments, the (-)-epicatechin, 4-hydroxybenzoic acid and gallic acid yields were higher in the LBG extract (from 37 to $215 \mu \mathrm{g} / \mathrm{mL}$ ) (Table 9) than the individual phenolic concentration used in this experiment $(10 \mu \mathrm{g} / \mathrm{mL})$, suggesting that these components can also contribute to the inhibition of violacein production. The positive correlation $(r=0.820)$ between the violacein production inhibition values (Figure 19) and (-)-epicatechin content of the untreated and treated LA extracts (Table 9) could also support this suggestion. In this context, Borges et al. (2014) reported noticeable activity against the violacein production of $C$. violaceum for gallic acid and (-)-epicatechin at $1 \mathrm{mg} / \mathrm{mL}$ concentration. Also, in different concentrations, catechin, resveratrol and vanillic acid demonstrated anti-QS activity in $P$. aeruginosa (Vandeputte et al. 2010), C. violaceum (Alvarez et al. 2012, Erdönmez et al. 2018) and Serratia marcescens (Sethupathy et al. 2017), respectively. 


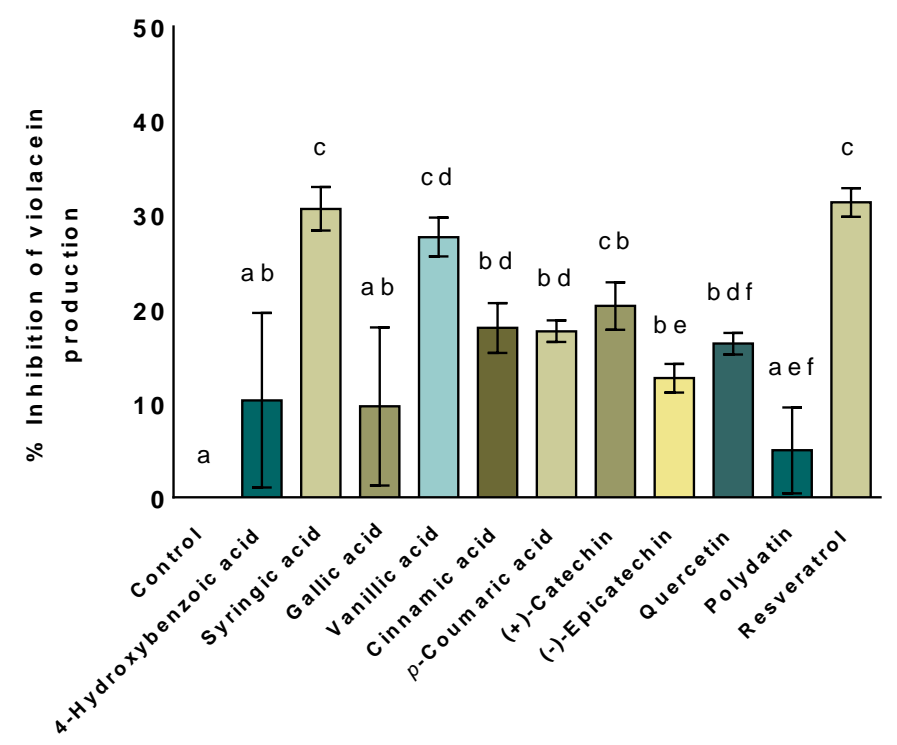

Figure 19. Percentage inhibition of violacein production in $C$. violaceum $85 \mathrm{WT}$ by phenolic acids and other phenolic compounds. The violacein inhibition measured in the absence of a given compound was taken as the control. Results are presented as averages from three replicates; error bars represent standard deviation. The different letters above the columns indicate significant differences according to one-way ANOVA followed by Tukey's Multiple Comparison Test $(\mathrm{p}<0.05)$.

\subsubsection{Effects on biofilm formation of food-related bacteria}

QS inhibitory potential of the enzyme treated/untreated extracts and phenolics led us to investigate their influence on the biofilm formation. In these studies, the biofilm formation of seven pathogens involved in the antimicrobial tests in the presence or absence of extracts and individual phenolics was investigated. As can be seen on Table 14, majority of the extracts inhibited the biofilm formation in vitro, however, the effect varied depending on the types of substrate pretreatment and enzyme treatment, and the sensitivity of the bacterium analyzed. Overall, the most sensitive bacteria were the P. putida, $P$. aeruginosa and S. aureus. In this context, earlier studies verified that phenolic extracts and certain phenolic compounds, especially flavonoids, can efficiently prevent the biofilm formation in P. aeruginosa and S. aureus (Vandeputte et al. 2010, Rasamiravaka et al. 2015, Pratiwi et al. 2015, Lopes et al. 2017). All the studied extracts except LP contained considerable amounts of flavonoids, mainly (+)-catechin and (-)-epicatechin (see 5.3.2.). 
Table 14. Effect of the black grape, apple and yellow pitahaya extracts $(50 \mathrm{mg} / \mathrm{mL})$ on biofilm formation against foodborne pathogenic and spoilage bacteria before and after treatment with $R$. miehei cellulase and/or A. niger pectinase. Biofilm formation occurred in the absence of a given extract was taken as the positive control.

\begin{tabular}{|c|c|c|c|c|c|c|c|c|}
\hline \multirow{2}{*}{ Fruit residues } & & \multicolumn{7}{|c|}{ Biofilm formation (\%) } \\
\hline & & L. monocytogenes & S. aureus & MRSA & E. coli & S. enterica & P. putida & P. aeruginosa \\
\hline \multicolumn{9}{|l|}{ Black grape } \\
\hline \multirow{5}{*}{ Oven-dried } & Positive control & $100 \pm 0.0 \mathrm{a}$ & $100 \pm 0.0 \mathrm{a}$ & $100 \pm 0.0 \mathrm{a}$ & $100 \pm 0.0 \mathrm{ab}$ & $100 \pm 0.0 \mathrm{a}$ & $100 \pm 0.0 \mathrm{a}$ & $100 \pm 0.0 \mathrm{a}$ \\
\hline & Enzyme-free & $44 \pm 3.3 \mathrm{~b}$ & $48 \pm 6.0 \mathrm{~b}$ & $53 \pm 8.0 \mathrm{bc}$ & $87 \pm 7.7 \mathrm{a}$ & $75 \pm 4.8 b$ & $48 \pm 6.0 \mathrm{bc}$ & $52 \pm 3.5 \mathrm{bc}$ \\
\hline & Cellulase & $70 \pm 11.7 \mathrm{c}$ & $35 \pm 0.4 b$ & $60 \pm 7.3 \mathrm{~b}$ & $128 \pm 16.4 b$ & $66 \pm 8.6 b$ & $33 \pm 7.3 b$ & $28 \pm 3.7 \mathrm{~d}$ \\
\hline & Pectinase & $49 \pm 5.1 b c$ & $44 \pm 8.4 b$ & $33 \pm 4.4 \mathrm{~d}$ & $88 \pm 13.1 \mathrm{a}$ & $81 \pm 5.5 \mathrm{ab}$ & $51 \pm 6.4 \mathrm{cde}$ & $55 \pm 2.0 \mathrm{bc}$ \\
\hline & Cellulase + Pectinase & $66 \pm 10.0 \mathrm{bc}$ & $37 \pm 1.3 \mathrm{~b}$ & $41 \pm 5.3 \mathrm{~cd}$ & $107 \pm 12.2 \mathrm{ab}$ & $133 \pm 7.1 \mathrm{c}$ & $44 \pm 4.2 \mathrm{bd}$ & $49 \pm 2.6$ be \\
\hline \multirow[t]{4}{*}{ Lyophilized } & Enzyme-free & $56 \pm 6.2 \mathrm{bc}$ & $55 \pm 2.0 \mathrm{~b}$ & $105 \pm 4.6 \mathrm{a}$ & $105 \pm 10.0 \mathrm{ab}$ & $200 \pm 0.4 \mathrm{~d}$ & $62 \pm 1.7 \mathrm{c}$ & $59 \pm 4.4 \mathrm{ce}$ \\
\hline & Cellulase & $115 \pm 6.8 \mathrm{ad}$ & $101 \pm 6.6 \mathrm{a}$ & $105 \pm 2.4 \mathrm{a}$ & $43 \pm 3.5 \mathrm{c}$ & $193 \pm 2.4 \mathrm{~d}$ & $35 \pm 1.7$ be & $43 \pm 4.2 \mathrm{~b}$ \\
\hline & Pectinase & $54 \pm 1.7 \mathrm{bc}$ & $53 \pm 6.0 \mathrm{~b}$ & $106 \pm 3.3 \mathrm{a}$ & $85 \pm 10.4 \mathrm{a}$ & $188 \pm 6.8 \mathrm{~d}$ & $52 \pm 2.4 \mathrm{dc}$ & $47 \pm 4.8$ be \\
\hline & Cellulase + Pectinase & $138 \pm 4.6 \mathrm{~d}$ & $88 \pm 9.3 \mathrm{a}$ & $105 \pm 2.2 \mathrm{a}$ & $44 \pm 5.1 \mathrm{c}$ & $196 \pm 5.7 \mathrm{~d}$ & $40 \pm 2.0 \mathrm{bd}$ & $62 \pm 2.0 \mathrm{c}$ \\
\hline \multicolumn{9}{|l|}{ Apple } \\
\hline \multirow{5}{*}{ Oven-dried } & Positive control & $100 \pm 0.0 \mathrm{a}$ & $100 \pm 0.0 \mathrm{a}$ & $100 \pm 0.0 \mathrm{a}$ & $100 \pm 0.0 \mathrm{a}$ & $100 \pm 0.0 \mathrm{a}$ & $100 \pm 0.0 \mathrm{a}$ & $100 \pm 0.0 \mathrm{a}$ \\
\hline & Enzyme-free & $40 \pm 5.3 b$ & $38 \pm 2.6 b$ & $74 \pm 4.2 b$ & $53 \pm 4.6 b$ & $193 \pm 4.8 b$ & $57 \pm 7.5 \mathrm{bc}$ & $36 \pm 7.1 \mathrm{bc}$ \\
\hline & Cellulase & $138 \pm 0.4 \mathrm{c}$ & $104 \pm 3.5 \mathrm{a}$ & $71 \pm 5.3 \mathrm{~b}$ & $140 \pm 11.1 \mathrm{c}$ & $176 \pm 14.4 b c$ & $71 \pm 7.5 b$ & $58 \pm 4.4 \mathrm{~d}$ \\
\hline & Pectinase & $26 \pm 4.2 \mathrm{~b}$ & $5 \pm 0.8 \mathrm{c}$ & $67 \pm 4.2 \mathrm{~b}$ & $60 \pm 5.5 b$ & $143 \pm 12.0 \mathrm{~cd}$ & $32 \pm 3.1 \mathrm{de}$ & $34 \pm 4.0 \mathrm{bc}$ \\
\hline & Cellulase + Pectinase & $121 \pm 4.6 \mathrm{~d}$ & $104 \pm 2.0 \mathrm{a}$ & $54 \pm 7.3 \mathrm{bc}$ & $49 \pm 10.0 \mathrm{~b}$ & $139 \pm 17.3 \mathrm{de}$ & $55 \pm 4.2 \mathrm{bc}$ & $48 \pm 4.2 \mathrm{bd}$ \\
\hline \multirow[t]{4}{*}{ Lyophilized } & Enzyme-free & $61 \pm 5.1 \mathrm{e}$ & $38 \pm 5.1 \mathrm{~b}$ & $42 \pm 4.0 \mathrm{c}$ & $56 \pm 11.7 \mathrm{~b}$ & $190 \pm 12.6 b$ & $53 \pm 8.2 b c$ & $33 \pm 5.5 \mathrm{bc}$ \\
\hline & Cellulase & $80 \pm 4.8 \mathrm{f}$ & $64 \pm 7.5 \mathrm{~d}$ & $36 \pm 4.6 \mathrm{c}$ & $38 \pm 5.3 \mathrm{~b}$ & $79 \pm 1.1 \mathrm{a}$ & $22 \pm 3.1 \mathrm{e}$ & $22 \pm 5.1 \mathrm{c}$ \\
\hline & Pectinase & $34 \pm 6.0 \mathrm{~b}$ & $40 \pm 3.3 b$ & $44 \pm 7.3 \mathrm{c}$ & $62 \pm 5.7 b$ & $90 \pm 3.3 \mathrm{a}$ & $44 \pm 4.4 \mathrm{dc}$ & $40 \pm 6.0 \mathrm{be}$ \\
\hline & Cellulase + Pectinase & $93 \pm 3.7$ af & $46 \pm 8.4 \mathrm{~b}$ & $74 \pm 6.8 b$ & $68 \pm 12.0 \mathrm{~b}$ & $105 \pm 2.6 \mathrm{ae}$ & $28 \pm 2.6 \mathrm{de}$ & $25 \pm 1.7 \mathrm{ce}$ \\
\hline \multicolumn{9}{|l|}{ Pitahaya } \\
\hline \multirow{5}{*}{ Oven-dried } & Positive control & $100 \pm 0.0 \mathrm{a}$ & $100 \pm 0.0 \mathrm{a}$ & $100 \pm 0.0 \mathrm{ab}$ & $100 \pm 0.0 \mathrm{a}$ & $100 \pm 0.0 \mathrm{a}$ & $100 \pm 0.0 \mathrm{a}$ & $100 \pm 0.0 \mathrm{a}$ \\
\hline & Enzyme-free & $76 \pm 2.6 b$ & $37 \pm 3.1 \mathrm{bc}$ & $108 \pm 0.4 \mathrm{a}$ & $154 \pm 14.6 b$ & $143 \pm 12.6 b$ & $86 \pm 7.1 \mathrm{ab}$ & $72 \pm 0.8 \mathrm{~b}$ \\
\hline & Cellulase & $129 \pm 7.1 \mathrm{c}$ & $74 \pm 4.2 \mathrm{~d}$ & $104 \pm 1.5 \mathrm{a}$ & $26 \pm 5.3 \mathrm{c}$ & $195 \pm 8.0 \mathrm{c}$ & $100 \pm 1.3 \mathrm{a}$ & $89 \pm 4.4 \mathrm{c}$ \\
\hline & Pectinase & $30 \pm 1.7 \mathrm{~d}$ & $18 \pm 4.8 \mathrm{e}$ & $102 \pm 4.0 \mathrm{ab}$ & $36 \pm 1.5 \mathrm{c}$ & $50 \pm 2.6 \mathrm{~d}$ & $38 \pm 0.4 \mathrm{c}$ & $17 \pm 1.5 \mathrm{~d}$ \\
\hline & Cellulase + Pectinase & $127 \pm 5.3 \mathrm{c}$ & $99 \pm 1.7 \mathrm{a}$ & $106 \pm 3.1 \mathrm{a}$ & $198 \pm 6.0 \mathrm{~d}$ & $189 \pm 6.2 \mathrm{c}$ & $28 \pm 3.7 \mathrm{c}$ & $45 \pm 3.5 \mathrm{e}$ \\
\hline \multirow[t]{4}{*}{ Lyophilized } & Enzyme-free & $66 \pm 5.1 \mathrm{~b}$ & $33 \pm 5.7$ be & $105 \pm 2.6 \mathrm{a}$ & $44 \pm 7.5 \mathrm{c}$ & $54 \pm 5.7 d$ & $43 \pm 5.5 c$ & $22 \pm 2.0 \mathrm{~d}$ \\
\hline & Cellulase & $79 \pm 3.1 b$ & $42 \pm 3.7 b$ & $95 \pm 4.0 \mathrm{~b}$ & $169 \pm 16.2 \mathrm{bd}$ & $183 \pm 9.7 \mathrm{c}$ & $65 \pm 9.7 \mathrm{~d}$ & $51 \pm 3.1 \mathrm{ef}$ \\
\hline & Pectinase & $33 \pm 4.2 \mathrm{~d}$ & $23 \pm 4.6 \mathrm{ce}$ & $77 \pm 2.4 \mathrm{c}$ & $43 \pm 3.5 \mathrm{c}$ & $34 \pm 6.4 \mathrm{~d}$ & $31 \pm 2.0 \mathrm{c}$ & $21 \pm 1.7 \mathrm{~d}$ \\
\hline & Cellulase + Pectinase & $82 \pm 3.5 \mathrm{~b}$ & $92 \pm 5.7 \mathrm{a}$ & $73 \pm 1.5 \mathrm{c}$ & $33 \pm 3.1 \mathrm{c}$ & $180 \pm 7.1 \mathrm{c}$ & $67 \pm 7.7 \mathrm{bd}$ & $61 \pm 3.1 \mathrm{f}$ \\
\hline
\end{tabular}

Average values from three tests \pm standard deviation. Different letters represent significant changes ( $p<0.05)$ compared to respective positive controls (two-way ANOVA followed by Tukey's Multiple Comparison Test; independent variables: pretreatment and type of the enzyme treatment). 
Concerning the type of pretreatment of fruit residues, biofilm formation decreasing effect of the DBG extracts was superior against MRSA and S. enterica than that detected for the lyophilized ones $(p<0.05)$, irrespectively from the enzyme treatments (Table 14). However, in case of the other fruit residues, no general conclusion could be deduced regarding to the influence of pretreatment on the biofilm formation, since the effect of the extracts was different depending on the enzyme treatment. For example, a slight decrease ( $p>0.05)$ in biofilm formation was noted in the $S$. aureus biofilms when cellulase treated DBG extract was added, while biofilm formation similar to positive control was detected in the presence of cellulase treated LBG extract, compared to the corresponding enzyme-free sample (Table 14). If samples presenting the highest inhibitory potential were considered, oven-drying pretreatment was effective for black grape and pitahaya residues to inhibit the formation of most of the bacterial biofilms analyzed. In contrast, except for $L$. monocytogenes and S. aureus, apple residues subjected to lyophilization pretreatment resulted the maximal reduction in biofilm formation.

Surprisingly, in some cases, addition of the extract affected positively the formation of the biofilms (Table 14). This was particularly found for S. enterica; for instance, the DA and LBG extracts, irrespectively from the enzyme treatments, caused 1.5- and 2-fold increase in the biofilm formation $(\mathrm{p}<0.05)$, respectively. Also, some extracts had stimulating effect on the L. monocytogenes and E. coli biofilms. Another important observation is that despite the increased QS inhibition activity of some of the extracts after enzyme treatments (see Figure 18), the cellulase and/or cellulase-pectinase combined treatments decreased the antibiofilm activity of many enzyme-free extracts; however, it depended on the type of the bacterium tested. L. monocytogenes biofilm, for example, was significantly enhanced by the cellulase treated DA and DP extracts, and the cellulasepectinase treated LBG and DP samples compared to the positive control $(\mathrm{p}<0.05)$ (Table 14). Interestingly, all pectinase treated extracts facilitated the biofilm formation reduction in L. monocytogenes, and pectinase treated samples presented the highest inhibition against MRSA (DBG sample), S. aureus (DA sample), S. enterica (LP sample) and S. aureus and P. aeruginosa (DP sample) biofilms (Table 14).

The reason for the enhanced biofilm formation caused by some of the extracts could ascribe to the influences of various factors, such as the different sensitivity of the bacteria towards the tested extract, the amount of individual phenolic compounds in the extract, and the polysaccharides derived from the fruit residues. Namely, the cellulose fibers, oligomers and other polysaccharides, e.g., pectin and xylan, present in the residue 
extracts can induce more structural stability and protection to the cells in the biofilm layer (Beauregard et al. 2013, Limoli et al. 2015). In this sense, cellulase treatment could facilitate the formation of such oligomers from the residue causing enhanced biofilm formation in some of the bacteria tested. Concerning plant phenolics, several studies have shown their excellent antibiofilm properties (Slobodníková et al. 2016), and numbers of them have been tested as potential antibiofilm agent in the food industry (Papuc et al. 2017). However, some results exist on that certain fruit extracts (Priha et al. 2014) and phenolic compounds (Vikram et al. 2010, Plyuta et al. 2013) can trigger biofilm formation by the bacterium with a concentration dependent interaction. As an example, Plyuta et al. (2013) found that the 4-hydroxybenzoic, gallic and cinnamic acids in subinhibitory concentrations up to $100 \mu \mathrm{g} / \mathrm{mL}$, and the vanillic acid and (-)-epicatechin up to $750 \mu \mathrm{g} / \mathrm{mL}$ can stimulate the biofilm formation of $P$. aeruginosa. Presence of these compounds in the extracts studied here, at concentrations up to $215 \mu \mathrm{g} / \mathrm{mL}$ (see Tables 8 and 9), may also explain the observed biofilm-stimulating effects. In this context, correlations $(r>0.636)$ between the amounts of vanillic acid, syringic acid, (+)-catechin, (-)-epicatechin and resveratrol (Tables 8 and 9) and the biofilm-modulating capacity of LBG and DA extracts toward L. monocytogenes (Table 14) were observed. Also, vanillic and syringic acid concentrations in the pitahaya extracts found to be correlated with their influence on $L$. monocytogenes biofilm $(0.582<r<0.983)$.

In further assays, the antibiofilm capacity of phenolic compounds identified in the extracts was examined. Here, a sub-MIC concentration $(100 \mu \mathrm{g} / \mathrm{mL})$ of the chemicals was applied and results showed an inhibitory effect by them against the biofilm formation of the bacteria tested (Table 15). Based on these experiments, it appears that a more detailed characterization of the polyphenolic profile in the extracts, followed by bioactivity analysis, is needed to prove the function of phenolics in the biofilm formation enhancement. Nevertheless, our investigations revealed potential antibiofilm phenolics that can be obtained from black grape, apple and pitahaya extracts after cellulase and cellulasepectinase combined treatments. Vanillic and syringic acid content of LA extracts (Table 9), and (+)-catechin and (-)-epicatechin yields of DBG samples (Table 8), for instance, correlated well with their antibiofilm activity against $P$. putida and $P$. aeruginosa (Table $15)$, respectively $(0.905<r<0.998)$. 
Table 15. Effect of phenolic acids and other phenolic compounds $(100 \mu \mathrm{g} / \mathrm{mL})$ on biofilm formation against foodborne pathogenic and spoilage bacteria. Biofilm formation occurred in the absence of a given compound was taken as the positive control.

\begin{tabular}{|c|c|c|c|c|c|c|c|}
\hline & \multicolumn{7}{|c|}{ Biofilm formation (\%) } \\
\hline & $\begin{array}{c}\text { L. } \\
\text { monocytogenes }\end{array}$ & S. aureus & MRSA & E. coli & S. enterica & P. putida & $\begin{array}{c}P . \\
\text { aeruginosa } \\
\end{array}$ \\
\hline Positive control & $100 \pm 0 \mathrm{a}$ & $100 \pm 0 \mathrm{a}$ & $100 \pm 0 \mathrm{a}$ & $100 \pm 0 \mathrm{a}$ & $100 \pm 0 \mathrm{a}$ & $100 \pm 0 \mathrm{a}$ & $100 \pm 0 \mathrm{a}$ \\
\hline \multicolumn{8}{|l|}{ Compounds } \\
\hline $\begin{array}{l}\text { 4-Hydroxybenzoic } \\
\text { acid }\end{array}$ & $64 \pm 7 b c$ & $40 \pm 2 b$ & $54 \pm 3 b c$ & $50 \pm 7 b$ & $57 \pm 6 b$ & $77 \pm 5 b$ & $48 \pm 7 b$ \\
\hline Syringic acid & $48 \pm 6 b$ & $49 \pm 6 b$ & $59 \pm 11 \mathrm{~cd}$ & $25 \pm 6 c$ & $38 \pm 4 \mathrm{c}$ & $40 \pm 4 \mathrm{~cd}$ & $33 \pm 8 b c$ \\
\hline Gallic acid & $89 \pm 3 \mathrm{ac}$ & $45 \pm 6 b$ & $59 \pm 2 \mathrm{~cd}$ & $39 \pm 10 b c$ & $52 \pm 5 \mathrm{bc}$ & $58 \pm 2$ ce & $45 \pm 4 b$ \\
\hline Vanillic acid & $40 \pm 3 b$ & $40 \pm 1 \mathrm{~b}$ & $49 \pm 10 \mathrm{bc}$ & $29 \pm 6 \mathrm{bc}$ & $49 \pm 8 \mathrm{bc}$ & $57 \pm 4$ ce & $39 \pm 6 \mathrm{bd}$ \\
\hline Cinnamic acid & $47 \pm 4 b$ & $40 \pm 2 b$ & $63 \pm 6 \mathrm{~cd}$ & $31 \pm 3 \mathrm{bc}$ & $51 \pm 3 \mathrm{bc}$ & $72 \pm 6$ be & $38 \pm 6$ bd \\
\hline$p$-Coumaric acid & $41 \pm 11 b$ & $38 \pm 3 b$ & $68 \pm 5 c$ & $33 \pm 8 b c$ & $43 \pm 3 \mathrm{bc}$ & $60 \pm 6$ be & $50 \pm 4 b$ \\
\hline$(+)$-Catechin & $47 \pm 11 b$ & $15 \pm 1 \mathrm{c}$ & $43 \pm 7 \mathrm{bc}$ & $19 \pm 1 \mathrm{c}$ & $16 \pm 2 \mathrm{~d}$ & $18 \pm 3 \mathrm{f}$ & $15 \pm 0 \mathrm{c}$ \\
\hline (-)-Epicatechin & $61 \pm 10 \mathrm{bc}$ & $18 \pm 4 \mathrm{c}$ & $41 \pm 0 \mathrm{bd}$ & $38 \pm 6 \mathrm{bc}$ & $20 \pm 3 d$ & $24 \pm 5 \mathrm{df}$ & $25 \pm 2 \mathrm{~cd}$ \\
\hline Quercetin & $40 \pm 5 b$ & $14 \pm 0 \mathrm{c}$ & $33 \pm 5 b$ & $23 \pm 6 \mathrm{c}$ & $17 \pm 2 \mathrm{~d}$ & $19 \pm 2 \mathrm{f}$ & $20 \pm 2 \mathrm{~cd}$ \\
\hline Polydatin & $49 \pm 9 b$ & $37 \pm 5 b$ & $40 \pm 4 \mathrm{bd}$ & $16 \pm 2 c$ & $17 \pm 3 d$ & $19 \pm 4 \mathrm{f}$ & $19 \pm 1 \mathrm{~cd}$ \\
\hline Resveratrol & $60 \pm 10 \mathrm{bc}$ & $17 \pm 3 c$ & $41 \pm 7 \mathrm{bd}$ & $17 \pm 3 \mathrm{c}$ & $18 \pm 3 d$ & $19 \pm 1 \mathrm{f}$ & $20 \pm 2 \mathrm{~cd}$ \\
\hline
\end{tabular}

Average values from three tests \pm standard deviation. Values within a column with different letters are significantly different according to the one-way ANOVA followed by Tukey's Multiple Comparison Test (p $<0.05$ ). 


\section{SUMMARY}

Nowadays, the phenolic antioxidants have become frequently applied as natural additives in functional foods. These compounds are capable to enhance the stability of food and beverage products, increase their antioxidative capacity, and inhibit the growth of a range of foodborne pathogenic and spoilage bacteria and fungi. Many fruit residues contain such phytochemicals. However, most phenolic antioxidants in plants are bounded in glycosides forming a sugar linked compound with reduced bioavailability. Through hydrolytic action, the carbohydrate-cleaving enzymes can mobilize the phenolic aglycone molecules from their conjugated forms. For enrichment purposes, substrate treatment with carbohydrases and/or fermentation with the producing organisms can be a well-applicable and ecofriendly approach. Thus, extracts rich in bioactive and bioavailable natural phenolics can be generated from antioxidative plant byproducts.

There are good carbohydrase producers among filamentous fungi, and the obtained enzyme activities can be utilized in many food industrial applications. For instance, organoleptic properties and/or shelf life of certain food products can effectively be improved by these activities. In a preliminary research performed by our group, the zygomycete fungus Rhizomucor miehei NRRL 5282 was identified as an excellent cellulase producer. Hence, the present work aimed the mobilization of bioactive phenolic compounds from different fruit byproducts through solid-state fermentation (SSF) and direct enzyme treatment using the $R$. miehei NRRL 5282 strain and its cellulolytic enzyme cocktail. The antioxidative Othello black grape (Vitis vinifera $x$ (Vitis labrusca $x$ Vitis riparia)), Saszla white grape (Vitis vinifera), Jonagold apple (Malus domestica cv. Jonagold), yellow pitahaya (Hylocereus megalanthus), Tommy Atkins mango (Mangifera indica L.) and naranjilla (Solanum quitoense) fruits have been selected for the studies. From these substances, byproducts usually remaining after wine, juice and/or jam production were prepared, dried in an oven or lyophilized, and used for subsequent fermentation and enzyme treatments tests. Results achieved during our researches are the follows:

\section{Phenolic rich extracts with improved antioxidant activity have been prepared by SSF of residues.}

In this assay, mobilization of antioxidative phenolics from oven-dried and lyophilized black and white grape, apple, pitahaya, mango and naranjilla residues was 
studied after SSF using the high yield cellulase producer $R$. miehei NRRL 5282 isolate. Samples were collected at specified intervals, then, cellulase ( $\beta$-glucosidase) activity, total phenolic content (TPC), ferric reducing antioxidant power (FRAP) and 1,1-diphenyl-2picrylhydrazyl (DPPH) radical scavenging activity measurements were conducted. Results showed positive associations between the $\beta$-glucosidase activity and/or the TPC and FRAP on lyophilized apple (LA), pitahaya (LP), white grape (LWG) and naranjilla (LN) substrates. The $\beta$-glucosidase activity increased during the fermentation process on most fruit residues. In some experiments, the $\beta$-glucosidase activity increased slowly, most probably due to the high sugar content of the substrate. These compounds, mainly the cellobiose and the glucose, can bind to the active site of the $\beta$-glucosidase inhibiting its activity if they are present in excess. Furthermore, the catabolite repression can also explain the phenomenon. When glucose is present, the enzymes and transporters necessary for the utilization of a carbon source different from glucose are repressed. Additionally, the interaction of polyphenols and free aglycones with glucosidases may also reduce the enzyme activity. A positive correlation between the TPC, the FRAP and DPPH radical scavenging activity was detected for LP and oven-dried pitahaya (DP), oven-dried and lyophilized black grape (DBG and LBG), oven-dried mango (DMG) and LWG, LA and LN substrates. The phenolic content increased during the fungal growth when LWG, LA, LP and LN substrates were used as substrate. Depending on the fruit residue, the type of pretreatment (oven-drying or lyophilization) also influenced the TPC, $\beta$-glucosidase activity and/or antioxidant potential of the samples. In addition, the fermentation time required to achieve maximal enzyme activity and antioxidant effect also depended on the type of fruit residue. The highest $\beta$-glucosidase activity was achieved at different days during the bioconversions: 5th day for naranjilla, 10th day for pitahaya, 15th day for white and black grapes and 18th day for apple and mango. The FRAP was highest mostly during the first phase of fermentations, reaching maximal yields on the 3rd day for black grape and naranjilla, 5th day for white grape, 10th day for pitahaya and mango and 13th day for apple.

\section{Enzyme-assisted extraction of antioxidative phenolics from fruit residues has been performed.}

Enzyme treatment of oven-dried and/or lyophilized residues using a cellulolytic cocktail produced from $R$. miehei NRRL 5282 on wheat bran was carried out in these experiments. Except for naranjilla residues, commercial Aspergillus niger pectinase was 
also added to the reaction mixtures to improve the extraction of the phenolic compounds and decrease the tissue rigidity in the residues. TPC, FRAP and DPPH radical scavenging activity were analyzed in the obtained phenolic-rich extracts.

Overall, enzyme treatments enhanced the TPC and antioxidant potential in many fruit residues tested. The FRAP was superior for DP and LBG after each enzyme treatment, and for DBG and LN after cellulase, for LWG after pectinase, for DMG after pectinase and cellulase-pectinase and for oven-dried apple (DA) after cellulase-pectinase treatments than that measured in the corresponding control. Level of TPC and FRAP exposed similar pattern for most of the fruit extracts examined; moreover, in some samples, positive association was found between the TPC and the FRAP/DPPH radical scavenging activity. It seems that the substrate pretreatment was an important factor in the enzyme aided liberation tests as well. In the case of grape, apple and naranjilla fruit residues, for instance, lyophilized samples showed higher TPC after enzyme treatment than the oven-dried ones. However, irrespectively from enzyme treatment, extracts obtained on DP exhibited more TPC than the lyophilized forms. The antioxidant effect depended on both the type of fruit residues and the pretreatment.

\section{Individual phenolics in the extracts have been analyzed and compared.}

We studied the concentration of 11 individual phenolic compounds, namely the 4hydroxybenzoic acid, syringic acid, gallic acid, vanillic acid, cinnamic acid, $p$-coumaric acid, (+)-catechin, (-)-epicatechin, quercetin, polydatin and resveratrol, in black grape, apple, pitahaya and mango samples before and after enzyme treatments. In these assays, the analytical HPLC data also confirmed a phenolic content increase after cellulase treatments. The concentration of phenolic compounds changed by different degrees after the enzyme treatments depending on the substrate and the pretreatment: $(+)$-catechin and $(-)$-epicatechin were the major small compounds in the black grape and apple residue extracts, while the content of gallic and vanillic acids increased significantly in case of the DP samples. Except for stilbenoids and cinnamic acid, concentrations of all phenols tested were enhanced in DMG sample after the cellulase treatment. Anyway, HPLC analysis also confirmed an increase in the phenolic content after enzyme treatment of residues.

Antioxidant activity of the individual phenolic compounds investigated in the extracts was also determined. The syringic acid, gallic acid and (+)-catechin exhibited the highest antioxidant activity among the tested phenolic compounds. For some phenolic compounds, results showed correlation between the antioxidant activity and the 
concentration found in the extracts, indicating a possible role of the studied phenolics in the antioxidant potential increase of samples.

\section{Antimicrobial activity of extracts and individual phenolics against food-related bacteria has been studied. Antioxidative samples with effective growth inhibitory potential have been identified.}

We investigated the antimicrobial activity of grape, apple, pitahaya, mango and naranjilla extracts before and after enzyme treatments against selected food spoilage and foodborne pathogen bacteria. Results were compared with the antimicrobial properties of individual phenolics analyzed to investigate the association between the concentration of the compounds in the extracts and the growth inhibitory effect displayed. Bacillus subtilis, Bacillus cereus, Listeria monocytogenes, Staphylococcus aureus, methicillin-resistant $S$. aureus (MRSA), Escherichia coli, Salmonella enterica subsp. enterica serovar Typhimurium, Pseudomonas putida and Pseudomonas aeruginosa isolates were included in the assay.

In disk-diffusion tests, grape samples performed the highest growth inhibition potential followed by apple and pitahaya residues. Moreover, the antimicrobial activity of most fruit samples was improved after enzyme treatments. In general, the cellulase and cellulase-pectinase treated samples were more effective against most of the pathogens tested. No significant differences were found in the inhibitory effects between the ovendried and the lyophilized samples. The B. subtilis, S. aureus and S. enterica were the most sensitive to all extracts, while the lowest inhibitory effect was identified in case of the $L$. monocytogenes and the both Pseudomonas strains.

Minimum inhibitory and minimum bactericidal concentrations (MIC and MBC) of the extracts were also studied. In these assays, majority of samples had MIC value within the tested concentration ranging from 12.5 to $100 \mathrm{mg} / \mathrm{mL}$. The Pseudomonas and Bacillus strains were quite sensitive to the extracts, while growth inhibition was the lowest towards L. monocytogenes, E. coli and S. enterica. Among the samples tested, black grape and enzyme treated mango and naranjilla displayed the highest bacteriostatic effect. In many extracts, carbohydrase treatments reduced the initial MIC depending on the bacteria tested. Moreover, the MBC of black grape extract towards S. aureus, MRSA, E. coli and $S$. enterica was improved after the cellulase treatment, while the pectinase treatment caused an increase in bactericidal effect of apple samples against Pseudomonas. All three enzyme 
treatments affected positively the bactericidal effect of pitahaya residues against $P$. aeruginosa and $P$. putida.

Concerning individual phenolic compounds, no inhibitory effect has been recorded at the tested quantity in disk-diffusion tests (10 $\mu \mathrm{g}$ per disk). In the concentration range (from 125 to $500 \mu \mathrm{g} / \mathrm{mL}$ ) studied, MIC was determined only for cinnamic acid, $p$-coumaric acid and quercetin against the two Bacillus strains, and resveratrol against the Bacillus and Pseudomonas isolates. This suggests that most phenolic compounds analyzed would have a minor role in the antimicrobial activity of the samples. No MBC was identified for the compounds within the used concentration range.

\section{Anti-quorum sensing (anti-QS) activity of residue extracts, and phenolic compounds has been evaluated using the model organism Chromobacterium violaceum.}

Because the cell-to-cell communication with chemical molecules, namely the quorum sensing (QS), is responsible for the development of many food deterioration phenotypes, we have screened the enzyme-free and enzyme-treated black grape, apple and pitahaya extracts and the phenolic compounds as possible inhibitors of QS by monitoring the QS regulated pigment (violacein) production of $C$. violaceum in liquid cultures.

The fruit residue extracts presented anti-QS effect in an inhibition range of 6 to $36 \%$, at $2 \mathrm{mg} / \mathrm{mL}$ concentration used. Except for apple samples, inhibitory effect of the enzyme-free sample was not influenced by the nature of pretreatment. More importantly, the enzyme treatments enhanced the anti-QS activity of the DBG, LBG, DP, LP and LA extracts. The individual phenolics tested in $10 \mu \mathrm{g} / \mathrm{mL}$ concentration showed inhibition within the range of 5 to $31 \%$. Results revealed that syringic acid, vanillic acid, (+)catechin, (-)-epicatechin, 4-hydroxybenzoic acid, gallic acid and resveratrol yields obtained after enzyme treatments might have contributed to the violacein production inhibitory effect of some extracts.

\section{Biofilm formation of foodborne pathogens and spoilage bacteria was studied in the presence of phenolic extracts and compounds.}

It is known that the QS mechanism has important role in the biofilm formation of many microorganisms. Because most extracts of black grape, apple and pitahaya residues before and after enzyme treatments, as well as many phenolic compounds inhibited the QS communication system, we considered analyzing their effects against biofilm forming ability of food-related bacteria to be important. The above studied L. monocytogenes, $S$. 
aureus, MRSA, E. coli, S. enterica, $P$. putida and P. aeruginosa bacteria were included in this assay. Most extracts exhibited biofilm formation inhibitory effect, and P. putida, $P$. aeruginosa and $S$. aureus showed the highest sensitivity to them. However, the degree of inhibition depended on the substrate pretreatment and enzyme treatment procedures as well as on the sensitivity of bacterium subjected to analysis. For instance, the DBG and DP residues provided more inhibition against the biofilms compared to LBG and LP samples, respectively. For apple extracts, however, most bacterial biofilms were inhibited by samples obtained from lyophilized materials. In addition, it was interesting to observe that some extracts, irrespectively from enzyme treatments, supported the formation of certain biofilms. This was particularly found for the S. enterica, L. monocytogenes and E. coli biofilms. The different sensitivity of the bacteria to extracts and/or the concentration of phenolic compounds and polysaccharides in the samples might be responsible for the biofilm stimulating effect. The phenolics could be stressors forcing the cells to biofilm formation while saccharides can stabilize the biofilm matrix during reaction. Biofilm inhibitory effect of phenolic compounds was the highest in the case of $S$. aureus, E. coli, $S$. enterica and the two Pseudomonas bacteria. Flavonoids, i.e. (+)-catechin, (-)-epicatechin and quercetin, and stilbenoids, i.e. polydatin and resveratrol, showed greater activity against most bacterial biofilms than the phenolic acids.

In conclusion, our study provides useful data on the application of $R$. miehei and its cellulase enzymes to generate free phenolic compounds from grape, apple, pitahaya, mango and naranjilla wastes. The obtained phenolic extracts can be used as a source of natural compounds having antioxidative, antimicrobial, anti-biofilm and anti-QS potential. We expect that the phenolic compounds and extracts may substitute or support the activity of synthetic additive products, which, by the way, can provoke serious concern in consumers. In line with this, the produced extracts could be potential sources of food preservatives and/or sanitizers as well. In addition, the ecofriendly utilization of food processing residues can also be achieved during the treatment processes. Moreover, as we know, this study is the first that has applied fermentation and enzyme aided techniques for production of natural bioactives from pitahaya and naranjilla residues. 


\section{7. ÖSSZEFOGLALÁS}

A fenolos antioxidánsok természetes eredetü kiegészítőként alkalmazhatók funkcionális élelmiszerekben. Jelenlétükkel növelhetik az élelmiszerek stabilitását és antioxidáns képességét, valamint gátolhatják az élelmiszer eredetü patogén és romlást okozó mikroorganizmusok növekedését. Bioaktív fenolokat sokféle gyümölcs feldolgozás utáni maradványa tartalmaz. Többségük biológiailag nehezen hozzáférhető, cukormolekulákkal képzett glikozidokban lekötve található a növényben. A szénhidrátbontó enzimek azonban hidrolitikus aktivitásukkal mobilizálni képesek a fenolos aglikon molekulákat. Ezáltal a növényi anyag szubsztrát szénhidrázokkal történő kezelése és/vagy fermentációja enzimtermelő mikroorganizmusokkal egy jól alkalmazható megközelítés lehet a szabad fenolos összetevők környezetbarát kivonására. A módszerrel bioaktív és biológiailag hozzáférhető, természetes fenolokban gazdag kivonatok állíthatók elő antioxidáns növényi melléktermékekből.

A fonalas gombák között vannak jó hozamú szénhidráz-termelő törzsek. A kinyert enzimek számos élelmiszeripari célra hasznosíthatók; alkalmazásukkal például hatékonyan javítható egyes élelmiszerek eltarthatósági és/vagy érzékszervi tulajdonsága. Előzetes kutatások a Rhizomucor miehei NRRL 5282 járomspórás gombát kitűnő celluláz termelőnek azonosították. Ezt a gombatörzset és az általa termelt celluláz enzimet felhasználva célul tüztük ki bioaktív szabad fenolok szilárd-fázisú fermentációval és közvetlen enzimatikus kezeléssel történő kivonását különféle gyümölcsök feldolgozás utáni maradványaiból. A kutatási munkához az antioxidatív Otelló fekete szőlő (Vitis vinifera $x$ (Vitis labrusca $x$ Vitis riparia)), Saszla fehér szőlő (Vitis vinifera), Jonagold alma (Malus domestica cv. Jonagold), sárga sárkánygyümölcs (Hylocereus megalanthus), Tommy Atkins mangó (Mangifera indica L.) és naranjilla (Solanum quitoense) gyümölcsöket választottuk ki. Az alapanyagokból bor-, gyümölcslé- és/vagy lekvárkészítés után rendszerint visszamaradó melléktermékeket állítottunk elő, melyeket ezután szárítószekrényben szárítottunk vagy liofilizáltunk. Aprítást követően fermentációs és enzimatikus kezeléseknek vetettük alá a mintákat. A következő eredményeket értük el:

\section{Megnövelt antioxidáns aktivitású, fenolokban dúsított kivonatokat állítottunk elő a maradványok szilárd-fázisú fermentációjával.}

Ezekben a vizsgálatokban az antioxidáns hatás és a szabad fenol hozam változását tanulmányoztuk szárítószekrényben szárított és liofilizált szőlő, alma, sárkánygyümölcs, 
mangó és naranjilla maradványok $R$. miehei gombával történő szilárd-fázisú fermentációját követően. A kijelölt időközönként levett mintákban meghatároztuk az összfenol-tartalmat és a celluláz ( $\beta$-glükozidáz) aktivitást, majd az antioxidáns aktivitást a vasredukáló képesség (FRAP módszer) és szabadgyök-fogó kapacitás (DPPH módszer) monitorozásával követtük. A liofilizált alma (LA), sárkánygyümölcs (LP), fehér szőlö (LWG) és naranjilla (LN) szubsztrátok esetén pozitív összefüggést tapasztaltunk a $\beta$ glükozidáz aktivitás és/vagy az összfenol-tartalom és a vasredukáló képesség között. A $\beta$ glükozidáz aktivitás a legtöbb minta esetén növekedést mutatott a fermentáció alatt. Néhány mintánál az enzimaktivitás lassú emelkedését tapasztaltuk, mely valószínűleg a szubsztrát nagy cukortartalmának tudható be. Nagy koncentrációban való jelenlét esetén a cellobióz és a glükóz kötődhet a $\beta$-glükozidáz aktív centrumához gátolva annak müködését. A jelenséget a katabolit represszió szintén magyarázhatja, illetve a glükozidáz aktivitás polifenolokkal és szabad aglikonokkal való interakció okán is csökkenhet. Vizsgálatainkban pozitív korrelációt mutattunk ki az összfenol-tartalom, a vasredukáló képesség és a szabadgyök-fogó aktivitás között szárítószekrényben szárított sárkánygyümölcs (DP), fekete szőlő (DBG) és mangó (DMG), illetve liofilizált fekete szőlő (LBG), LWG, LP, LA és LN mintákon. A fenoltartalom folyamatos növekedését azonosítottuk LWG, LA, LP és LN szubsztrátokon a fermentáció alatt. Gyümölcsmaradványtól függően azonban az előkezelés típusa (szárítószekrényben szárítás vagy liofilizálás) is befolyásolta a minták összfenol-tartalmát, $\beta$-glükozidáz aktivitását és/vagy antioxidáns potenciálját. Emellett, a maradvány típusától függően változott a legnagyobb enzimaktivitás és antioxidáns hatás eléréséhez szükséges fermentációs idő is. A legnagyobb $\beta$-glükozidáz aktivitást például naranjilla mintánál az 5 ., sárkánygyümölcsnél a 10., szőlőnél a 15., míg alma és mangó mintáknál a 18. napokon kaptuk. A vasredukáló képesség ezzel szemben a fermentációk kezdeti fázisában volt a legnagyobb; fekete szőlő és naranjilla esetén a 3., fehér szőlőn az 5., sárkánygyümölcs és mangó mintákon a 10., míg almán a 13. napokon mértünk maximális értékeket.

\section{Antioxidatív fenolokat vontunk ki gyümölcsmaradvány mintákból enzimatikus kezelésekkel.}

Szárítószekrényben szárított és/vagy liofilizált gyümölcsmaradvány minták enzimatikus kezelését végeztük búzakorpa alapú fermentációban elöállított $R$. miehei celluláz koktéllal. A fenolkivonás hatékonyságának növelése érdekében Aspergillus niger pektinázt is adtunk a legtöbb minta reakcióelegyéhez. A maradványokat így háromféle 
kezelésnek vetettük alá: celluláz, pektináz és celluláz-pektináz kombinált kezelés. A kivonatokban ezután meghatároztuk az összfenol-tartalmat és az antioxidáns aktivitást.

A legtöbb tesztelt gyümölcsmaradvány-kivonatban fokozódott az összfenoltartalom és az antioxidáns potenciál az enzimatikus kezeléseket követően. A vasredukáló képesség a DP és LBG mintáknál mindegyik enzimes kezelés után, míg DBG és LN esetén celluláz, LWG mintánál pektináz, DMG szubsztrátnál pektináz és celluláz-pektináz, illetve szárítószekrényben szárított alma (DA) minta esetén celluláz-pektináz kombinált kezelést követően jelentősen nagyobb volt, mint az enzimmentes kontrollban. A legtöbb kivonatnál az összfenol-tartalom és vasredukáló képesség hasonló mintázatban változott az enzimes kezeléseket követően. Néhány minta esetében pozitív asszociációt tapasztaltunk az összfenol-tartalom és a vasredukáló képesség/gyökfogó kapacitás között. A szubsztrát előkezelése ezekben a kísérletekben is jelentős hatással volt a fenol felszabadulásra. Liofilizált szőlő, alma és naranjilla maradványok kivonataiban például nagyobb összfenoltartalmat mértünk az enzimatikus kezeléseket követően, mint szárítószekrényben szárított mintáknál. Sárkánygyümölcsnél a szárítószekrényben szárított minták kivonataiban volt nagyobb összfenol-tartalom, enzimatikus kezeléstől függetlenül. Az antioxidáns aktivitás mértéke is függést mutatott a maradványok típusától és az előkezelések jellegétől.

\section{Vizsgáltuk fenolos vegyületek jelenlétét és koncentrációját a kivonatokban.}

A fekete szőlő, alma, sárkánygyümölcs és mangó minták enzimatikus kezelés előtti és utáni kivonatait HPLC analízisnek is alávetettük, melyben egyedi fenolos vegyületek (4hidroxi-benzoesav, galluszsav, vanillinsav, sziringsav, $p$-kumársav, fahéjsav, kvercetin, polidatin, rezveratrol, (+)-katekin és (-)-epikatekin) mennyiségi meghatározását végeztük el. Számos vegyület esetén koncentrációnövekedést tapasztaltunk a celluláz kezelést követően. Az egyes fenolok mennyisége azonban az enzimatikus kezelésektől, a szubsztrát típusától és az előkezeléstől függően különböző módon változott: fekete szőlő és alma kivonatokban a (+)-katekin és az (-)-epikatekin volt a meghatározó vegyület, míg DP esetén a galluszsav és vanillinsav tartalom mutatott jelentős növekedést. A stilbenoid és a fahéjsav vegyületeken kívül növekedést tapasztaltunk a vizsgált fenolok koncentrációjában a DMG minták celluláz kezelését követően.

A kivonatokban vizsgált fenolos összetevők antioxidáns aktivitását is meghatároztuk. A legnagyobb aktivitást sziringsav, galluszsav és (+)-katekin vegyületeknél tapasztaltuk. Emellett, néhány fenol esetén korrelációt azonosítottunk az 
antioxidáns hatás és a kivonatban mért koncentráció között, ami az adott vegyület lehetséges szerepére utal a minta antioxidáns aktivitásának emelkedésében.

\section{Felmértük az enzimatikus kezeléssel előállított kivonatok antimikrobiális hatását élelmiszerekkel kapcsolatos baktériumokon. Azonosítottunk növekedést gátló tulajdonsággal rendelkező mintákat.}

Élelmiszer-eredetű patogén és romlást okozó baktériumokon vizsgáltuk enzimes kezelés elötti és utáni gyümölcsmaradvány-kivonatok növekedést gátló aktivitását. A kísérletekbe bevontuk az előzetesen azonosított egyedi fenolvegyületeket is, majd vizsgáltuk az összefüggést a kivonatokban található vegyületek koncentrációja és a növekedést gátló hatás között. A kísérletekbe Bacillus subtilis, Bacillus cereus, Listeria monocytogenes, Staphylococcus aureus, meticillin-rezisztens S. aureus (MRSA), Escherichia coli, Salmonella enterica subsp. enterica serovar Typhimurium, Pseudomonas putida és Pseudomonas aeruginosa baktériumokat vontunk be.

Korongdiffúziós tesztekben a szőlö, alma és sárkánygyümölcs kivonatai mutatták a legnagyobb növekedésgátló hatást. Az enzimatikus kezelés megnövelte a legtöbb kivonat gátló hatását: a celluláz és a celluláz-pektináz kezelt kivonatok számos patogén ellen nagyobb aktivitást mutattak az enzimmentes kivonattal összehasonlítva. A különböző módon elökezelt (szárítószekrényben szárított vagy liofilizált) minták kivonatai között viszont nem azonosítottunk szignifikáns eltéréseket az aktivitásban. A B. subtilis, S. aureus és $S$. enterica baktériumok érzékenyek voltak minden tesztelt kivonatra, míg a legkisebb gátló hatást L. monocytogenes és a két Pseudomonas izolátum esetén tapasztaltuk.

A kivonatok minimális gátló és minimális baktericid koncentrációját (MIC és MBC) is meghatároztuk. A 12,5-100 $\mathrm{mg} / \mathrm{mL}$ vizsgált koncentráción belül a legtöbb mintánál azonosítottunk MIC értéket. Ezekben a tesztekben a Pseudomonas és a Bacillus baktériumok érzékenyek voltak a kivonatokra. A növekedést gátló hatás L. monocytogenes, E. coli és $S$. enterica esetén volt a legkisebb. A tesztelt minták közül a fekete szőlö és az enzimkezelt mangó és naranjilla kivonatok mutatták a legnagyobb bakteriosztatikus hatást. Baktériumtól függően ugyan, de számos kivonat kezdeti MIC értéke csökkent a szénhidráz kezeléseket követően. Söt, a $S$. aureus, MRSA, E. coli és $S$. enterica baktériumokra azonosított MBC is csökkent fekete szőlő maradvány celluláz kezelését követően. Alma mintáknál pektináz kezelés után tapasztaltunk hasonlót Pseudomonas baktériumokon. Mindhárom enzimatikus kezelés pozitívan befolyásolta a sárkánygyümölcs minták $P$. aeruginosa és $P$. putida ellen mutatott baktericid hatását. 
A fenolos vegyületek a vizsgált koncentrációban (10 $\mu \mathrm{g}$ per korong) nem mutattak gátló hatást a korongdiffúziós tesztek alatt. MIC értéket a fahéjsav, $p$-kumársav és kvercetin vegyületeknél Bacillus baktériumok ellen, és rezveratrol alkalmazásakor Bacillus és Pseudomonas izolátumoknál azonosítottunk a vizsgált 125-500 $\mu \mathrm{g} / \mathrm{mL}$ koncentráción belül. Eszerint a vizsgált fenolos vegyületek többsége kismértékben járul hozzá a kivonatok antimikrobiális aktivitásához. A tesztelt koncentrációtartományon belül MBC adatot nem kaptunk a fenolos vegyületeknél.

\section{Vizsgáltuk a kivonatok és a fenolos vegyületek quorum sensing folyamatot gátló} képességét.

A kémiai molekulákkal történő sejt-sejt kommunikáció, azaz a quorum sensing (QS), számos élelmiszerromlást és fertőzést okozó fenotípusért felelős, ezért fontosnak tartottuk megvizsgálni a kivonatok és fenolos komponenseik esetleges QS folyamatot gátló hatását is. A kísérletsorozatba a fekete szőlő, alma és sárkánygyümölcs maradványok enzimes kezelés előtti és utáni kivonatait vontuk be. A hatást Chromobacterium violaceum modellorganizmus QS szabályzás alatt álló pigmenttermelésének (violacein) monitorozásán keresztül követtük, folyadék tenyészetben.

A kivonatok az egységesen alkalmazott $2 \mathrm{mg} / \mathrm{mL}$ koncentrációban 6-36\% közötti mértékü QS gátló aktivitást mutattak. Szőlő és sárkánygyümölcs esetén az enzimmentes minta gátló hatását az előkezelés jellege nem befolyásolta. Ugyanakkor az enzimatikus kezelés képes volt megnövelni a DBG, LBG, DP, LP és LA kivonatok által kifejtett QS gátló hatást. A fenolos vegyületeket $10 \mu \mathrm{g} / \mathrm{mL}$ koncentrációban vittük be a tesztekbe, és 531\% között azonosítottunk QS gátló hatást. Eredményeink alapján az enzimkezelések után kapott sziringsav, vanillinsav, (+)-katekin, (-)-epikatekin, 4-hidroxi-benzoesav, galluszsav és rezveratrol hozamok hozzájárulhattak egyes kivonatok QS gátló aktivitásához.

\section{Tanulmányoztuk élelmiszer eredetü patogén és romlást okozó baktériumok} biofilmképzését fenolos kivonatok és vegyületek jelenlétében.

A QS mechanizmus fontos szerepet játszik mikroorganizmusok biofilmképzésében. Mivel a legtöbb enzimmentes és enzimkezelt fekete szőlö, alma és pitahaya kivonat, valamint számos fenolos vegyület jól gátolta a QS folyamatot, fontosnak tartottuk megvizsgálni mintáink élelmiszerekkel kapcsolatos baktériumok biofilmképző képességére gyakorolt hatását is. Az előző tesztjeinkben alkalmazott L. monocytogenes, S. aureus, MRSA, E. coli, S. enterica, P. putida és $P$. aeruginosa baktériumokkal dolgoztunk. A legtöbb kivonatnál tapasztaltunk biofilmképzést gátló hatást; a $P$. putida, $P$. aeruginosa és 
S. aureus biofilmeknél mutattunk ki nagy érzékenységet a kivonatokra. A gátló hatás a szubsztrát előkezelés módszerétől, az enzimkezelési eljárástól, valamint az vizsgált baktérium érzékenységétől függően változatos mértéket mutatott. A szárítószekrényben szárított fekete szőlő és sárkánygyümölcs maradványok kivonatai például nagyobb gátló hatást mutattak, mint a liofilizált szubsztrátokon készített minták. Alma kivonatok esetén ezzel szemben a liofilizált maradványokból származó minták hatékonyabban gátolták a legtöbb baktérium biofilmképzését. Néhány kivonat azonban, enzimkezeléstől függetlenül, támogató hatással volt bizonyos biofilmek képződésére. A jelenség a $S$. enterica, $L$. monocytogenes és $E$. coli biofilmeknél volt leginkább jellemző. A biofilmképzést fokozó hatásért a baktériumok kivonatokkal szembeni eltérő érzékenysége és/vagy a minták fenolos vegyület és poliszacharid koncentrációja lehet felelős. A fenolok stresszorként biofilm képzésre kényszeríthetik a sejteket, míg a szacharidok a képződés folyamata során stabilizálhatják a biofilm mátrixot. A fenolos vegyületek a $S$. aureus, E. coli, S. enterica és a Pseudomonas biofilmeket gátolták a legnagyobb mértékben. A flavonoidok, azaz a (+)katekin, (-)-epikatekin és kvercetin, valamint a stibenoidok, azaz a polidatin és a rezveratrol, nagyobb gátló aktivitást mutattak a legtöbb általunk vizsgált baktérium biofilmképzésére, mint a fenolsavak.

Eredményeink alapján a $R$. miehei és az általa termelt cellulázok alkalmazhatók szabad fenolokat tartalmazó antioxidatív kivonatok előállítására szőlő, alma, sárkánygyümölcs, mangó és naranjilla maradványokból. A kapott fenolos kivonatok felhasználhatók antioxidáns, antimikrobiális, anti-biofilm és antiquorum sensing tulajdonságokkal rendelkező természetes vegyületek forrásául. Reményeink szerint a fenolvegyületek és kivonatok helyettesíthetik vagy támogathatják szintetikus élelmiszer-adalékok aktivitását, mely utóbbi szerek napjainkban komoly fogyasztói ellenérzéssel bírnak. Ezzel összhangban az előállított kivonatok tartósítószerek és/vagy fertőtlenítőszerek potenciális forrásai is lehetnek. Emellett a kutatási programban alkalmazott kezelési módszerekkel élelmiszerek feldolgozás utáni maradványainak környezetbarát hasznosítása is elérhető. Tudomásunk szerint elsőként alkalmaztunk fermentációs és enzimatikus kezelés technikákat bioaktív természetes vegyületek előállítására sárkánygyümölcs és naranjilla mintákból. 


\section{REFERENCES}

Abu Zarin, M., Wan, H.Y., Isha, A., Armania, N. (2016) Antioxidant, antimicrobial and cytotoxic potential of condensed tannins from Leucaena leucocephala hybridRendang. Food Science and Human Wellness 5, 65-75.

Acosta, Ó., Pérez, A.M., Vaillant, F. (2009) Chemical characterization, antioxidant properties, and volatile constituents of naranjilla (Solanum quitoense Lam.) cultivated in Costa Rica. Archivos Latinoamericanos de Nutricion 59, 88-94.

Acosta-Estrada, B.A., Gutiérrez-Uribe, J.A., Serna-Saldívar, S.O. (2014) Bound phenolics in foods, a review. Food Chemistry 152, 46-55.

Addis, M., Sisay, D. (2015) A review on major food borne bacterial illnesses. Journal of Tropical Diseases \& Public Health 3, 176.

Adnan, M., Zheng, W., Islam, W., Arif, M., Abubakar, Y.S., Wang, Z., Lu, G. (2018) Carbon catabolite repression in filamentous fungi. International Journal of Molecular Sciences 19, 48.

Afaq, F., Katiyar, S.K. (2011) Polyphenols: skin photoprotection and inhibition of photocarcinogenesis. Mini Reviews in Medicinal Chemistry 11, 1200-1215.

Aggarwal, S., Jain, T. (2019) Modern pretreatment techniques for phytochemical extraction. Nutrition \& Food Science 49, 441-454.

Ahmed, I.S., Tohami, S.M., Almagboul, Z.A. and Verpoorte, R. 2012. Characterization of anti-microbial compounds isolated from Mangifera indica L seed kernel. University of Africa Journal of Sciences 2, 77-91.

Ajila, C.M., Brar, S.K., Verma, M., Tyagi, R.D., Valéro, J.R. (2011) Solid-state fermentation of apple pomace using Phanerocheate chrysosporium-Liberation and extraction of phenolic antioxidants. Food Chemistry 126, 1071-1080.

Ajila, C.M., Gassara, F., Brar, S.K., Verma, M., Tyagi, R.D., Valéro, J.R. (2012) Polyphenolic antioxidant mobilization in apple pomace by different methods of solid-state fermentation and evaluation of its antioxidant activity. Food and Bioprocess Technology 5, 2697-2707.

Ajila, C.M., Naidu, K.A., Bhat, S.G., Rao, U.P. (2007) Bioactive compounds and antioxidant potential of mango peel extract. Food Chemistry 105, 982-988.

Ajila, C.M., Prasada Rao, U.J.S. (2013) Mango peel dietary fibre: Composition and associated bound phenolics. Journal of Functional Foods 5, 444-450. 
Ali, K., Maltese, F., Choi, Y.H., Verpoorte, R. (2010) Metabolic constituents of grapevine and grape-derived products. Phytochemistry Reviews 9, 357-378.

Ali, U.F., Ibrahim, Z.M. (2008) Production and some properties of fibrinolytic enzyme from Rhizomucor miehei (Cooney \& Emerson) Schipper. Journal of Applied Sciences Research 4, 892-899.

Alonso, E., Bourzeix, M., Revilla, E. (1991) Suitability of water/ethanol mixtures for the extraction of catechins and proanthocyanidins from Vitis vinifera seeds contained in a winery by-product. Seed Science and Technology 19, 542-552.

Alvarez, M.V., Moreira, M.R., Ponce, A. (2012) Antiquorum sensing and antimicrobial activity of natural agents with potential use in food. Journal of Food Safety 32, 379-387.

Alves, M.J., Ferreira, I.C.F.R., Froufe, H.J.C., Abreu, R.M.V., Martins, A., Pintado, M. (2013) Antimicrobial activity of phenolic compounds identified in wild mushrooms, SAR analysis and docking studies. Journal of Applied Microbiology $115,346-357$.

Andrade-Cuvi, M.J., Moreno-Guerrero, C., Guijarro-Fuertes, M., Concellón, A. (2015) Caracterización de la naranjilla (Solanum quitoense) común en tres estados de madurez. Revista Iberoamericana de Tecnologia Postcosecha 16, 215-221.

Anwar, H., Hussain, G., Mustafa, I. (2018) Antioxidants from natural sources. In: Shalaby, E., Azzam, G.M. (eds.) Antioxidants in foods and its applications. IntechOpen, London, pp. 3-28.

Apastambh, A.R., Baig, M.M.V. (2017) Proteolytic enzyme production by Fusarium oxysporium under solid-state fermentation. International Journal of Life Sciences and Technology 10, 106-108.

Asfour, H.Z. (2018) Anti-quorum sensing natural compounds. Journal of Microscopy and Ultrastructure 6, 1-10.

Assefa, A., Kechero, Y., Tolemariyam, T. (2017) Antimicrobial activity of condensed tannin extracts from indigenous fodder plants of Gambella region on mastitis pathogens. Advances in Biological Research 11, 79-82.

Ayala-Zavala, J., Vega-Vega, V., Rosas-Domínguez, C., Palafox-Carlos, H., VillaRodriguez, J.A., Siddiqui, M.W., Dávila-Aviña, J.E., González-Aguilar, G.A. (2011) Agro-industrial potential of exotic fruit byproducts as a source of food additives. Food Research International 44, 1866-1874. 
Azmir, J., Zaidul, I.S.M., Rahman, M.M., Sharif, K.M., Mohamed, A., Sahena, F., Jahurul, M.H.A., Ghafoor, K., Norulaini, N.A.N., Omar, A.K.M. (2013) Techniques for extraction of bioactive compounds from plant materials: a review. Journal of Food Engineering 117, 426-436.

Babitha, S., Soccol, C.R., Pandey, A. (2007) Solid-state fermentation for the production of Monascus pigments from jackfruit seed. Bioresource Technology 98, 1554-1560.

Bacciottini, L., Falchetti, A., Pampaloni, B., Bartolini, E., Carossino, A.M., Brandi, M.L. (2007) Phytoestrogens: food or drug? Clinical Cases in Mineral and Bone Metabolism 4, 123-130.

Bahadoran, Z., Mirmiran, P., Azizi, F. (2013) Dietary polyphenols as potential nutraceuticals in management of diabetes: a review. Journal of Diabetes \& Metabolic Disorders 12, 43.

Bakkiyaraj, D., Nandhini, J.R., Malathy, B., Pandian, S.K. (2013) The anti-biofilm potential of pomegranate (Punica granatum L.) extract against human bacterial and fungal pathogens. Biofouling 29, 929-937.

Balasundram, N., Sundram, K., Samman, S. (2006) Phenolic compounds in plants and agri-industrial by-products: Antioxidant activity, occurrence, and potential uses. Food Chemistry 99, 191-203.

Barrios-González, J. (2012) Solid-state fermentation: Physiology of solid medium, its molecular basis and applications. Process Biochemistry 47, 175-185.

Beauregard, P.B., Chai, Y., Vlamakis, H., Losick, R., Kolter, R. (2013) Bacillus subtilis biofilm induction by plant polysaccharides. Proceedings of the National Academy of Sciences of the United States of America 110, E1621-E1630.

Begley, M., Hill, C. (2015) Stress adaptation in foodborne pathogens. Annual Review of Food Science and Technology 6, 191-210.

Behera, S.S., Ray, R.C. (2016) Solid state fermentation for production of microbial cellulases: recent advances and improvement strategies. International Journal of Biological Macromolecules 86, 656-669.

Bele, A.A., Jadhav, V.M., Kadam, V.J. (2010) Potential of tannins: a review. Asian Journal of Plant Sciences 9, 209-214.

Benítez, V., Mollá, E., Martín-Cabrejas, M.A., Aguilera, Y., López-Andréu, F.J., Cools, K., Terry, L.A., Esteban, R.M. (2011) Characterization of industrial onion wastes (Allium cepa L.): dietary fibre and bioactive compounds. Plant Foods for Human Nutrition 66, 48-57. 
Bhalla, T.C., Joshi, M. (1994) Protein enrichment of apple pomace by co-culture of cellulolytic moulds and yeasts. World Journal of Microbiology and Biotechnology 10, 116-117.

Bhargav, S., Panda, B.P., Ali, M., Javed, S. (2008) Solid-state fermentation: an overview. Chemical and Biochemical Engineering Quarterly 22, 49-70.

Binod, P., Sandhya, C., Suma, P., Szakacs, G., Pandey, A. (2007) Fungal biosynthesis of endochitinase and chitobiase in solid state fermentation and their application for the production of $\mathrm{N}$-acetyl-D-glucosamine from colloidal chitin. Bioresource Technology 98, 2742-2748.

Borges, A., Serra, S., Abreu, A.C., Saavedra, M.J., Salgado, A., Simões, M. (2014) Evaluation of the effects of selected phytochemicals on quorum sensing inhibition and in vitro cytotoxicity. Biofouling 30, 183-195.

Bravo, L. (1998) Polyphenols: chemistry, dietary sources, metabolism, and nutritional significance. Nutrition Reviews 56, 317-333.

Cáceres, C.X., Cáceres, R.E., Hein, D., Molina, M.G., Pia, J.M. (2012) Biogas production from grape pomace: Thermodynamic model of the process and dynamic model of the power generation system. International Journal of Hydrogen Energy 37, 1011110117.

Cairns, J.R., Esen, A. (2010) $\beta$-Glucosidases. Cellular and Molecular Life Sciences 67, 3389-3405.

Chae, S.C., Lee, J.H., Park, S.U. (2013) Recent studies on flavonoids and their antioxidant activities. EXCLI Journal 12, 226-230.

Chahar, M.K., Sharma, N., Dobhal, M.P., Joshi, Y.C. (2011) Flavonoids: A versatile source of anticancer drugs. Pharmacognosy Reviews 5, 1-12.

Chamorro, S., Viveros, A., Alvarez, I., Vega, E., Brenes, A. (2012) Changes in polyphenol and polysaccharide content of grape seed extract and grape pomace after enzymatic treatment. Food Chemistry 133, 308-314.

Chandini, S.K., Rao, L.J., Gowthaman, M.K., Haware, D.J., Subramanian, R. (2011) Enzymatic treatment to improve the quality of black tea extracts. Food Chemistry 127, 1039-1045.

Chen, G.L., Chen, S.G., Zhao, Y.Y., Luo, C.X., Li, J., Gao, Y.Q. (2014) Total phenolic contents of 33 fruits and their antioxidant capacities before and after in vitro digestion. Industrial Crops and Products 57, 150-157. 
Cheng, V.J., Bekhit, A.E.D.A., McConnell, M., Mros, S., Zhao, J. (2012) Effect of extraction solvent, waste fraction and grape variety on the antimicrobial and antioxidant activities of extracts from wine residue from cool climate. Food Chemistry 134, 474-482.

Chmielewski, R.A.N., Frank, J.F. (2003) Biofilm formation and control in food processing facilities. Comprehensive Reviews in Food Science and Food Safety 2, 22-32.

Cho, H.S., Lee, J.H., Cho, M.H., Lee, J. (2015) Red wines and flavonoids diminish Staphylococcus aureus virulence with anti-biofilm and anti-hemolytic activities. Biofouling 31, 1-11.

Choo, J.C., Koh, R.Y., Ling, A.P.K. (2016) Medicinal properties of Pitaya: a review. Spatula DD 6, 69-76.

Choo, J.H., Rukayadi, Y., Hwang, J.K. (2006) Inhibition of bacterial quorum sensing by vanilla extract. Letters in Applied Microbiology 42, 637-641.

Clifford, M.N., Scalbert, A. (2000) Ellagitannins - nature, occurrence and dietary burden. Journal of the Science of Food and Agriculture 80, 1118-1125.

Contreras-Calderón, J., Calderón-Jaimes, L., Guerra-Hernández, E., García-Villanova, B. (2011) Antioxidant capacity, phenolic content and vitamin C in pulp, peel and seed from 24 exotic fruits from Colombia. Food Research International 44, 2047-2053.

Correia, R.T.P., McCue, P., Magalhães, M.M.A., Macêdo, G.R., Shetty, K. (2004) Production of phenolic antioxidants by the solid-state bioconversion of pineapple waste mixed with soy flour using Rhizopus oligosporus. Process Biochemistry 39, 2167-2172.

Daglia, M. (2012) Polyphenols as antimicrobial agents. Current Opinion in Biotechnology 23, 174-181.

Das, A., Paul, T., Halder, S.K., Jana, A., Maity, C., Mohapatra, P.K.D., Pati, B.R., Mondal, K.C. (2013) Production of cellulolytic enzymes by Aspergillus fumigatus ABK9 in wheat bran-rice straw mixed substrate and use of cocktail enzymes for deinking of waste office paper pulp. Bioresource Technology 128, 290-296.

De Ancos, B., Colina-Coca, C., González-Peña, D., Sánchez-Moreno, C. (2015) Bioactive compounds from vegetable and fruit by-products. In: Gupta, V.K., Tuohy M.G. (eds.) Biotechnology of Bioactive Compounds. Sources and Applications. John Wiley \& Sons, Ltd., Chichester, UK, pp. 3-36.

de Castro, R.J.S., Ohara, A., Nishide, T.G., Bagagli, M.P., Dias, F.F.G., Sato, H.H. (2015) A versatile system based on substrate formulation using agro industrial wastes for 
protease production by Aspergillus niger under solid state fermentation. Biocatalysis and Agricultural Biotechnology 4, 678-684.

Di Luccio, M., Capra, F., Ribeiro, N.P., Vargas, G.D., Freire, D.M., De Oliveira, D. (2004) Effect of temperature, moisture, and carbon supplementation on lipase production by solid-state fermentation of soy cake by Penicillium simplicissimum. Applied Biochemistry and Biotechnology 113, 173-180.

Dias, C., Domínguez-Perles, R., Aires, A., Teixeira, A., Rosa, E., Barros, A., Saavedra, M.J. (2015) Phytochemistry and activity against digestive pathogens of grape (Vitis vinifera L.) stem's (poly)phenolic extracts. LWT-Food Science and Technology 61, $25-32$.

Díaz-Gómez, R., López-Solís, R., Obreque-Slier, E., Toledo-Araya, H. (2013) Comparative antibacterial effect of gallic acid and catechin against Helicobacter pylori. LWT-Food Science and Technology 54, 331-335.

Dobrev, G., Strinska, H., Hambarliiska, A., Zhekova, B., Dobreva, V. (2018) Optimization of lipase production in solid-state fermentation by Rhizopus arrhizus in nutrient medium containing agroindustrial wastes. The Open Biotechnology Journal 12, 189-203.

Doiron, J.A., Leblanc, L.M., Hébert, M.J., Levesque, N.A., Paré, A.F., Jean-François, J., Cormier, M., Surette, M.E., Touaibia, M. (2017) Structure-activity relationship of caffeic acid phenethyl ester analogs as new 5-lipoxygenase inhibitors. Chemical Biology \& Drug Design 89, 514-528.

Dorta, E., Lobo, M.G., González, M. (2012) Using drying treatments to stabilise mango peel and seed: Effect on antioxidant activity. LWT-Food Science and Technology 45, 261-268.

Dulf, F.V., Vodnar, D.C., Socaciu, C. (2016) Effects of solid-state fermentation with two filamentous fungi on the total phenolic contents, flavonoids, antioxidant activities and lipid fractions of plum fruit (Prunus domestica L.) by-products. Food Chemistry 209, 27-36.

Dwyer, K., Hosseinian, F., Rod, M.R. (2014) The market potential of grape waste alternatives. Journal of Food Research 3, 91-106.

Ekambaram, S.P., Perumal, S.S., Balakrishnan, A. (2016) Scope of hydrolysable tannins as possible antimicrobial agent. Phytotherapy Research 30, 1035-1045. 
Erdönmez, D., Rad, A.Y., Aksöz, N. (2018) Anti-quorum sensing potential of antioxidant quercetin and resveratrol. Brazilian Archives of Biology and Technology 61, e18160756.

Farag, R.S., Daw, Z.Y., Hewedi, F.M., El-Baroty, G.S.A. (1989) Antimicrobial activity of some Egyptian spice essential oils. Journal of Food Protection 52, 665-667.

Favela-Torres, E., Volke-Sepúlveda, T. Viniegra-González, G. (2006) Production of hydrolytic depolymerising pectinases. Food Technology \& Biotechnology 44, 221227.

Fawzi, E.M. (2010) Highly thermostable purified xylanase from Rhizomucor miehei NRRL 3169. Annals of Microbiology 60, 363-368.

Ferreira, J.A., Lennartsson, P.R., Edebo, L., Taherzadeh, M.J. (2013) Zygomycetes-based biorefinery: Present status and future prospects. Bioresource Technology 135, 523532.

Flemming H.C., Ridgway H. (2009) Biofilm Control: Conventional and Alternative Approaches. In: Flemming H.C., Murthy P.S., Venkatesan R., Cooksey K. (eds) Marine and Industrial Biofouling. Springer Series on Biofilms, vol 4. Springer, Berlin, Heidelberg, pp. 103-117.

Fratianni, F., Coppola, R., Nazzaro, F. (2011) Phenolic composition and antimicrobial and antiquorum sensing activity of an ethanolic extract of peels from the apple cultivar Annurca. Journal of Medicinal Food 14, 957-963.

Gadallah, M.G.E., Abdel Fattah, A.A. (2011) The antibacterial effect of mango seed kernel powder in minced beef during refrigerated storage. World Journal of Dairy \& Food Sciences 6, 219-228.

Galanakis, C.M. (2012) Recovery of high added-value components from food wastes: conventional, emerging technologies and commercialized applications. Trends in Food Science \& Technology 26, 68-87.

Gancel, A.L., Alter, P., Dhuique-Mayer, C., Ruales, J., Vaillant, F. (2008) Identifying carotenoids and phenolic compounds in naranjilla (Solanum quitoense Lam. var. Puyo hybrid), an Andean fruit. Journal of Agricultural and Food Chemistry 56, 11890-11899.

García-Ruiz, A., Moreno-Arribas, M.V., Martín-Álvarez, P.J., Bartolomé, B. (2011) Comparative study of the inhibitory effects of wine polyphenols on the growth of enological lactic acid bacteria. International Journal of Food Microbiology 145, 426-431. 
Gupta, C., Garg, A.P., Gupta, S. (2010) Antimicrobial and phytochemical studies of fresh ripe pulp and dried unripe pulp of Mangifera indica (AMCHUR). Middle-East Journal of Scientific Research 5, 75-80.

Gülçin, İ. (2010) Antioxidant properties of resveratrol: a structure-activity insight. Innovative Food Science \& Emerging Technologies 11, 210-218.

Gyawali, R., Ibrahim S.A. (2014) Natural products as antimicrobial agents. Food Control 46, 412-429.

Han, X., Shen, T., Lou, H. (2007) Dietary polyphenols and their biological significance. International Journal of Molecular Sciences 8, 950-988.

Harivaindaran, K.V., Rebecca, O.P.S., Chandran, S. (2008) Study of optimal temperature, $\mathrm{pH}$ and stability of dragon fruit (Hylocereus polyrhizus) peel for use as potential natural colorant. Pakistan Journal of Biological Sciences 11, 2259-2263.

Harman, D. (2006) Free radical theory of aging: An update - Increasing the functional life span. Annals of the New York Academy of Sciences 1067, 10-21.

He, F., Pan, Q.H., Shi, Y., Duan, C.Q. (2008) Biosynthesis and genetic regulation of proanthocyanidins in plants. Molecules 13, 2674-2703.

He, M., Du, M., Fan, M., Bian, Z. (2007) In vitro activity of eugenol against Candida albicans biofilms. Mycopathologia 163, 137-143.

Hendriks, A.T.W.M., Zeeman, G. (2009) Pretreatments to enhance the digestibility of lignocellulosic biomass. Bioresource Technology 100, 10-18.

Heras-Ramírez, M.E., Quintero-Ramos, A., Camacho-Dávila, A.A., Barnard, J., TalamásAbbud, R., Torres-Muñoz, J.V., Salas-Muñoz, E. (2012) Effect of blanching and drying temperature on polyphenolic compound stability and antioxidant capacity of apple pomace. Food and Bioprocess Technology 5, 2201-2210.

Hollands, W.J., Hart, D.J., Dainty, J.R., Hasselwander, O., Tiihonen, K., Wood, R., Kroon, P. A. (2013) Bioavailability of epicatechin and effects on nitric oxide metabolites of an apple flavanol-rich extract supplemented beverage compared to a whole apple puree: a randomized, placebo-controlled, crossover trial. Molecular Nutrition \& Food Research 57, 1209-1217.

Hong, Y.H., Jung, E.Y., Park, Y., Shin, K.S., Kim, T.Y., Yu, K.W., Chang, U.J., Suh, H.J. (2013) Enzymatic improvement in the polyphenol extractability and antioxidant activity of green tea extracts. Bioscience, Biotechnology, and Biochemistry 77, 2229. 
Iwai, K. (2008) Antidiabetic and antioxidant effects of polyphenols in brown alga Ecklonia stolonifera in genetically diabetic KK-Aymice. Plant Foods for Human Nutrition 63, 163-169.

Jaganath, I.B., Crozier, A. (2010) Dietary flavonoids and phenolic compounds. In: Fraga, C.G. (ed.) Plant phenolics and human health: biochemistry, nutrition, and pharmacology. John Wiley \& Sons, Inc., Hoboken, New Jersey, pp. 1-50.

Jahurul, M.H.A., Zaidul, I.S.M., Ghafoor, K., Al-Juhaimi, F.Y., Nyam, K.L., Norulaini, N.A.N., Sahena, F., Omar, A.M. (2015) Mango (Mangifera indica L.) by-products and their valuable components: A review. Food Chemistry 183, 173-180.

Jang, H.D., Yang, S.S. (2008) Polyunsaturated fatty acids production with a solid-state column reactor. Bioresource Technology 99, 6181-6189.

Jayaprakasha, G.K., Singh, R.P., Sakariah, K.K. (2001) Antioxidant activity of grape seed (Vitis vinifera) extracts on peroxidation models in vitro. Food Chemistry 73, 285290.

Johnston, K., Sharp, P., Clifford, M., Morgan, L. (2005) Dietary polyphenols decrease glucose uptake by human intestinal Caco-2 cells. FEBS Letters 579, 1653-1657.

Kalia, V.C. (2013) Quorum sensing inhibitors: an overview. Biotechnology Advances 31, 224-245.

Kallithraka, S., Garcia-Viguera, C., Bridle, P., Bakker, J. (1995) Survey of solvents for the extraction of grape seed phenolics. Phytochemical Analysis 6, 265-267.

Kalogeropoulos, N., Chiou, A., Pyriochou, V., Peristeraki, A., Karathanos, V.T. (2012) Bioactive phytochemicals in industrial tomatoes and their processing byproducts. LWT-Food Science and Technology 49, 213-216.

Kamboh, A.A., Arain, M.A., Mughal, M.J., Zaman, A., Arain, Z.M., Soomro, A.H. (2015) Flavonoids: Health promoting phytochemicals for animal production-A review. Journal of Animal Health and Production 3, 6-13.

Kammerer, D., Claus, A., Schieber, A., Carle, R. (2005) A novel process for the recovery of polyphenols from grape (Vitis vinifera L.) pomace. Journal of Food Science 70, C157-C163.

Kammerer, D.R., Kammerer, J., Valet, R., Carle, R. (2014) Recovery of polyphenols from the by-products of plant food processing and application as valuable food ingredients. Food Research International 65, 2-12.

Kang, N.J., Lee, K.W., Shin, B.J., Jung, S.K., Hwang, M.K., Bode, A.M., Heo, Y.S., Lee, H.J., Dong, Z. (2008) Caffeic acid, a phenolic phytochemical in coffee, directly 
inhibits Fyn kinase activity and UVB-induced COX-2 expression. Carcinogenesis 30, 321-330.

Kerekes, E.B., Deák, É., Takó, M., Tserennadmid, R., Petkovits, T., Vágvölgyi, C., Krisch, J. (2013) Anti-biofilm forming and anti-quorum sensing activity of selected essential oils and their main components on food-related micro-organisms. Journal of Applied Microbiology 115, 933-942.

Khanal, R.C., Howard, L.R., Prior, R.L. (2010) Effect of heating on the stability of grape and blueberry pomace procyanidins and total anthocyanins. Food Research International 43, 1464-1469.

Kim, H., Choi, H.K., Moon, J.Y., Kim, Y.S., Mosaddik, A., Cho, S.K. (2011) Comparative antioxidant and antiproliferative activities of red and white pitayas and their correlation with flavonoid and polyphenol content. Journal of Food Science 76, C38-C45.

King, J.C., Black, R.E., Doyle, M.P., Fritsche, K.L., Halbrook, B.H., Levander, O.A., Meydani, S.N., Walker, W.A., Woteki, C.E. (2000) Foodborne illnesses and nutritional status: a statement from an American Society for Nutritional Sciences Working Group. The Journal of Nutrition 130, 2613-2617.

Kozłowska, A., Szostak-Wegierek, D. (2014) Flavonoids - food sources and health benefits. Roczniki Państwowego Zakładu Higieny 65, 79-85.

Krisch, J., Bencsik, O., Papp, T., Vágvölgyi, C., Takó, M. (2012) Characterization of a $\beta$ glucosidase with transgalactosylation capacity from the zygomycete Rhizomucor miehei. Bioresource Technology 114, 555-560.

Krishna, C. (2005). Solid-State Fermentation Systems-An Overview. Critical Reviews in Biotechnology 25, 1-30.

Kruczek, M., Drygaś, B., Habryka, C. (2016) Pomace in fruit industry and their contemporary potential application. World Scientific News 48, 259-265.

Kumar, K., Yadav, A.N., Kumar, V., Vyas, P., Dhaliwal, H.S. (2017) Food waste: a potential bioresource for extraction of nutraceuticals and bioactive compounds. Bioresources and Bioprocessing 4, 18.

Kunradi Vieira, F.G., Da Silva Campelo Borges, G., Copetti, C., Da Valdemiro Gonzaga, L., Costa Nunes, E., Fett, R. (2009) Activity and contents of polyphenolic antioxidants in the whole fruit, flesh and peel of three apple cultivars. Archivos Latinoamericanos de Nutrición 59, 101-106. 
Landini, P., Antoniani, D., Burgess, J.G., Nijland, R. (2010) Molecular mechanisms of compounds affecting bacterial biofilm formation and dispersal. Applied Microbiology and Biotechnology 86, 813-823.

Laroze, L., Soto, C., Zúñiga, M.E. (2010) Phenolic antioxidants extraction from raspberry wastes assisted by-enzymes. Electronic Journal of Biotechnology 13, 12.

Laufenberg, G., Kunz. B., Nystroem M. (2003) Transformation of vegetable waste into value added products: (A) the upgrading concept; (B) practical implementations. Bioresource Technology 87, 167-198.

Le Bellec, F., Vaillant, F. (2011) Pitahaya (pitaya) (Hylocereus spp.). In: Yahia, E.M. (ed.) Postharvest biology and technology of tropical and subtropical fruits. Volume 4: Mangosteen to white sapote. Woodhead Publishing Limited, Cambridge, pp. 247271.

Le Bellec, F., Vaillant, F., Imbert, E. (2006) Pitahaya (Hylocereus spp.): a new fruit crop, a market with a future. Fruits 61, 237-250.

Lee, J.H., Kim, Y.G., Ryu, S.Y., Cho, M.H., Lee, J. (2014) Ginkgolic acids and Ginkgo biloba extract inhibit Escherichia coli O157: H7 and Staphylococcus aureus biofilm formation. International Journal of Food Microbiology 174, 47-55.

Lee, J.H., Regmi, S.C., Kim, J.A., Cho, M.H., Yun, H., Lee, C.S., Lee, J. (2011) Apple flavonoid phloretin inhibits Escherichia coli O157: H7 biofilm formation and ameliorates colon inflammation in rats. Infection and Immunity 79, 4819-4827.

Li, A.N., Li, S., Zhang, Y.J., Xu, X.R., Chen, Y.M., Li, H.B. (2014) Resources and biological activities of natural polyphenols. Nutrients 6, 6020-6047.

Li, S., Yang, X., Yang, S., Zhu, M., Wang, X. (2012) Technology prospecting on enzymes: application, marketing and engineering. Computational and Structural Biotechnology Journal 2, e201209017.

Lim, H.K., Tan, C.P., Karim, R., Ariffin, A.A., Bakar, J. (2010) Chemical composition and DSC thermal properties of two species of Hylocereus cacti seed oil: Hylocereus undatus and Hylocereus polyrhizus. Food Chemistry 119, 1326-1331.

Limoli, D.H., Jones, C.J., Wozniak, D.J. (2015) Bacterial extracellular polysaccharides in biofilm formation and function. Microbiology Spectrum 3, MB-0011-2014.

Lin, M.H., Chang, F.R., Hua, M.Y., Wu, Y.C., Liu, S.T. (2011) Inhibitory effects of 1,2,3,4,6-penta- $O$-galloyl- $\beta$-D-glucopyranose on biofilm formation by Staphylococcus aureus. Antimicrobial Agents and Chemotherapy 55, 1021-1027. 
Lizardi-Jiménez, M.A., Hernández-Martínez, R. (2017) Solid state fermentation (SSF): diversity of applications to valorize waste and biomass. 3 Biotech 7, 44 .

Lopes, L.A.A., dos Santos Rodrigues, J.B., Magnani, M., de Souza, E.L., de SiqueiraJúnior, J.P. (2017) Inhibitory effects of flavonoids on biofilm formation by Staphylococcus aureus that overexpresses efflux protein genes. Microbial Pathogenesis 107, 193-197.

López-Miranda, S., Serrano-Martínez, A., Hernández-Sánchez, P., Guardiola, L., PérezSánchez, H., Fortea, I., Gabaldón, J.A., Núñez-Delicado, E. (2016) Use of cyclodextrins to recover catechin and epicatechin from red grape pomace. Food Chemistry 203, 379-385.

Lu, Y., Yeap Foo, L. (1999) The polyphenol constituents of grape pomace. Food Chemistry 65, 1-8.

Luís, Â., Silva, F., Sousa, S., Duarte, A.P., Domingues, F. (2014) Antistaphylococcal and biofilm inhibitory activities of gallic, caffeic, and chlorogenic acids. Biofouling 30, 69-79.

Macé, S., Hansen, L.T., Rupasinghe, H.P.V. (2017) Anti-bacterial activity of phenolic compounds against Streptococcus pyogenes. Medicines 4, 25.

Madeira Junior, J.V., Teixeira, C.B., Macedo, G.A. (2015) Biotransformation and bioconversion of phenolic compounds obtainment: an overview. Critical Reviews in Biotechnology 35, 75-81.

Madrera, R.R., Bedriñana, R.P., Valles, B.S. (2015) Production and characterization of aroma compounds from apple pomace by solid-state fermentation with selected yeasts. LWT-Food Science and Technology 64, 1342-1353.

Mahattanatawee, K., Manthey, J.A., Luzio, G., Talcott, S.T., Goodner, K., Baldwin, E.A. (2006) Total antioxidant activity and fiber content of select Florida-grown tropical fruits. Journal of Agricultural and Food Chemistry 54, 7355-7363.

Maheshwari, R., Bharadwaj, G., Bhat, M.K. (2000) Thermophilic fungi: Their physiology and enzymes. Microbiology and Molecular Biology Reviews 64, 461-488.

Maier, T., Göppert, A., Kammerer, D., Schieber, A., Carle, R. (2008) Optimization of a process for enzyme-assisted pigment extraction from grape (Vitis vinifera L.) pomace. European Food Research and Technology 227, 267-275.

Makris, D.P., Boskou, G., Andrikopoulos, N.K. (2007) Polyphenolic content and in vitro antioxidant characteristics of wine industry and other agri-food solid waste extracts. Journal of Food Composition and Analysis 20, 125-132. 
Manach, C., Scalbert, A., Morand, C., Rémésy, C., Jiménez, L. (2004) Polyphenols: food sources and bioavailability. The American Journal of Clinical Nutrition 79, 727747.

Mandalari, G., Bennett, R.N., Bisignano, G., Trombetta, D., Saija, A., Faulds, C.B., Gasson, M.J., Narbad, A. (2007) Antimicrobial activity of flavonoids extracted from bergamot (Citrus bergamia Risso) peel, a byproduct of the essential oil industry. Journal of Applied Microbiology 103, 2056-2064.

Martins, S., Mussatto, S.I., Martínez-Avila, G., Montañez-Saenz, J., Aguilar, C.N., Teixeira, J.A. (2011) Bioactive phenolic compounds: production and extraction by solid-state fermentation. A review. Biotechnology Advances 29, 365-373.

Mendonça, E., Martins, A., Anselmo, A.M. (2004) Biodegradation of natural phenolic compounds as single and mixed substrates by Fusarium flocciferum. Electronic Journal of Biotechnology 7, 38-46.

Michalczyk, M., Macura, R., Matuszak, I. (2009) The effect of air-drying, freeze-drying and storage on the quality and antioxidant activity of some selected berries. Journal of Food Processing and Preservation 33, 11-21.

Morohoshi, T., Kato, M., Fukamachi, K., Kato, N, Ikeda, T. (2008) N-Acylhomoserine lactone regulates violacein production in Chromobacterium violaceum type strain ATCC 12472. FEMS Microbiology Letters 279, 124-130.

Moure, A., Cruz, J.M., Franco, D., Domínguez, J.M., Sineiro, J., Domínguez, H., Núñez, M.J., Parajó, J.C. (2001) Natural antioxidants from residual sources. Food Chemistry 72, 145-171.

Mushtaq, M., Sultana, B., Anwar, F., Adnan, A., Rizvi, S.S. (2015) Enzyme-assisted supercritical fluid extraction of phenolic antioxidants from pomegranate peel. The Journal of Supercritical Fluids 104, 122-131.

Naczk, M., Shahidi, F. (2004) Extraction and analysis of phenolics in food. Journal of Chromatography A 1054, 95-111.

Naczk, M., Shahidi, F. (2006) Phenolics in cereals, fruits and vegetables: Occurrence, extraction and analysis. Journal of Pharmaceutical and Biomedical Analysis 41, 1523-1542.

Nayak, B., Dahmoune, F., Moussi, K., Remini, H., Dairi, S., Aoun, O., Khodir, M. (2015) Comparison of microwave, ultrasound and accelerated-assisted solvent extraction for recovery of polyphenols from Citrus sinensis peels. Food Chemistry 187, 507516. 
Ngwoke, K.G., Odimegwu, D.C., Esimone, C.O. (2011) Antimicrobial natural products. In: Mendez-Vilas, A. (ed.) Science against microbial pathogens: communicating current research and technology advances. FORMATEX, Badajoz, 1011.

Nitiema, L.W., Savadogo, A., Simpore, J., Dianou, D., Traore, A.S. (2012) In vitro antimicrobial activity of some phenolic compounds (coumarin and quercetin) against gastroenteritis bacterial strains. International Journal of Microbiological Research 3, 183-187.

Niu, Y., Na, L., Feng, R., Gong, L., Zhao, Y., Li, Q., Li, Y., Sun, C. (2013) The phytochemical, EGCG, extends lifespan by reducing liver and kidney function damage and improving age-associated inflammation and oxidative stress in healthy rats. Aging Cell 12, 1041-1049.

Nurmahani, A., Osman, A., Abdul Hamid, F., Mohamad, G., Pak Dek, M.S. (2012) Antibacterial property of Hylocereus polyrhizus and Hylocereus undatus peel extracts. International Food Research Journal 19, 77-84.

Nurul, S.R., Asmah, R. (2014) Variability in nutritional composition and phytochemical properties of red pitaya (Hylocereus polyrhizus) from Malaysia and Australia. International Food Research Journal 21, 1689-1697.

Oliveira, D.A., Salvador, A.A., Smânia Jr, A., Smânia, E.F., Maraschin, M., Ferreira, S.R.S. (2013) Antimicrobial activity and composition profile of grape (Vitis vinifera) pomace extracts obtained by supercritical fluids. Journal of Biotechnology $164,423-432$.

Orallo, F., Alvarez, E., Camiña, M., Leiro, J.M., Gómez, E., Fernández, P. (2002) The possible implication of trans-resveratrol in the cardioprotective effects of long-term moderate wine consumption. Molecular Pharmacology 61, 294-302.

Orijajogun, J.O., Batari, L.M., Aguzue, O.C. (2014) Chemical composition and phytochemical properties of mango (Mangifera indica) seed kernel. International Journal of Advanced Chemistry 2, 185-187.

O’Shea, N., Arendt, E.K., Gallagher, E. (2012) Dietary fibre and phytochemical characteristics of fruit and vegetable by-products and their recent applications as novel ingredients in food products. Innovative Food Science \& Emerging Technologies 16, 1-10.

Oszmiański, J., Wojdyło, A., Kolniak, J. (2011) Effect of pectinase treatment on extraction of antioxidant phenols from pomace, for the production of puree-enriched cloudy apple juices. Food Chemistry 127, 623-631. 
Ouyang, J., Sun, F., Feng, W., Sun, Y., Qiu, X., Xiong, L., Liu, Y., Chen, Y. (2016) Quercetin is an effective inhibitor of quorum sensing, biofilm formation and virulence factors in Pseudomonas aeruginosa. Journal of Applied Microbiology 120, 966-974.

Özkan, G., Sagdiç, O., Göktürk Baydar, N., Kurumahmutoglu, Z. (2004) Antibacterial activities and total phenolic contents of grape pomace extracts. Journal of the Science of Food and Agriculture 84, 1807-1811.

Panche, A.N., Diwan, A.D., Chandra, S.R. (2016) Flavonoids: an overview. Journal of Nutritional Science 5, e47.

Pandey, K.B., Rizvi, S.I. (2009) Plant polyphenols as dietary antioxidants in human health and disease. Oxidative Medicine and Cellular Longevity 2, 270-278.

Papuc, C., Goran, G.V., Predescu, C.N., Nicorescu, V., Stefan, G. (2017) Plant polyphenols as antioxidant and antibacterial agents for shelf-life extension of meat and meat products: classification, structures, sources, and action mechanisms. Comprehensive Reviews in Food Science and Food Safety 16, 1243-1268.

Parmar, I., Rupasinghe, H.P.V. (2013) Bio-conversion of apple pomace into ethanol and acetic acid: enzymatic hydrolysis and fermentation. Bioresource Technology 130, 613-620.

Pastorkova, E., Zakova, T., Landa, P., Novakova, J., Vadlejch, J., Kokoska, L. (2013) Growth inhibitory effect of grape phenolics against wine spoilage yeasts and acetic acid bacteria. International Journal of Food Microbiology 161, 209-213.

Pereira, D.M., Valentão, P., Pereira, J.A., Andrade, P.B. (2009) Phenolics: From chemistry to biology. Molecules 14, 2202-2211.

Pirovani, M.E., Piagentini, A.M., Van de Velde, F. (2015) Bioactive compounds in freshcut fruits: Occurrence and impact of processing and cold storage. In: Gupta, V.K., Tuohy, M.G. (eds.) Biotechnology of bioactive compounds. Sources and applications. Wiley, pp. 37-62.

Plyuta, V., Zaitseva, J., Lobakova, E., Zagoskina, N., Kuznetsov, A., Khmel, I. (2013) Effect of plant phenolic compounds on biofilm formation by Pseudomonas aeruginosa. Acta Pathologica, Microbiologica et Immunologica Scandinavica 121, 1073-1081.

Porquet, D., Casadesús, G., Bayod, S., Vicente, A., Canudas, A.M., Vilaplana, J., Pelegrí, C., Sanfeliu, C., Camins, A., Pallàs, M., Del Valle, J. (2013) Dietary resveratrol 
prevents Alzheimer's markers and increases life span in SAMP8. Age 35, 18511865 .

Prabhakar, P.K., Prasad, R., Ali, S., Doble, M. (2013) Synergistic interaction of ferulic acid with commercial hypoglycemic drugs in streptozotocin induced diabetic rats. Phytomedicine 20, 488-494.

Pratiwi, S.U.T., Lagendijk, E.L., Hertiani, T., de Weert, S., Van Den Hondel, C.A.M.J.J. (2015) Antimicrobial effects of Indonesian medicinal plants extracts on planktonic and biofilm growth of Pseudomonas aeruginosa and Staphylococcus aureus. Journal of Horticulture 2, 119.

Priha, O., Virkajärvi, V., Juvonen, R., Puupponen-Pimiä, R., Nohynek, L., Alakurtti, S., Pirttimaa, M., Storgårds, E. (2014) Quorum sensing signalling and biofilm formation of brewery-derived bacteria, and inhibition of signalling by natural compounds. Current Microbiology 69, 617-627.

Puspita, M., Deniel, M., Widowati, I., Radjasa, O.K., Douzenel, P., Bedoux, G., Bourgougnon, N. (2017) Antioxidant and antibacterial activity of solid-liquid and enzyme-assisted extraction of phenolic compound from three species of tropical Sargassum. IOP Conference Series: Earth and Environmental Science 55, 012057.

Puupponen-Pimiä, R., Nohynek, L., Ammann, S., Oksman-Caldentey, K.M., Buchert, J. (2008) Enzyme-assisted processing increases antimicrobial and antioxidant activity of bilberry. Journal of Agricultural and Food Chemistry 56, 681-688.

Quiñones, M., Miguel, M., Aleixandre, A. (2012) Los polifenoles, compuestos de origen natural con efectos saludables sobre el sistema cardiovascular. Nutricion Hospitalaria 27, 76-89.

Raimbault, M. (1998) General and microbiological aspects of solid substrate fermentation. Electronic Journal of Biotechnology 1, 26-27.

Ramachandran, S., Roopesh, K., Nampoothiri, K.M., Szakacs, G., Pandey, A. (2005) Mixed substrate fermentation for the production of phytase by Rhizopus spp. using oilcakes as substrates. Process Biochemistry 40, 1749-1754.

Rao, M.B., Tanksale, A.M., Ghatge, M.S., Deshpande, V.V. (1998) Molecular and biotechnological aspects of microbial proteases. Microbiology and Molecular Biology Reviews 62, 597-635.

Rapisarda, P., Tomaino, A., Lo Cascio, R., Bonina, F., De Pasquale, A., Saija, A. (1999) Antioxidant effectiveness as influenced by phenolic content of fresh orange juices. Journal of Agricultural and Food Chemistry 47, 4718-4723. 
Rasamiravaka, T., Labtani, Q., Duez, P., El Jaziri, M. (2015) The formation of biofilms by Pseudomonas aeruginosa: a review of the natural and synthetic compounds interfering with control mechanisms. BioMed Research International 2015, 759348.

Ratnasooriya, C.C., Rupasinghe, H.V. (2012) Extraction of phenolic compounds from grapes and their pomace using $\beta$-cyclodextrin. Food Chemistry 134, 625-631.

Ratz-Łyko, A., Arct, J. (2015) Evaluation of antioxidant and antimicrobial properties of enzymatically hydrolysed Cucurbita pepo and Linum usitatissimum seedcakes. Food Science and Biotechnology 24, 1789-1796.

Ravagnan, G., De Filippis, A., Cartenì M., De Maria, S., Cozza, V., Petrazzuolo, M., Tufano, M.A., Donnarumma, G. (2013) Polydatin, a natural precursor of resveratrol, induces $\beta$-defensin production and reduces inflammatory response. Inflammation 36, 26-34.

Reinisalo, M., Kårlund, A., Koskela, A., Kaarniranta, K., Karjalainen, R.O. (2015) Polyphenol stilbenes: molecular mechanisms of defence against oxidative stress and aging-related diseases. Oxidative Medicine and Cellular Longevity 2015, 340520.

Rentzsch, M., Wilkens, A., Winterhalter, P. (2009) Non-flavonoid phenolic compounds. In: Moreno-Arribas, M.V., Polo, M.C. (eds) Wine chemistry and biochemistry. Springer, New York, pp. 509-521.

Rodrigues, R.C., Fernandez-Lafuente, R. (2010) Lipase from Rhizomисor miehei as an industrial biocatalyst in chemical process. Journal of Molecular Catalysis B: Enzymatic 64, 1-22.

Rodríguez Couto, S. (2008) Exploitation of biological wastes for the production of value-added products under solid-state fermentation conditions. Biotechnology Journal 3, 859-870.

Rodríguez Montealegre, R., Romero Peces, R., Chacón Vozmediano, J.L., Martínez Gascueña, J., García Romero, E. (2006) Phenolic compounds in skins and seeds of ten grape Vitis vinifera varieties grown in a warm climate. Journal of Food Composition and Analysis 19, 687-693.

Romero-Pérez, A.I., Ibern-Gómez, M., Lamuela-Raventós, R.M., De la Torre-Boronat, M.C. (1999) Piceid, the major resveratrol derivative in grape juices. Journal of Agricultural and Food Chemistry 47, 1533-1536. 
Sabel, A., Bredefeld, S., Schlander, M., Claus, H. (2017) Wine phenolic compounds: antimicrobial properties against yeasts, lactic acid and acetic acid bacteria. Beverages 3, 29.

Sadilova, E., Carle, R., Stintzing, F.C. (2007) Thermal degradation of anthocyanins and its impact on color and in vitro antioxidant capacity. Molecular Nutrition \& Food Research 51, 1461-1471.

Sagar, N.A., Pareek, S., Sharma, S., Yahia, E.M., Lobo, M.G. (2018) Fruit and vegetable waste: bioactive compounds, their extraction, and possible utilization. Comprehensive Reviews in Food Science and Food Safety 17, 512-531.

Salehi, B., Mishra, A., Nigam, M., Sener, B., Kilic, M., Sharifi-Rad, M., Fokou, P., Martins, N., Sharifi-Rad, J. (2018) Resveratrol: a double-edged sword in health benefits. Biomedicines 6, 91 .

Sandri, I.G., Fontana, R.C., Barfknecht, D.M., da Silveira, M.M. (2011) Clarification of fruit juices by fungal pectinases. LWT-Food Science and Technology 44, 22172222.

Santos, V.L., Linardi, V.R. (2004) Biodegradation of phenol by a filamentous fungi isolated from industrial effluents - identification and degradation potential. Process Biochemistry 39, 1001-1006.

Scalbert, A., Williamson, G. (2000) Dietary intake and bioavailability of polyphenols. The Journal of Nutrition 130, 2073S-2085S.

Schieber, A., Hilt, P., Streker, P., Endreß, H.U., Rentschler, C., Carle, R. (2003) A new process for the combined recovery of pectin and phenolic compounds from apple pomace. Innovative Food Science \& Emerging Technologies 4, 99-107.

Sethupathy, S., Ananthi, S., Selvaraj, A., Shanmuganathan, B., Vigneshwari, L., Balamurugan, K., Mahalingam, S., Pandian, S.K. (2017) Vanillic acid from Actinidia deliciosa impedes virulence in Serratia marcescens by affecting S-layer, flagellin and fatty acid biosynthesis proteins. Scientific Reports 7, 16328.

Shah, N.N.A.K., Rahman, R.A., Shamsuddin, R., Adzahan, N.M. (2015) Effects of pectinase clarification treatment on phenolic compounds of pummelo (Citrus grandis 1. Osbeck) fruit juice. Journal of Food Science and Technology 52, 50575065 .

Shahidi, F., Ambigaipalan, P. (2015) Phenolics and polyphenolics in foods, beverages and spices: Antioxidant activity and health effects - A review. Journal of Functional Foods 18, 820-897. 
Shahidi, F., Yeo, J. (2016) Insoluble-bound phenolics in food. Molecules 21, 1216.

Shen, X., Sun, X., Xie, Q., Liu, H., Zhao, Y., Pan, Y., Hwang, C.A., Wu, V.C. (2014) Antimicrobial effect of blueberry (Vaccinium corymbosum L.) extracts against the growth of Listeria monocytogenes and Salmonella Enteritidis. Food Control 35, 159-165.

Sheng, L., Olsen, S.A., Hu, J., Yue, W., Means, W.J., Zhu, M.J. (2016) Inhibitory effects of grape seed extract on growth, quorum sensing, and virulence factors of CDC "top-six" non-O157 Shiga toxin producing E. coli. International Journal of Food Microbiology 229, 24-32.

Shikongo-Nambabi, M., Shoolongela, A., Schneider, M.B. (2011) Control of bacterial contamination during marine fish processing. Journal of Biology and Life Science $3,1-17$.

Shojaosadati, S.A., Babaeipour, V. (2002) Citric acid production from apple pomace in multi-layer packed bed solid-state bioreactor. Process Biochemistry 37, 909-914.

Silva, L.N., Zimmer, K.R., Macedo, A.J., Trentin, D.S. (2016) Plant natural products targeting bacterial virulence factors. Chemical Reviews 116, 9162-9236.

Singh nee' Nigam P., Pandey A. (2009) Solid-state fermentation technology for bioconversion of biomass and agricultural residues. In: Singh nee' Nigam, P., Pandey, A. (eds) Biotechnology for agro-industrial residues utilisation. Springer, Dordrecht, pp. 197-221.

Singhania, R.R., Sukumaran, R.K., Pandey, A. (2007) Improved cellulase production by Trichoderma reesei RUT C30 under SSF through process optimization. Applied Biochemistry and Biotechnology 142, 60-70.

Slobodníková, L., Fialová, S., Hupková, H., Grančai, D. (2013) Rosmarinic acid interaction with planktonic and biofilm Staphylococcus aureus. Natural Product Communications 8, 1747-1750.

Slobodníková, L., Fialová, S., Rendeková, K., Kováč, J., Mučaji, P. (2016) Antibiofilm activity of plant polyphenols. Molecules 21, 1717.

Socaci, S.A., Fărcaş, A.C., Vodnar, D.C., Tofană, M. (2017) Food wastes as valuable sources of bioactive molecules. In: Waisundara, V., Shiomi, N. (eds.) Superfood and functional food - The development of superfoods and their roles as medicine. IntechOpen, London, pp. 75-93. 
Sogi, D.S., Siddiq, M., Greiby, I., Dolan, K.D. (2013) Total phenolics, antioxidant activity, and functional properties of "Tommy Atkins" mango peel and kernel as affected by drying methods. Food Chemistry 141, 2649-2655.

Song, H., Zheng, Z., Wu, J., Lai, J., Chu, Q., Zheng, X. (2016) White pitaya (Hylocereus undatus) juice attenuates insulin resistance and hepatic steatosis in diet-induced obese mice. PloS One 11, e0149670.

Soobrattee, M.A., Neergheen, V.S., Luximon-Ramma, A., Aruoma, O.I., Bahorun, T. (2005) Phenolics as potential antioxidant therapeutic agents: mechanism and actions. Mutation Research/Fundamental and Molecular Mechanisms of Mutagenesis 579, 200-213.

Soto-Maldonado, C., Zúñiga-Hansen, M.E. (2018) Enzyme-assisted extraction of phenolic compounds. In: Dominguez González, H., González Muñoz, M.J. (eds.) Water extraction of bioactive compounds. Elsevier Inc., Amsterdam, pp. 369-384.

Souquet, J.M., Labarbe, B., Le Guernevé, C., Cheynier, V., Moutounet, M. (2000) Phenolic composition of grape stems. Journal of Agricultural and Food Chemistry 48, 1076-1080.

Srivastava, N., Rathour, R., Jha, S., Pandey, K., Srivastava, M., Thakur, V.K., Sengar, R.S., Gupta, V.K., Mazumder, P.B., Khan, A.F., Mishra, P.K. (2019) Microbial beta glucosidase enzymes: recent advances in biomass conversation for biofuels application. Biomolecules 9, 220.

Stojković, D., Petrović, J., Soković, M., Glamočlija, J., Kukić-Marković, J., Petrović, S. (2013) In situ antioxidant and antimicrobial activities of naturally occurring caffeic acid, p-coumaric acid and rutin, using food systems. Journal of the Science of Food and Agriculture 93, 3205-3208.

Strlič, M., Radovič, T., Kolar, J., Pihlar, B. (2002) Anti-and prooxidative properties of gallic acid in fenton-type systems. Journal of Agricultural and Food Chemistry 50, 6313-6317.

Sumantha, A., Sandhya, C., Szakacs, G., Soccol, C.R., Pandey, A. (2005) Production and partial purification of a neutral metalloprotease by fungal mixed substrate fermentation. Food Technology and Biotechnology 43, 313-319.

Sun, B. Spranger, M.I. (2005) Review: Quantitative extraction and analysis of grape and wine proanthocyanidin and stilbenes. Ciência e Técnica Vitivinícola 20, 59-89. 
Takó, M., Farkas, E., Lung, S., Krisch, J., Vágvölgyi, C., Papp, T. (2010) Identification of acid-and thermotolerant extracellular $\beta$-glucosidase activities in Zygomycetes fungi. Acta Biologica Hungarica 61, 101-110.

Takó, M., Kotogán, A., Krisch, J., Vágvölgyi, C., Mondal, K.C., Papp, T. (2015) Enhanced production of industrial enzymes in Mucoromycotina fungi during solid-state fermentation of agricultural wastes/by-products. Acta Biologica Hungarica 66, 348360.

Takó, M., Kotogán, A., Papp, T., Kadaikunnan, S., Alharbi, N.S., Vágvölgyi, C. (2017) Purification and properties of extracellular lipases with transesterification activity and 1,3-regioselectivity from Rhizomucor miehei and Rhizopus oryzae. Journal of Microbiology and Biotechnology 27, 277-288.

Teixeira, A., Baenas, N., Dominguez-Perles, R., Barros, A., Rosa, E., Moreno, D.A., Garcia-Viguera, C. (2014) Natural bioactive compounds from winery by-products as health promoters: a review. International Journal of Molecular Sciences 15, $15638-15678$.

Tengerdy, R.P. (1998) Solid substrate fermentation for enzyme production. In: Pandey, A. (ed.) Advances in Biotechnology. Educational Publishers and Distributors, New Delhi, p. 13.

Tenore, G.C., Novellino, E., Basile, A. (2012) Nutraceutical potential and antioxidant benefits of red pitaya (Hylocereus polyrhizus) extracts. Journal of Functional Foods 4, 129-136.

Tomiyama, K., Mukai, Y., Saito, M., Watanabe, K., Kumada, H., Nihei, T., Hamada, N., Teranaka, T. (2016) Antibacterial action of a condensed tannin extracted from astringent persimmon as a component of food addictive pancil PS-M on oral polymicrobial biofilms. BioMed Research International 2016, 5730748.

Tsao, R., Yang, R., Xie, S., Sockovie, E., Khanizadeh, S. (2005) Which polyphenolic compounds contribute to the total antioxidant activities of apple? Journal of Agricultural and Food Chemistry 53, 4989-4995.

Tseng, A., Zhao, Y. (2012) Effect of different drying methods and storage time on the retention of bioactive compounds and antibacterial activity of wine grape pomace (Pinot Noir and Merlot). Journal of Food Science 77, H192-H201.

Tsuchiya, K., Nagashima, T., Yamamoto, Y., Gomi, K., Kitamoto, K., Kumagai, C., Tamura, G. (1994) High level secretion of calf chymosin using a glucoamylase- 
prochymosin fusion gene in Aspergillus oryzae. Bioscience, Biotechnology, and Biochemistry 58, 895-899.

Ultee, A., Bennik, M.H.J., Moezelaar, R. (2002) The phenolic hydroxyl group of carvacrol is essential for action against the food-borne pathogen Bacillus cereus. Applied and Environmental Microbiology 68, 1561-1568.

Vaillant, F., Perez, A., Dornier, M., Reynes, M. (2005) Colorant and antioxidant properties of red-purple pitahaya (Hylocereus sp.). Fruits 60, 3-12.

Vandenberghe, L.P., Soccol, C.R., Pandey, A., Lebeault, J.M. (2000) Solid-state fermentation for the synthesis of citric acid by Aspergillus niger. Bioresource Technology 74, 175-178.

Vandeputte, O.M., Kiendrebeogo, M., Rajaonson, S., Diallo, B., Mol, A., El Jaziri, M., Baucher, M. (2010) Identification of catechin as one of the flavonoids from Combretum albiflorum bark extract that reduces the production of quorum-sensingcontrolled virulence factors in Pseudomonas aeruginosa PAO1. Applied and Environmental Microbiology 76, 243-253.

Vandeputte, O.M., Kiendrebeogo, M., Rasamiravaka, T., Stevigny, C., Duez, P., Rajaonson, S., Diallo, B., Mol, A., Baucher, M., El Jaziri, M. (2011) The flavanone naringenin reduces the production of quorum sensing-controlled virulence factors in Pseudomonas aeruginosa PAO1. Microbiology 157, 2120-2132.

Vasco, C., Ruales, J., Kamal-Eldin, A. (2008) Total phenolic compounds and antioxidant capacities of major fruits from Ecuador. Food Chemistry 111, 816-823.

Vashisth, T., Singh, R.K., Pegg, R.B. (2011) Effects of drying on the phenolics content and antioxidant activity of muscadine pomace. LWT-Food Science and Technology 44, 1649-1657.

Vattem, D.A., Lin, Y.T., Labbe, R.G., Shetty, K. (2004) Phenolic antioxidant mobilization in cranberry pomace by solid-state bioprocessing using food grade fungus Lentinus edodes and effect on antimicrobial activity against select food borne pathogens. Innovative Food Science and Emerging Technologies 5, 81-91.

Vattem, D.A., Mihalik, K., Crixell, S.H., McLean, R.J.C. (2007) Dietary phytochemicals as quorum sensing inhibitors. Fitoterapia 78, 302-310.

Vikram, A., Jayaprakasha, G.K., Jesudhasan, P.R., Pillai, S.D., Patil, B.S. (2010) Suppression of bacterial cell-cell signalling, biofilm formation and type III secretion system by citrus flavonoids. Journal of Applied Microbiology 109, 515527. 
Viswanathan, P., Rathinam P., Suneeva, S.C. (2015) Plant quorum sensing inhibitors: food, medicinal plants, and others. In: Kalia, V.C. (ed) Quorum sensing vs quorum quenching: a battle with no end in sight. Springer India, New Delhi, pp. 269-281.

Wang, L., Weller, C.L. (2006) Recent advances in extraction of nutraceuticals from plants. Trends in Food Science \& Technology 17, 300-312.

Watkins, C.B., Liu, R.H. (2011) Pome fruit. In: Terry, L.A. (ed) Health-promoting properties of fruits and vegetables. CABI International, Wallingford, pp. 196-217.

Will, F., Bauckhage, K., Dietrich, H. (2000) Apple pomace liquefaction with pectinases and cellulases: analytical data of the corresponding juices. European Food Research and Technology 211, 291-297.

Wolfe, K.L., Liu, R.H. (2003) Apple peels as a value-added food ingredient. Journal of Agricultural and Food Chemistry 51, 1676-1683.

Wu, L.C., Hsu, H.W., Chen, Y.C., Chiu, C.C., Lin, Y.I., Ho, J.A.A. (2006) Antioxidant and antiproliferative activities of red pitaya. Food Chemistry 95, 319-327.

Xia, E.Q., Deng, G.F., Guo, Y.J., Li, H.B. (2010) Biological activities of polyphenols from grapes. International Journal of Molecular Sciences 11, 622-646.

Ximenes, E., Kim, Y., Mosier, N., Dien, B., Ladisch, M. (2010) Inhibition of cellulases by phenols. Enzyme and Microbial Technology 46, 170-176.

Xu, C., Yagiz, Y., Borejsza-Wysocki, W., Lu, J., Gu, L., Ramírez-Rodrigues, M.M., Marshall, M.R. (2014) Enzyme release of phenolics from muscadine grape (Vitis rotundifolia Michx.) skins and seeds. Food Chemistry 157, 20-29.

Xu, Y., Burton, S., Kim, C., Sismour, E. (2016) Phenolic compounds, antioxidant, and antibacterial properties of pomace extracts from four Virginia-grown grape varieties. Food Science \& Nutrition 4, 125-133.

Xue, J., Davidson, P.M., Zhong, Q. (2013) Thymol nanoemulsified by whey proteinmaltodextrin conjugates: the enhanced emulsifying capacity and antilisterial properties in milk by propylene glycol. Journal of Agricultural and Food Chemistry 61, 12720-12726.

Yadav, D., Kumar, A., Kumar, P., Mishra, D. (2015) Antimicrobial properties of black grape (Vitis vinifera L.) peel extracts against antibiotic-resistant pathogenic bacteria and toxin producing molds. Indian Journal of Pharmacology 47, 663-667.

Yadegary, M., Hamidi, A., Alavi, S.A., Khodaverdi, E., Yahaghi, H., Sattari, S., Bagherpour, G., Yahaghi, E. (2013) Citric acid production from sugarcane bagasse through solid state fermentation method using Aspergillus niger mold and 
optimization of citric acid production by Taguchi method. Jundishapur Journal of Microbiology 6, e7625.

Ye, M., Yue, T., Yuan, Y. (2014) Evolution of polyphenols and organic acids during the fermentation of apple cider. Journal of the Science of Food and Agriculture 94, 2951-2957.

Yong, Y.Y., Dykes, G., Lee, S.M., Choo, W.S. (2017) Comparative study of betacyanin profile and antimicrobial activity of red pitahaya (Hylocereus polyrhizus) and red spinach (Amaranthus dubius). Plant Foods for Human Nutrition 72, 41-47.

Yong, Y.Y., Dykes, G., Lee, S.M., Choo, W.S. (2018) Effect of refrigerated storage on betacyanin composition, antibacterial activity of red pitahaya (Hylocereus polyrhizus) and cytotoxicity evaluation of betacyanin rich extract on normal human cell lines. LWT-Food Science and Technology 91, 491-497.

Yu, J., Ahmedna, M. (2013) Functional components of grape pomace: their composition, biological properties and potential applications. International Journal of Food Science and Technology 48, 221-237.

Zhang, S., Gao, X., He, L., Qiu, Y., Zhu, H., Cao, Y. (2015) Novel trends for use of microbial tannases. Preparative Biochemistry and Biotechnology 45, 221-232.

Zhang, T., Wei, X., Miao, Z., Hassan, H., Song, Y., Fan, M. (2016) Screening for antioxidant and antibacterial activities of phenolics from Golden Delicious apple pomace. Chemistry Central Journal 10, 47.

Zheng, Z., Shetty, K. (2000) Solid-state bioconversion of phenolics from cranberry pomace and role of Lentinus edodes $\beta$-glucosidase. Journal of Agricultural and Food Chemistry 48, 895-900. 


\section{ACKNOWLEDGEMENTS}

The research project presented was conducted at the Department of Microbiology, University of Szeged.

I would like to thank Prof. Dr. Csaba Vágvölgyi that I could become a part in his team and for the opportunity to carry out the project research at the Department.

I thank to my supervisors, Dr. Judit Krisch and Dr. Miklós Takó, for being my inspiration and guide at all times and sharing with me their knowledge, theoretical and practical expertise that contributed deeply to my professional development.

I thank Dr. Ottó Bencsik and Dr. András Szekeres for their important contribution in the HPLC studies, and Prof. Dr. Tamás Papp for his valuable contribution in reviewing the publications associated with this research. I thank Dr. Alexandra Kotogán, Dr. Erika Beáta Kerekes, Elvira Nacsa-Farkas, Dr. Liliána Tóth, Dr. Anita Vidács and Anikó Fehér for their training and help in the execution of experiments.

I thank all the teachers and administrative staff for helping me at the different stages of my academic development and research by providing in addition to knowledge, tools, and advice for achieving my goal.

I thank my colleagues throughout the department for welcoming me warmly, for their help whenever I need it and above all because of their friendship.

I thank my family and friends who supported me unconditionally, especially my mother and sister for believing in me and their encouragement words; to my husband for accompanying me and waiting for me during this long process, though that meant being away from home.

I thank Tempus Foundation for Stipendium Hungaricum Scholarship Programme that made this project and my big dream possible. 


\section{APPENDICES}

Appendix 1. Correlation coefficients (Pearson $r$ ) between the antimicrobial activity against different pathogens and total phenolic content of oven-dried and lyophilized black grape, apple and pitahaya extracts after enzyme treatments.

\begin{tabular}{|c|c|c|c|c|c|c|c|c|c|}
\hline Fruit residues & B. subtilis & B. cereus & L. monocytogenes & S. aureus & MRSA & E. coli & S. enterica & P. putida & P. aeruginosa \\
\hline \multicolumn{10}{|l|}{ Black grape } \\
\hline Oven-dried & -0.291 & -0.369 & 0.974 & -0.180 & -0.180 & 0.571 & 0.998 & 0.453 & -0.291 \\
\hline Lyophilized & 0.922 & 0.597 & -0.796 & 0.992 & 0.778 & 0.960 & -0.239 & 0.387 & -0.387 \\
\hline \multicolumn{10}{|l|}{ White grape } \\
\hline Oven-dried & 0.291 & 0.978 & -0.974 & 0.010 & -0.179 & -0.897 & -0.703 & 0.984 & 0.626 \\
\hline Lyophilized & -0.284 & 0.972 & 0.234 & 0.006 & 0.284 & 0.006 & 0.460 & -0.284 & 0.972 \\
\hline \multicolumn{10}{|l|}{ Apple } \\
\hline Oven-dried & -0.720 & 0.906 & 0.819 & 0.906 & 0.888 & 0.962 & 0.087 & 0.639 & 0.906 \\
\hline Lyophilized & 0.687 & -0.584 & 0.996 & 0.746 & 0.961 & 0.746 & 0.276 & 0.907 & 0.411 \\
\hline \multicolumn{10}{|l|}{ Pitahaya } \\
\hline Oven-dried & -0.999 & 0.584 & -0.411 & 0.861 & 0.584 & 0.887 & -0.231 & -0.231 & 0.985 \\
\hline Lyophilized & 0.385 & 0.607 & 0.385 & 0.385 & -0.607 & 0.385 & 0.061 & -0.607 & 0.385 \\
\hline \multicolumn{10}{|l|}{ Mango } \\
\hline Oven-dried & 0.982 & 0.827 & 0.312 & 0.329 & $\mathrm{NT}^{*}$ & 0.827 & 0.827 & 0.827 & -0.073 \\
\hline \multicolumn{10}{|l|}{ Naranjilla } \\
\hline Oven-dried & -1 & -1 & NT & 1 & NT & NT & NT & NT & NI \\
\hline Lyophilized & 1 & -1 & NT & NT & 1 & -1 & -1 & NT & NI \\
\hline
\end{tabular}

* not tested. Neither the control nor the treated sample showed antimicrobial activity. 
Appendix 2. Minimum bactericidal concentration (MBC) of fruit residue extracts against foodborne pathogenic and spoilage bacteria before and after treatment with $R$. miehei cellulase and/or A. niger pectinase.

\begin{tabular}{|c|c|c|c|c|c|c|c|c|c|c|}
\hline \multirow{2}{*}{ Fruit residues } & & \multicolumn{9}{|c|}{$\mathrm{MBC}(\mathrm{mg} / \mathrm{mL})$} \\
\hline & & B. subtilis & B. cereus & L. monocytogenes & S. aureus & MRSA & E. coli & S. enterica & P. putida & P. aeruginosa \\
\hline \multicolumn{11}{|l|}{ Black grape } \\
\hline \multirow[t]{4}{*}{ Oven-dried } & Enzyme-free & $>100$ & $>100$ & $>100$ & $>100$ & $>100$ & $>100$ & $>100$ & 100 & 100 \\
\hline & Cellulase & $>100$ & $>100$ & 100 & 100 & 100 & 100 & 100 & 100 & 100 \\
\hline & Pectinase & $>100$ & $\mathrm{NT}^{*}$ & $>100$ & 100 & 100 & 100 & NT & 100 & 100 \\
\hline & Cellulase + Pectinase & $>100$ & $>100$ & 50 & 100 & 100 & 100 & $>100$ & 100 & $>100$ \\
\hline \multirow[t]{4}{*}{ Lyophilized } & Enzyme-free & $>100$ & $>100$ & $>100$ & 100 & $>100$ & $>100$ & $>100$ & 100 & 100 \\
\hline & Cellulase & $>100$ & $>100$ & NT & 50 & 100 & 100 & 100 & $>100$ & 100 \\
\hline & Pectinase & $>100$ & $>100$ & $>100$ & 100 & $>100$ & $>100$ & 100 & 100 & 100 \\
\hline & Cellulase + Pectinase & $>100$ & $>100$ & $>100$ & 100 & 100 & 100 & 100 & 100 & $>100$ \\
\hline \multicolumn{11}{|l|}{ White grape } \\
\hline \multirow{5}{*}{ Oven-dried } & Enzyme-free & $>100$ & $>100$ & 100 & 100 & $>100$ & 100 & 100 & 100 & 100 \\
\hline & Cellulase & $>100$ & $>100$ & $>100$ & 100 & 100 & 100 & 100 & 100 & 100 \\
\hline & Pectinase & $>100$ & $>100$ & $>100$ & $>100$ & $>100$ & $>100$ & $>100$ & $>100$ & $>100$ \\
\hline & Cellulase + Pectinase & $>100$ & $>100$ & $>100$ & $>100$ & $>100$ & $>100$ & $>100$ & $>100$ & $>100$ \\
\hline & Enzyme-free & $>100$ & $>100$ & 100 & 100 & $>100$ & $>100$ & 100 & $>100$ & $>100$ \\
\hline \multirow{3}{*}{ Lyophilized } & Cellulase & $>100$ & $>100$ & 100 & 100 & $>100$ & $>100$ & $>100$ & $>100$ & $>100$ \\
\hline & Pectinase & $>100$ & $>100$ & 100 & 100 & 100 & 100 & 100 & 100 & 100 \\
\hline & Cellulase + Pectinase & $>100$ & $>100$ & $>100$ & $>100$ & $>100$ & $>100$ & $>100$ & $>100$ & $>100$ \\
\hline \multicolumn{11}{|l|}{ Apple } \\
\hline \multirow[t]{4}{*}{ Oven-dried } & Enzyme-free & $>100$ & $>100$ & NT & $>100$ & NT & NT & NT & $>100$ & $>100$ \\
\hline & Cellulase & $>100$ & $>100$ & NT & $>100$ & $>100$ & $>100$ & NT & 100 & $>100$ \\
\hline & Pectinase & $>100$ & $>100$ & $>100$ & $>100$ & NT & $>100$ & $>100$ & 100 & 100 \\
\hline & Cellulase + Pectinase & $>100$ & $>100$ & NT & $>100$ & $>100$ & $>100$ & NT & $>100$ & $>100$ \\
\hline \multirow[t]{4}{*}{ Lyophilized } & Enzyme-free & $>100$ & $>100$ & $>100$ & NT & NT & NT & NT & $>100$ & $>100$ \\
\hline & Cellulase & $>100$ & $>100$ & NT & 100 & $>100$ & NT & $>100$ & $>100$ & $>100$ \\
\hline & Pectinase & $>100$ & $>100$ & $>100$ & $>100$ & NT & NT & $>100$ & 100 & 100 \\
\hline & Cellulase + Pectinase & $>100$ & $>100$ & $>100$ & 100 & $>100$ & $>100$ & 100 & $>100$ & $>100$ \\
\hline
\end{tabular}


Appendix 2. Continued.

\begin{tabular}{|c|c|c|c|c|c|c|c|c|c|c|}
\hline \multirow{2}{*}{ Fruit residues } & & \multicolumn{9}{|c|}{$\mathrm{MBC}(\mathrm{mg} / \mathrm{mL})$} \\
\hline & & B. subtilis & B. cereus & L. monocytogenes & S. aureus & MRSA & E. coli & S. enterica & P. putida & P. aeruginosa \\
\hline \multicolumn{11}{|l|}{ Pitahaya } \\
\hline \multirow{4}{*}{ Oven-dried } & Enzyme-free & $>100$ & $>100$ & $>100$ & $>100$ & NT & $>100$ & $>100$ & 100 & $>100$ \\
\hline & Cellulase & $>100$ & $>100$ & NT & $>100$ & $>100$ & $\mathrm{NT}$ & $>100$ & $>100$ & $>100$ \\
\hline & Pectinase & $>100$ & $>100$ & $>100$ & $>100$ & NT & NT & $>100$ & 100 & 100 \\
\hline & Cellulase + Pectinase & $>100$ & $>100$ & $>100$ & 100 & NT & 100 & $>100$ & 100 & 100 \\
\hline \multirow[t]{4}{*}{ Lyophilized } & Enzyme-free & $>100$ & $>100$ & $>100$ & $>100$ & $>100$ & $>100$ & $>100$ & $>100$ & $>100$ \\
\hline & Cellulase & $>100$ & $>100$ & $>100$ & NT & $>100$ & NT & 100 & 100 & 100 \\
\hline & Pectinase & $>100$ & $>100$ & $>100$ & $>100$ & $>100$ & $>100$ & $>100$ & 100 & 100 \\
\hline & Cellulase + Pectinase & $>100$ & $>100$ & $>100$ & $>100$ & $>100$ & 100 & 100 & 100 & 100 \\
\hline \multicolumn{11}{|l|}{ Mango } \\
\hline \multirow{4}{*}{ Oven-dried } & Enzyme-free & 100 & 100 & $>100$ & $>100$ & $>100$ & $>100$ & $>100$ & $>100$ & $>100$ \\
\hline & Cellulase & 100 & 100 & $>100$ & $>100$ & $>100$ & $>100$ & 100 & $>100$ & 100 \\
\hline & Pectinase & 100 & 100 & $>100$ & 100 & 100 & 100 & 100 & 100 & 100 \\
\hline & Cellulase + Pectinase & 100 & 100 & $>100$ & 100 & $>100$ & $>100$ & 100 & 100 & 100 \\
\hline \multicolumn{11}{|l|}{ Naranjilla } \\
\hline \multirow{2}{*}{ Oven-dried } & Enzyme-free & NT & $>100$ & NT & NT & NT & NT & NT & NT & $>100$ \\
\hline & Cellulase & $>100$ & NT & NT & $>100$ & $>100$ & $>100$ & $>100$ & $>100$ & $>100$ \\
\hline \multirow{2}{*}{ Lyophilized } & Enzyme-free & NT & NT & NT & NT & NT & $>100$ & NT & NT & NT \\
\hline & Cellulase & $>100$ & $>100$ & $>100$ & $>100$ & $>100$ & $>100$ & $>100$ & $>100$ & $>100$ \\
\hline
\end{tabular}


Appendix 3. Correlation coefficients (Pearson $r$ ) between violacein production inhibitory activity and syringic acid, vanillic acid, (+)-catechin and resveratrol content of oven-dried and lyophilized black grape, apple and pitahaya extracts after enzyme treatments.

\begin{tabular}{rllll}
\hline Fruit residues & Syringic acid & Vanillic acid & (+)-Catechin & Resveratrol \\
\hline Black grape & & & & \\
Oven-dried & 0.951 & 0.933 & 0.463 & n.d.* \\
Lyophilized & 0.878 & 0.906 & 0.923 & 0.874 \\
Apple & & & & \\
Oven-dried & -0.974 & -0.919 & -0.820 & -0.215 \\
Lyophilized & 0.981 & 0.848 & 0.193 & 0.117 \\
Pitahaya & & & & \\
Oven-dried & 0.923 & 0.991 & -0.958 & -0.793 \\
Lyophilized & -0.574 & -0.337 & n.d. & -0.352 \\
\hline$*$ no data & & & &
\end{tabular}




\section{PUBLICATIONS UNDERLYING THE THESIS}

\section{Full papers}

Zambrano, C., Kerekes, E.B., Kotogán, A., Papp, T., Vágvölgyi, Cs., Krisch, J., Takó, M. (2019) Antimicrobial activity of grape, apple and pitahaya residue extracts after carbohydrase treatment against food-related bacteria. LWT-Food Science and Technology $100,416-425$.

Zambrano, C., Kotogán, A., Bencsik, O., Papp, T., Vágvölgyi, Cs., Mondal, K.C., Krisch, J., Takó, M. (2018) Mobilization of phenolic antioxidants from grape, apple and pitahaya residues via solid state fungal fermentation and carbohydrase treatment. LWT-Food Science and Technology 89, 457-465.

\section{Book chapter}

Takó, M., Zambrano, C., Kotogán, A., Kerekes, E.B., Papp, T., Krisch, J., Vágvölgyi, Cs. (2019) Fermentative and enzyme-assisted production of phenolic antioxidants from plant residues. In: Thatoi, H.N., Das Mohapatra, P.K., Mondal, K.C., Mohapatra, S. (eds.) Microbial Fermentation and Enzyme Technology. Boca Raton (FL), USA: CRC Press Taylor and Francis Group, Paper: Chapter 12 (accepted, in press)

\section{Abstracts}

Takó, M., Zambrano, C., Kotogán, A., Kerekes, E.B., Bencsik, O., Szekeres, A., Papp, T., Vágvölgyi, Cs., Krisch, J. (2018) Carbohydrase-assisted extraction of bioactive phenolic compounds from fruit residues. In: A Magyar Mikrobiológiai Társaság 2018. évi Nagygyülése és a XIII. Fermentációs Kollokvium: Absztraktfüzet. pp. 63-64.

Zambrano, C., Kerekes, E.B., Kotogán, A., Bencsik, O., Szekeres, A., Vágvölgyi, Cs., Papp, T., Krisch, J., Takó, M. (2018) Production of bioactive phenolic compounds from mango residues. In: Monostori, T. (ed.) 16th Wellmann International Scientific Conference: Book of Abstracts. pp. 102-103. 
Zambrano, C., Kovács, F., Kotogán, A., Papp, T., Mondal, K.C., Hargitai, F., Vágvölgyi, Cs., Krisch, J., Takó, M. (2017) Phenolic antioxidant mobilization in black grape, apple and dragon fruit residues by enzymatic treatment using a cellulolytic cocktail from Rhizomucor miehei. In: 7th Congress of European Microbiologists (FEMS 2017) p. 1327.

Zambrano, C., Kerekes, E.B., Kotogán, A., Bencsik, O., Mondal, K.C., Vágvölgyi, Cs., Papp, T., Takó, M., Krisch, J. (2017) Production of bioactive phenolic compounds from fruit residues by carbohydrase enzymes. Mikológiai Közlemények-Clusiana 56:1 pp. 1618.

Zambrano, C., Kotogán, A., Kerekes, E., Vágvölgyi, Cs., Krisch, J., Takó, M. (2017) Effect of carbohydrate hydrolyzing enzyme treatment on the antioxidant and antimicrobial activity of fruit pomace extracts. In: 19th Danube-Kris-Mures-Tisa (DKMT) Euroregional Conference on Environment and Health: Program and abstracts. p. 34.

Takó, M., Zambrano, C., Kotogán, A., Krisch, J., Papp, T., Mondal, K.C., Vágvölgyi, Cs. (2016) Solid-state fermentation of dragon fruit residues to produce phenolic antioxidants using Rhizomucor miehei. In: Škrbić, B. (ed.) 18th Danube-Kris-Mures-Tisa (DKMT) Euroregional Conference on Environment and Health: Book of abstracts. pp. 86-87.

Zambrano, C., Kotogán, A., Komáromi, L., Takó, M., Krisch, J., Vágvölgyi, Cs. (2016) Production of phenolic antioxidants from apple residues. In: Keszthelyi-Szabó, G., Hodúr, C., Krisch, J. (eds.) International Conference on Science and Technique Based on Applied and Fundamental Research (ICoSTAF'16): Book of Abstracts. p. 48. 


\section{FINANCIAL SUPPORT}

This work was supported by the Hungarian Government and the European Union within the framework of the Széchenyi 2020 Programme through grants GINOP-2.3.2-152016-00012, GINOP-2.3.3-15-2016-00006, GINOP-2.3.2-15-2016-00052 and EFOP3.6.1-16-2016-00008. 